\title{
Spatio-temporal
}

\section{variability of the}

\section{wet component of}

\section{the troposphere}

\section{- Application in}

\section{Satellite Altimetry}

\section{Eliana Patrícia Duarte Vieira}

Mestrado em Engenharia Geográfica

Departamento de Geociências, Ambiente e Ordenamento do Território 2015

\section{Orientador}

Maria Clara Gomes Quadros Lázaro da Silva, Professora Auxiliar,

Faculdade de Ciências da Universidade do Porto

\section{Coorientador}

Maria Joana Afonso Pereira Fernandes, Professora Auxiliar,

Faculdade de Ciências da Universidade do Porto
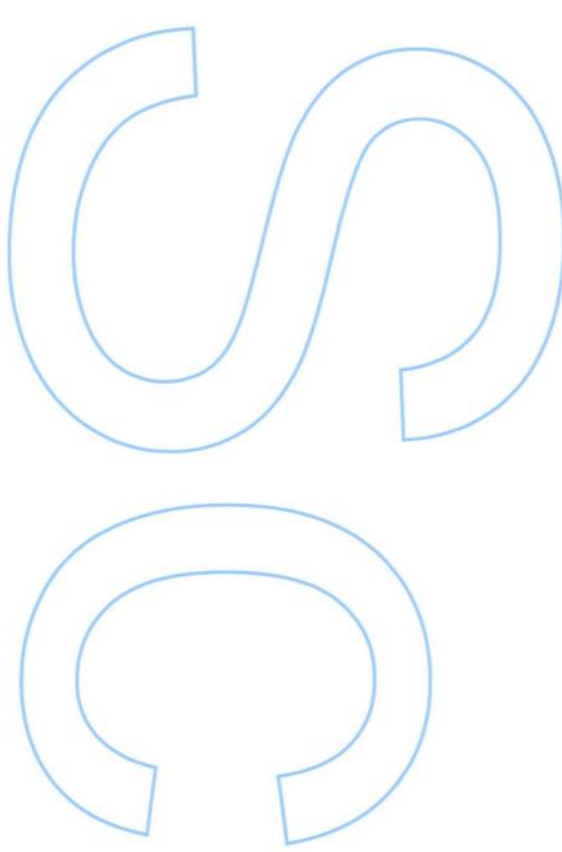


\section{U.PORTO \\ F Faculdade de CIencias \\ FC universidade do porto}

Todas as correções determinadas

pelo júri, e só essas, foram efetuadas.

O Presidente do Júri,

Porto

1
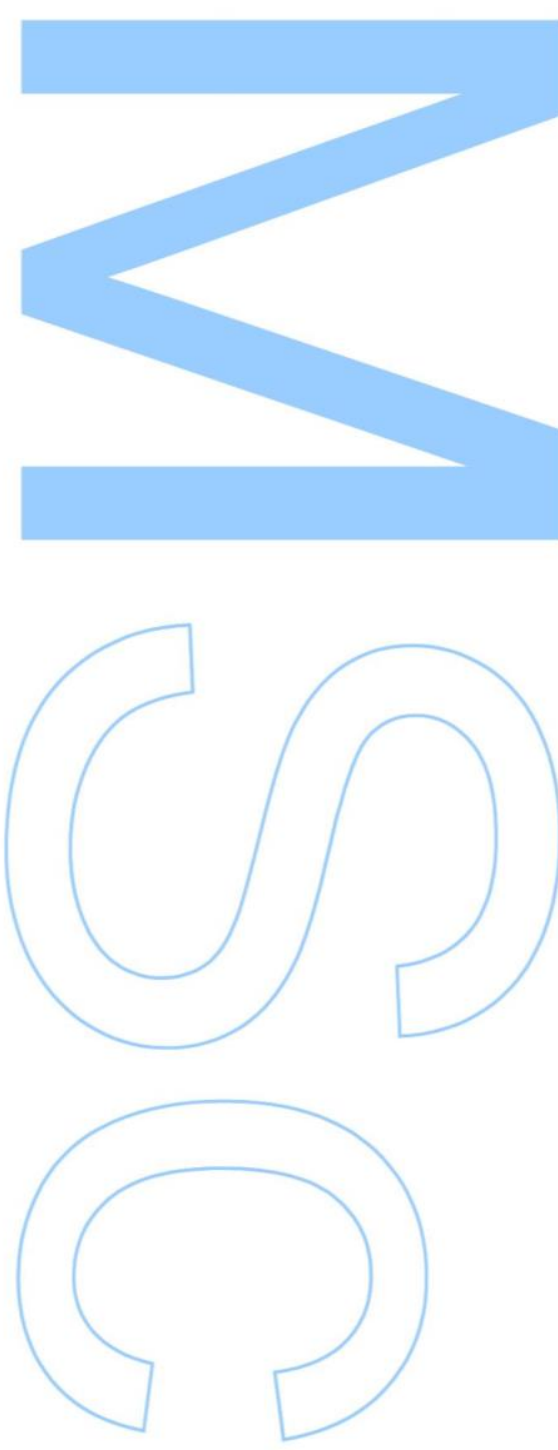


\section{Acknowledgements}

First of all, I would like to express my sincere gratitude to my advisers Prof. Joana Fernandes and Prof. Clara Lázaro, for the continuous support during my MSc, for their patience, motivation, enthusiasm, and immense knowledge. Their guidance helped me in all the time of research and writing of this thesis.

I also would like to thank my friends and MSc colleagues Telmo, Ana, Óscar and Nelson for providing good moments of familiarity, as well as the patience and support of Daniel.

Last but not the least, I would like to thank my family: my parents and my sister, for always supporting me throughout my life. 


\section{Abstract}

The exploitation of Satellite Altimetry for sea level, open-ocean and coastal variability studies depends on the ability to derive altimeter measurements accurately corrected for all external perturbations. Among these perturbations, those related to the troposphere characteristics, the wet and the dry path delays are of particular relevance. The wet component of the troposphere is due to the presence of water vapor and cloud liquid water in the atmosphere and is responsible by a delay in the propagation of the altimeter signals (Wet Path Delay, WPD). Due to the high variability of the water vapor distribution, both in space and time, the modeling of WPD is difficult and its correction is one of the main error sources in Satellite Altimetry. Moreover, the variability of the WPD with altitude is not fully understood at present and remains an interesting topic of research.

The WPD can be obtained from measurements of the microwave radiometer (MWR) on board altimetric missions with centimeter-level precision in open-ocean. However, in sea/land transition and polar regions the WPD retrieval is hampered by the contamination of the radiometer measurements due to the existence of land or ice in the MWR footprint, leading to the loss of accuracy or rejection of the altimetric measurements. Recently, an innovative methodology (GNSS Path Delay Plus, GPD+) that combines WPD observations from different sources with WPD derived from a numerical weather model (NWM) has been developed at University of Porto to improve the MWR-derived WPD. The methodology also requires the reduction at sea level of WPD calculated above sea level at coastal regions (e.g., at Global Navigation Satellite System (GNSS) stations). Consequently, the knowledge of the WPD variability in space and time and with altitude is of major importance for the GPD+ advancement.

The objectives of this work are twofold. First, the space-time variability of the WPD during the altimetric era is addressed using data from a NWM. Global products of TCWV (Total Column Water Vapor) and t2m (two-meter temperature) provided by ERA-Interim NWM were used to derive the WPD for the period of 25 years since January 1, 1990 until December 31, 2014. Results from this global analysis include a complete description of: the annual cycle of water vapor, as well as its long-period superimposed variability, both globally and hemispherically; the relation of WPD to several teleconnection patterns (e.g. ENSO, NAO), responsible for abnormal weather conditions; how WPD and sea level anomaly (SLA) are correlated. Since the oceans provide the primary reservoir for atmospheric water vapor and the source of precipitation is evaporation of seawater, this 
study can contribute to a better understanding of the hydrologic cycle variability and climate change.

Secondly, the variability of WPD with altitude is analyzed. To accomplish this analysis, WPD values derived at a set of stations selected from GNSS permanent networks were collocated in time with MWR-derived WPD from five main altimetric missions (ERS-2, ENVISAT, T/P, Jason-1 and Jason-2) and compared. Despite the scarceness of GNSS coastal stations at intermediate to high altitudes, which hindered the analysis, results from this study are in agreement with published empirical studies. A comprehensive analysis can be achieved using 3D data from an NWM such as ERA Interim. This analysis will be subject of future work. 


\section{Resumo}

A Altimetria por Satélite tem em vista o estudo da variabilidade do nível do mar, em oceano aberto e em costa. Este estudo depende da capacidade em obter medidas altimétricas precisas, ou seja, corrigidas de perturbações externas. Entre estas perturbações, têm destaque as relacionadas com características da troposfera, em particular, e de elevada importância, os atrasos devido às componentes húmida e seca. A componente húmida da troposfera, caracterizada pela presença de vapor de água e água na forma líquida nas nuvens na atmosfera, é responsável por um atraso na propagação dos sinais altimétricos (Wet path Delay, WPD). Devido à variabilidade elevada da distribuição do vapor de água, tanto espacial como temporal, é difícil modelar o WPD e a sua correção é considerada uma das principais fontes de erro em Altimetria por Satélite. Ainda de referir que atualmente a variabilidade do WPD com a altitude não é completamente conhecida, constituindo um interessante tópico de investigação.

Valores de WPD podem ser obtidos através de medidas de radiómetros de microondas (MicroWave Radiometer, MWR) a bordo de missões altimétricas com uma precisão centimétrica em oceano aberto. No entanto, na transição mar/terra e nas regiões polares, a aquisição do WPD é dificultada pela contaminação das medidas do radiómetro causadas pela existência de terra ou gelo na pegada do MWR, levando a uma perda de precisão ou rejeição das medidas altimétricas. Recentemente, uma metodologia inovadora que combina observações WPD fornecidas por diferentes fontes e usando medidas derivadas de modelos atmosféricos (GNSS Path Delay Plus, GPD+) tem sido desenvolvida na Universidade do Porto com vista a melhorar os valores de WPD derivados de MWR. A metodologia requer, ainda, que os valores de WPD calculados acima do nível do mar sejam reduzidos ao nível do mar nas regiões costeiras (por exemplo, em estações GNSS (Global Navigation Satellite System)). Por estes motivos, o conhecimento da variabilidade do WPD no espaço e no tempo e com a altitude é de elevada relevância no que diz respeito a progressos do GPD+.

São dois os principais objectivos deste trabalho. Primeiro, a variabilidade espáciotemporal do WPD ao longo da Era de altimetria é abordada usando dados de um modelo atmosférico (Numerical Weather Model, NWM). Foram usados produtos globais de quantidade total de vapor de água na coluna atmosférica (Total Column Water Vapor, TCWV) e da temperatura a dois metros da superfície (two-meter temperature, $\mathrm{t} 2 \mathrm{~m}$ ) fornecidos pelo ERA Interim NWM para calcular o WPD considerando um período de 25 
anos, desde 1 de Janeiro de 1990 até 31 de Dezembro de 2014. Os resultados para esta análise global incluem uma descrição completa: do ciclo anual do vapor de água, bem como a respectiva variabilidade ao longo do tempo considerado, quer global quer hemisférica; da relação do WPD com "padrões de teleconexão" (por exemplo, ENSO, NAO), responsáveis por condições atmosféricas anormais; da correlação entre WPD e a anomalia do nível do mar (Sea Level Anomaly, SLA). Uma vez que os oceanos constituem a principal fonte de vapor de água da atmosfera e a origem da precipitação consiste na evaporação de água do mar, este estudo contribui para uma melhoria da compreensão da variabilidade do ciclo hidrológico e de alterações climáticas.

Em segundo lugar, é analisada a variabilidade do WPD com a altitude. Com vista à realização desta análise, foram usados valores para a correção da componente húmida da troposfera WTC (Wet Tropospheric Correction), calculados num conjunto de estações de redes permanentes GNSS previamente selecionadas e interpoladas no tempo, e derivados do MWR de cinco missões altimétricas (ERS-2, ENVISAT, T/P, Jason-1 e Jason-2). Apesar da escassa existência de estações GNSS nas zonas costeiras com altitudes de intermédias a altas, o que dificultou a análise, os resultados estão em concordância com estudos anteriores. Uma análise mais abrangente pode ser alcançada usando dados 3D de um modelo atmosférico, como o ERA-Interim. Esta análise será um tópico a abordar num trabalho futuro. 


\section{Contents}

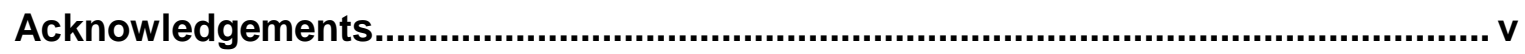

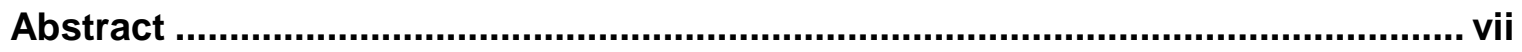

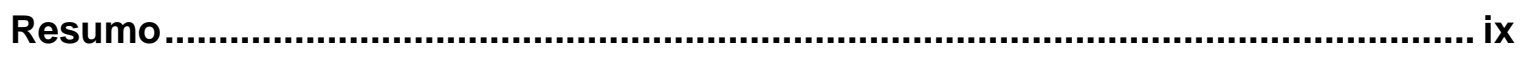

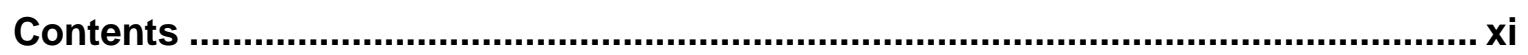

Figures ............................................................................................................. xiii

List of Acronyms and Abbreviations ............................................................. Xv

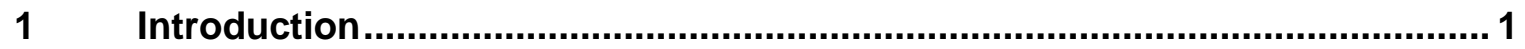

2 The Troposphere

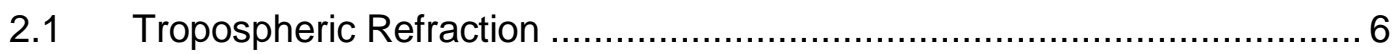

$2.2 \quad$ Wet and Dry Components .............................................................. 7

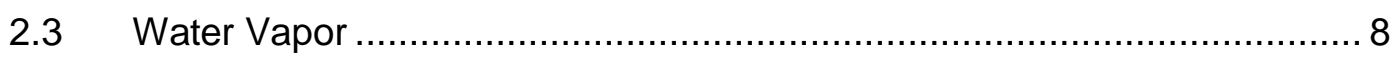

State-of-the-Art (or Water Vapor Variability) ............................................... 8

Water Vapor Measurement.................................................................. 9

$3 \quad$ Wet Tropospheric Correction.......................................................................... 11

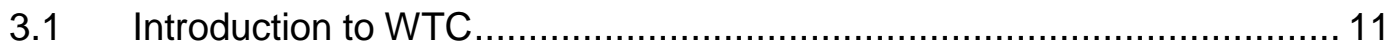

3.2 WPD from Microwave Radiometers …............................................. 12

On-board Satellite Altimetry Missions ……………..................................... 12

On-board Remote Sensing Missions ........................................................... 15

3.3 Numerical Weather Models......................................................... 15

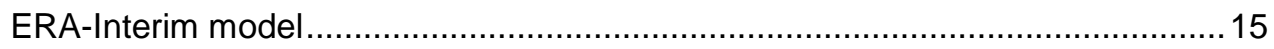

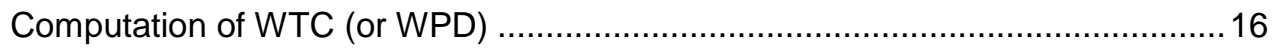

3.4 WPD from Permanent GNSS Networks .......................................... 16

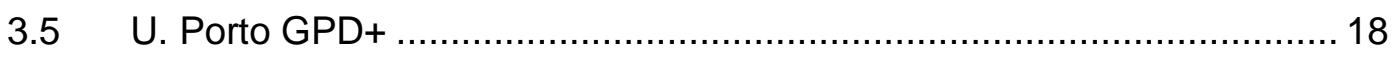

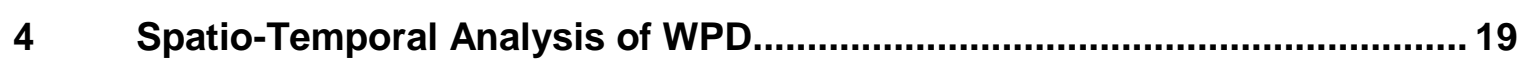

4.1 Data used and processing ........................................................ 19

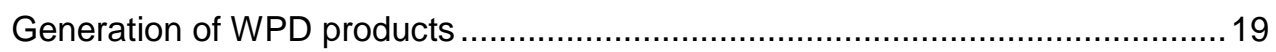

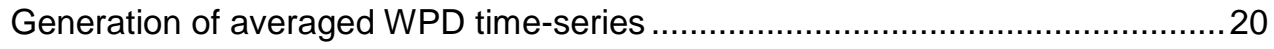

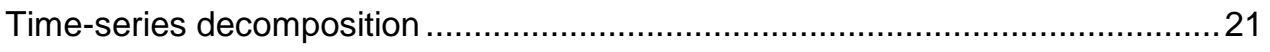

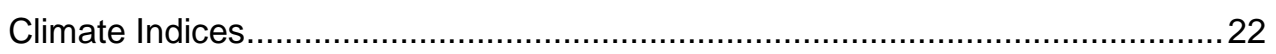

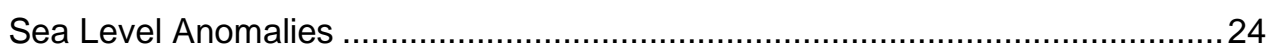

4.2 WPD and the influence of the Intertropical Convergence Zone.............. 25

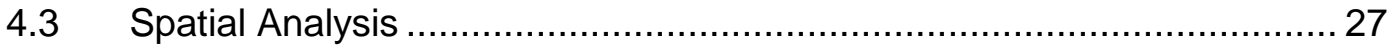


The Annual and Interannual patterns …..................................................... 30

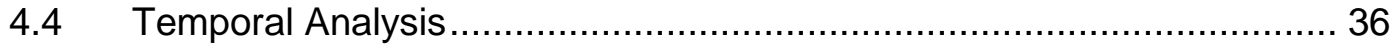

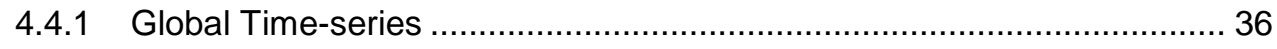

4.4.2 North vs South Hemisphere ........................................................... 37

$4.5 \quad$ WPD and Climate Indices............................................................... 38

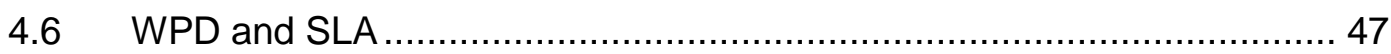

$5 \quad$ Variability of WTC with altitude ................................................................ 51

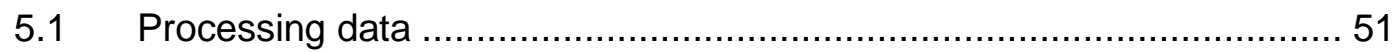

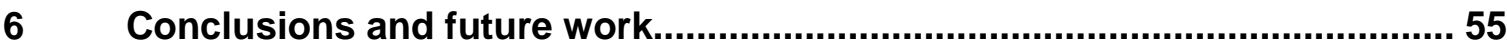

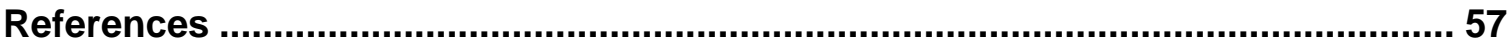

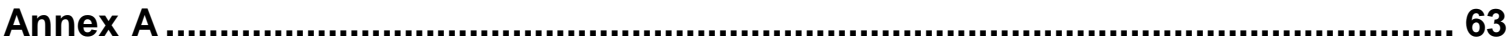




\section{Figures}

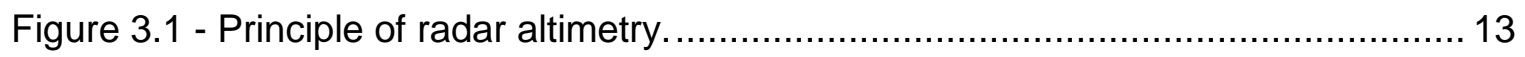

Figure 4.1 - Movement of the Intertropical Convergence Zone (ITCZ) . ....................... 27

Figure 4.2 - Spatial Distribution of WPD in January - Winter season........................... 27

Figure 4.3 - Spatial Distribution of WPD in July - Summer season............................. 27

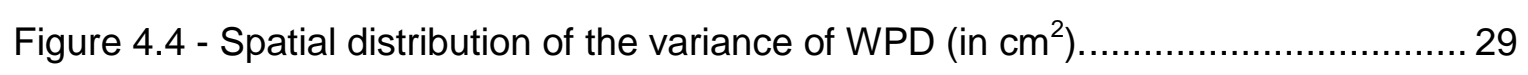

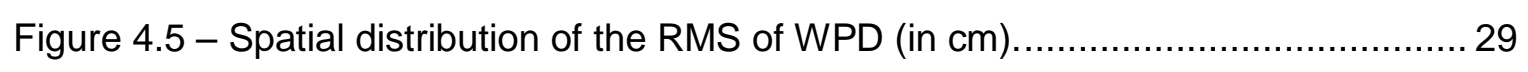

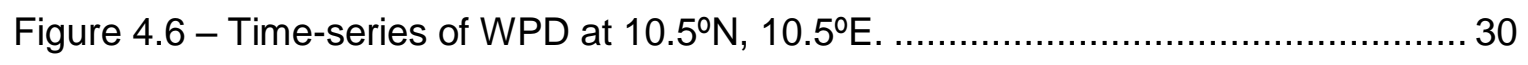

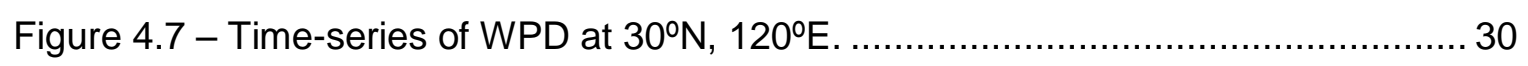

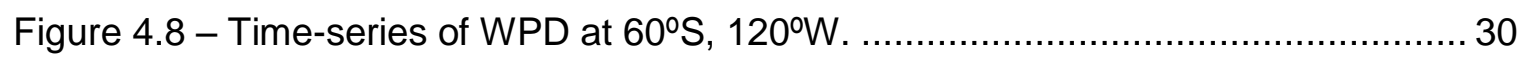

Figure 4.9 - Spatial distribution of the Determination Coefficient (\%) of the seasonal component (DC Seasonal) of WPD variability. ........................................................ 31

Figure 4.10 - Spatial distribution of the Determination Coefficient $(\%)$ of the trend

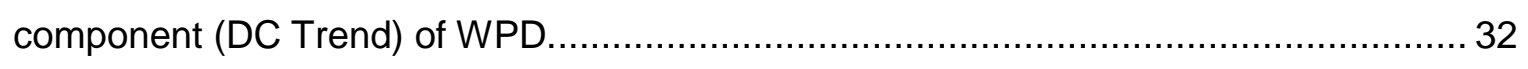

Figure 4.11 - Spatial distribution of the Determination Coefficient (\%) of the remainder

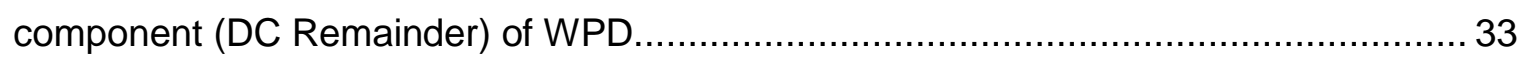

Figure 4.12 - Spatial distribution of the Amplitude $(\mathrm{cm})$ of the seasonal component of

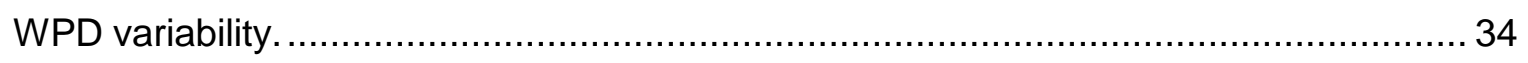

Figure 4.13 - Region of South of Asia, near the India. ............................................. 34

Figure 4.14 - Spatial distribution of the slope (cm/year) of the WPD trend component. . 35 Figure 4.15 - STL decomposition of the Global Time-series. Top panel represents the WPD time-series, middle panel represents the seasonal component and bottom panel represents the trend component and the correspondent linear fit (in red)..................... 36 Figure 4.16 - Comparison between global time-series for continental and oceanic regions separately.

Figure 4.17 - Comparison between the seasonal components of the WPD time-series for Global, North hemisphere and South hemisphere. 37

Figure 4.18 - Comparison between the trend components of time-series for Global, North hemisphere and South hemisphere.

Figure 4.19 - Teleconnections of WPD and Climate Indices: (top) Niño 3.4 and SOI; (middle) PDO and NAO; (bottom) TNA and TSA ................................................... 39

Figure 4.20 - Teleconnections of WPD and Climate Indices AMO and WP. .................. 40

Figure 4.21 - Teleconnection map of WPD and SOI. ............................................. 41

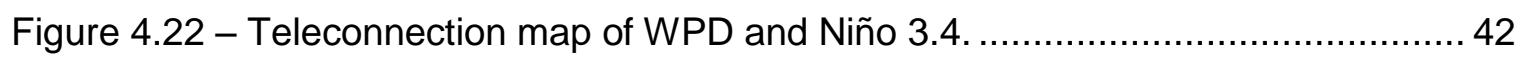


Figure 4.23 - Teleconnection map of WPD and NAO. 43

Figure 4.24 - Teleconnection map of WPD and PDO. 44

Figure 4.25 - Teleconnection map of WPD and TNA. 45

Figure 4.26 - Teleconnection map of WPD and TSA. 45

Figure 4.27 - Teleconnection map of WPD and AMO. 46

Figure 4.28 - Teleconnection map of WPD and WP. 47

Figure 4.29 - Correlation Coefficient of WPD and SLA. 49

Figure A.0.1 - Illustration of the peak-to-peak amplitude measurement.. 64 


\section{List of Acronyms and Abbreviations}

\begin{tabular}{|c|c|}
\hline ADT & Absolute Dynamic Topography \\
\hline AMO & Atlantic Multi-decadal Oscillation \\
\hline AMR & Advanced Microwave Radiometer \\
\hline AMSRE & Advanced Microwave Scanning Radiometer for EOS \\
\hline AMSU-A & Advanced Microwave Sounding Unit-A \\
\hline AMSU-B & Advanced Microwave Sounding Unit-B \\
\hline ATOVS & Advanced TIROS Operational Vertical Sounder \\
\hline CORS & Continuously Operating Reference Stations \\
\hline CSR & Clear-sky radiance \\
\hline DC & Determination Coefficient \\
\hline DPD & Dry Path Delay \\
\hline DTC & Dry Tropospheric Correction \\
\hline ECMWF & European Centre for Medium-Range Weather Forecasts \\
\hline ENSO & El Niño-Southern Oscillation \\
\hline EOS & Earth Observing System \\
\hline EPN & EUREF Permanent Network \\
\hline ERA & ECMWF ReAnalysis \\
\hline ERS & European Remote Sensing \\
\hline GNSS & Global Navigation Satellite System \\
\hline GPD+ & GNSS Path Delay Plus \\
\hline HIRS & High-Resolution Infrared Sounder \\
\hline IGS & International GNSS Service \\
\hline ITCZ & Intertropical Convergence Zone \\
\hline ITRF & International Terrestrial reference Frame \\
\hline MDT & Mean Dynamic Topography \\
\hline MHS & Microwave Humidity Sounder \\
\hline MSS & Mean Sea Surface \\
\hline MSU & Microwave Sounding Unit \\
\hline MWR & Microwave Radiometer \\
\hline NAO & North Atlantic Oscillation \\
\hline NCEP & National Centers for Environmental Prediction \\
\hline NOAA & National Oceanic and Atmospheric Administration \\
\hline
\end{tabular}




$\begin{array}{ll}\text { NWM } & \text { Numerical Weather Model } \\ \text { PDO } & \text { Pacific Decadal Oscillation } \\ \text { RADAR } & \text { Radio Detection and Ranging } \\ \text { RMS } & \text { Root Mean Square } \\ \text { SI-MWR } & \text { MWR imaging sensors } \\ \text { SLA } & \text { Sea Level Anomaly } \\ \text { SLP } & \text { Sea Level Pressure } \\ \text { SOI } & \text { Southern Oscillation Index } \\ \text { SSB } & \text { Sea State Bias } \\ \text { SSH } & \text { Sea Surface Height } \\ \text { SSM/I } & \text { Special Sensor Microwave Imager } \\ \text { SSM/S } & \text { Special Sensor Microwave Sounder } \\ \text { SSU } & \text { Stratospheric Sounding Unit } \\ \text { T/P } & \text { TOPEX/Pöseidon } \\ \text { TCWV } & \text { Total Column Water Vapor } \\ \text { TIROS } & \text { Television Infrared Observation Satellite } \\ \text { TNA } & \text { Tropical Northern Atlantic } \\ \text { TOVS } & \text { TIROS Operational Vertical Sounder } \\ \text { TSA } & \text { Tropical Southern Atlantic } \\ \text { WP } & \text { Western Pacific } \\ \text { WPD } & \text { Wet Path Delay } \\ \text { WTC } & \text { Wet Tropospheric Correction } \\ \text { ZHD } & \text { Zenith Hydrostatic Delay } \\ \text { ZTD } & \text { Zenith Total Delay } \\ \text { ZWD } & \text { Zenith Wet Delay } \\ & \end{array}$




\section{Introduction}

Satellite Altimetry has transformed the way we view Earth and its Ocean. With the forthcoming of precise satellite altimetry missions, the estimation of long-term sea level variability with an accuracy of a few centimeters became possible. To guaranty a high level of accuracy, corrections to the altimeter measurements are needed, since these measurements are affected by external effects, such as instrumental, geophysical (e.g., ocean and Earth tides, ocean and atmospheric loading), and those due to atmosphere (troposphere and ionosphere) and ocean interaction (sea surface state). Moreover, the satellite height above a reference ellipsoid provided by a precise orbit solution, referred to an International Terrestrial Reference Frame (ITRF), is required (Fernandes et al., 2014).

The effect of the atmospheric refraction is of major relevance. The atmosphere reduces the speed of the RADAR (Radio Detection and Ranging) pulse, bending its trajectory and, therefore, causing a "path delay" of the altimeter signal. This effect of the atmospheric refraction is due to both the dry and wet components of the troposphere and to the existence of free electrons in the upper atmosphere.

The dry component represents $90 \%$ of the tropospheric delay. The wet component represents only $10 \%$ of this delay and is related to the water vapor content in the atmosphere. Corrections related to the dry and wet components of troposphere are named Dry Tropospheric Correction (DTC) and Wet Tropospheric Correction (WTC), respectively. However, the symmetric values of the dry and wet tropospheric corrections are usually used, the Dry Path Delay (DPD) and the Wet Path Delay (WPD), respectively.

Because the tropospheric delay is the main error source of the Global Navigation Satellite System (GNSS) signals, permanent networks of GNSS stations provide routinely the total tropospheric delay (Zenith Total Delay, ZTD) products at the station location and height, with an accuracy of a few millimeters (Niell et al., 2001; Pacione et al., 2011). For use in Satellite Altimetry, the DTC is calculated with high accuracy using a Numerical Weather Model (NWM) and subtracted from the precise GNSS-derived ZTD to accurately estimate WTC at each GNSS station (Fernandes et al., 2010, 2013a). The WTC is therefore estimated at the station altitude and should be reduced to sea level before being combined with WTC derived from satellite altimetry since these are 
provided at sea level. The variability of the WTC with altitude is not fully understood at present and remains an interesting topic of research.

The most accurate (centimeter-level precision in open-ocean) WPD are obtained from measurements acquired by the microwave radiometer (MWR) on board altimetric missions, since they are collocated in space and time with the altimeter measurements. However, in coastal and polar areas the WPD retrieval is hampered by the contamination of the radiometer measurements due to the existence of land and ice in its footprint (roughly a circle with a frequency-dependent radius, generally in the range of 15 to 25 $\mathrm{km}$ ), leading to the loss of accuracy or rejection of the altimetric measurements.

The GNSS-Derived Path Delay Plus (GPD+) methodology was developed recently at University of Porto to improve the MWR correction. The methodology combines WPD observations from different sources (MWR on board altimetric missions, MWR on board Remote Sensing mission and at coastal and island GNSS stations) with WPD derived from Numerical Weather Model (NWM). The methodology also requires the reduction at sea level of WPD calculated at the GNSS stations. Consequently, the knowledge of the WPD variability in space and time and with altitude is of major importance for the GPD+ enhancement and validation and, in general, for Satellite Altimetry.

The objectives of this work are twofold. First, the study of the space-time variability of the WPD during the altimetric era, in global terms, is addressed using data from an NWM. Although the magnitude of the WPD ranges from 0 to $50 \mathrm{~cm}$, it is difficult to estimate due to the high variability of the water vapor and its fast change in space and time, and also due to the complexity of the water cycle at all spatial and time scales (Fernandes et al., 2013b). Studies focused on the mean and standard deviation of WTC, using observations of column water vapor from 6 years of Jason-1 data, report significant temporal and spatial variabilities (Andersen and Scharroo, 2011, Fernandes et al., 2013a), the seasonal variability mode being the strongest.

Since the Ocean covers $70 \%$ of the planet and plays a key role in regulating the global climate, it is important to investigate how WPD is related to teleconnection patterns, and to the sea level variability.

To accomplish these analyses, Global products of TCWV (Total Column Water Vapor) and $\mathrm{t} 2 \mathrm{~m}$ (two-meter temperature) provided by ERA (ECMWF ReAnalysis; ECMWF being the European Centre for Medium-Range Weather Forecasts) Interim NWM were used to derive the WPD for the period of 25 years since January 1, 1990 until December 31, 2014. The spatial resolution of these products is $0.75^{\circ}$.

Water vapor patterns reflect global-scale interactions among the oceans, atmosphere, and continents. Results from this global analysis are expected to contribute to the 
knowledge of: the annual cycle of water vapor, as well as its long-period superimposed variability; the relation of the latter variability to several teleconnection patterns, responsible for abnormal weather patterns; how WPD and sea level anomaly (SLA) are correlated. Since the main source of atmospheric moisture is the Ocean, this study can contribute to a better understanding of the hydrologic cycle variability and climate change.

Secondly, the variability of WPD with altitude is analyzed. Kouba (2008) based on punctual and scarce WTC acquired from radiosondes proposed an empirical exponential expression to perform WTC height reductions, however limiting the station altitude to $1000 \mathrm{~m}$. To accomplish this analysis, WPD values derived at a set of stations selected from the main permanent GNSS networks (International GNSS Service (IGS), EUREF Permanent Network (EPN) and SuomiNet) were collocated in time with MWR-derived WPD from five main altimetric missions (ERS-2, ENVISAT, T/P, Jason-1 and Jason-2) and compared. It is expected that this analysis provides an improved WTC and height relationship by using a larger amount of data. This analysis is of major importance, since the GPD+ methodology relies on WPD values derived at coastal and island GNSS stations which must be reduced to sea level previously to their use.

The outline of this thesis is as follows. The Troposphere is presented in Chapter 2, which includes the description of the dry and wet components of troposphere.

There are several ways to measure or compute the wet path delay (e.g., using radiosondes or microwave radiometers) and therefore to correct altimeter measurements. Those used in this study (WPD calculated from numerical weather models or measured by microwave radiometers on board satellite altimetry missions and at GNSS stations) are described in Chapter 3.

Chapters 4 and 5 describe all the analyses performed in the scope of this thesis. In Chapter 4 the data used are described and the spatio-temporal analysis of WPD is addressed. The spatial analysis includes the study of WPD seasonal and trend components and their contribution of the total WPD variability. Global and hemispherical time-series for WPD over oceanic and continental regions were generated to analyze the temporal variability. Chapter 5 describes the analyses performed on the WPD and height dependency, combining GNSS- and MWR-derived WPD. Chapter 6 summarizes the results of the study and presents the conclusions and suggestions for future work. 


\section{The Troposphere}

The atmosphere is part of what makes Earth livable. It is composed of a mixture of invisible gases and a large number of suspended microscopic solid particles and water droplets (Aguado and Burt, 2001). In a simple way, it is possible to distinct the layers of the atmosphere mainly by how temperature changes with height within them. In the context of signal propagation, the atmosphere reduces the speed of the electromagnetic waves bending its trajectory and, therefore, causing a "path delay" of the propagated signal. Among these electromagnetic waves, are of major importance in the scope of this study those with wavelength longer than that corresponding to the infrared region of the electromagnetic spectrum, also called radio waves.

This chapter starts with a brief description of the two main layers of the atmosphere which influence the propagation of the GNSS and altimetric radio signals: the ionosphere and the troposphere. The addressed sections describe the tropospheric correction, the wet and dry components of the troposphere and the variable gases that compose this layer of the atmosphere, including the water vapor and the carbon dioxide, giving relevance to water vapor, once the variability and distribution of this gas plays an important key in the variability and distribution of the correction due to the wet component of troposphere.

There are two principal layers of the atmosphere that influence radio waves: the ionosphere and the troposphere.

- The ionosphere is part of Earth's upper atmosphere, stretching from a height of about $50 \mathrm{~km}$ to more than $1000 \mathrm{~km}$ from Earth, and is ionized by solar radiation. The ionosphere is thus a shell of electrons and electrically charged atoms and molecules that surrounds the Earth (Montenbruck and Eberhard, 2000).

- The troposphere is the lowest atmospheric layer, typically located between Earth's surface and an altitude of about $8-15 \mathrm{~km}$ (Samama, 2008). The troposphere contains almost all of the atmosphere's water vapor (about 99\%), and small amounts of Carbon dioxide. The troposphere is not ionized since it is electrically neutral. Troposphere is where the vast majority of weather events occur and is marked by a general pattern in which temperature decreases with height (Aguado and Burt, 2001). 
The ionosphere is a dispersive medium for frequencies in the radio region of the electromagnetic spectrum that is the refraction index depends on the transmission frequency. On the other hand, the troposphere is a non-dispersive medium, thus it is independent of the frequency used (Subirana et al., 2011). This is why all electromagnetic waves in the total radio-spectrum up to about $15 \mathrm{GHz}$, including the ones propagated by GNSS and by altimetric satellites, are affected in the same way by the troposphere. An immediate consequence of being a non-frequency dependent delay is that the tropospheric refraction cannot be removed by combinations of dual frequency measurements, as it is done with the ionosphere delay, (Subirana et al., 2011).

\subsection{Tropospheric Refraction}

The tropospheric delay is produced by the tropospheric refraction which causes an increase in the observed range from satellites. Usually, the tropospheric path delay is expressed by two components: the dry (or hydrostatic) and wet components. Given the small difference between the hydrostatic and dry components of the tropospheric path delay, the term "dry tropospheric delay" is usually used within the altimetry community to refer to the hydrostatic tropospheric path delay (Fernandes et al., 2014).

The total tropospheric refractivity can be described as a function of meteorological parameters using an empirical formula, see equation 2.1 (Hartmann and Leitinger, 1984):

$$
N_{\text {trop }}=C_{1} \frac{P^{\prime}}{T}+C_{2} \frac{e}{T}+C_{3} \frac{e}{T^{2}}
$$

where

- $\quad \mathrm{P}^{\prime}=\mathrm{P}-\mathrm{e}$ is the pressure of the dry gas,

- $P$ is the air pressure, in Hectopascal [HPa],

- $\quad e$ is partial pressure of the water vapor, in $\mathrm{HPa}$,

- $T$ is the temperature, in Kelvin.

Since the troposphere consists of a mixture of different gases, the refractivity index of the tropospheric layer is the sum of the contribution of each constituent that composes the troposphere multiplied by its own density, see equation 2.2 (Hall, 1979; Debye, 1929).

$$
N_{\text {trop }}=N_{d r y}+N_{\text {wet }}
$$


where

- $N_{\text {trop }}$ is the Refractivity the total troposphere,

- $\quad N_{d r y}$ is the refractivity of the dry component of troposphere,

- $\quad N_{\text {wet }}$ is the refractivity of the wet component of troposphere.

\subsection{Wet and Dry Components}

The wet and dry components are composed by a mixture of gases. The dry component delay, also named as Dry Path Delay (DPD), is caused by the dry gases present in the troposphere (78\% of Nitrogen, $21 \%$ of Oxygen, $0.9 \%$ of Argon). The effect varies with local temperature and atmospheric pressure in a predictable way; furthermore this component varies in less than $1 \%$ in a few hours (Subirana et al., 2011). The error caused by this component is about 2.3 meters in the zenith direction and 10 meters for lower elevations (Subirana et al., 2013), contributing to about $90 \%$ of the total tropospheric delay, and it is closely correlated to the atmospheric pressure. DPD can be precisely modeled with an accuracy better than $1 \mathrm{~cm}$ from meteorological models (Fernandes et al., 2013a) that assimilate atmospheric temperature and pressure measurements. Studies performed by Fernandes et al. (2013a) on a set of GNSS coastal sites with heights up to $1000 \mathrm{~m}$ show that the DTC can be computed at a surface point, with an accuracy of a few $\mathrm{mm}$, from Sea Level Pressure (SLP) fields from an atmospheric model such as ERA Interim or ECMWF operational, using the modified Saastamoinen model (Davis et al., 1985), further reduced to surface height using an adequate model for the height dependence of atmospheric pressure such as the one given by Hopfield (1969).

The wet component delay, named as Wet Path Delay (WPD), is caused by the presence of water vapor and condensed water in the form of clouds in the troposphere and, consequently, depends on weather conditions. The amount of water vapor per amount of air, also known as humidity, is an important quantity of the atmosphere, especially of the lower troposphere, and is determined by evaporation, advection and precipitation (e.g. Bengtsson, 2010). It means that the size of the delay attributable to the wet component depends on the highly variable water vapor distribution in the troposphere. Therefore, WPD is much more difficult to estimate than DPD because of the high variability of water vapor (or humidity) and the complexity of the water cycle at all spatial and time scales (Fernandes et al., 2013a). 


\subsection{Water Vapor}

Water vapor is the most abundant of the variable gases of the atmosphere, and it is the principal source of the atmospheric energy that drives the development of weather systems on short time scales and influences the climate on longer time scales, therefore, water vapor is a critical component of Earth's climate systems (Aguado and Burt, 2001). It is the Earth's primary greenhouse gas, trapping more heat than carbon dioxide due to the incoming solar radiation and the infrared radiation reflected by the Earth's surface. Because the source of water vapor in the atmosphere is evaporation from Earth's surface, its concentration normally decreases with altitude and most atmospheric water vapor is found in troposphere (Aguado and Burt, 2001).

Water continuously evaporates from both open water and plants leaves into the atmosphere, where it eventually condenses to form liquid droplets and ice crystals. These liquid and solid particles are removed from the atmosphere by precipitation as rain, snow, sleet or hail. Because of the rapidity of global evaporation, condensation, and precipitation, water vapor has a very short residence time of only 10 days (Aguado and Burt, 2001).

The temperature, pressure and moisture characteristics of the atmosphere arise in large part from the continuous exchange of energy and water vapor near the surface. When energy inputs exceed energy losses, the temperature of the air increases. In the same way, when there is more evaporation than precipitation, the moisture content of the atmosphere increases. But because heat and water are not uniformly distributed across the globe, the cooling and warming of the atmosphere vary from place to place, as does the net input of water vapor (Aguado and Burt, 2001).

Most of the water vapor is in the troposphere, where water vapor acts as the main resource for precipitation in all weather systems, providing latent heating in the process and dominating the structure of diabatic heating in the troposphere (Trenberth and Stepaniak, 2003a). Hence, advancing the understanding of variability and change in water vapor is vital.

\section{State-of-the-Art (or Water Vapor Variability)}

Water vapor increases with increased temperature, and the greatest amount of water vapor is found near the equator (Thurman and Burton, 2001). Studies about the water vapor distribution in different regions around the world (e.g. Ross and Elliott, 1996; Zhai and Eskridge, 1997; Ross and Elliot, 2001; Seidel, 2002) including Europe, America, Africa, and Asia, allowed concluding that the distribution of water vapor changes with 
seasonal changes in temperature and atmospheric circulation patterns. Seidel (2002) revealed that the general decrease of water vapor from equator to poles is a reflection of the global distribution of temperature, because warm air is capable of holding more moisture than cold air. However, he found exceptions in the major desert regions, where the air is very dry despite its high temperature.

Ross and Elliott (2001) confirm the generally upward trends in precipitable water for 1973-1995 over China and southern Asia, strong upward trends in the tropical Pacific, but they found small and insignificant trends over Europe. There is an increase in global water vapor amount with El Niño, although the main increase is in the equatorial region from $10^{\circ} \mathrm{N}$ to $20^{\circ} \mathrm{S}$, often with compensating drier regions near $20^{\circ} \mathrm{N}$ (Trenberth et al, 2005).

El Niño is a climate cycle that occurs irregularly at about 3-6 year intervals in the Pacific Ocean with a global impact on weather patterns (Enfield, 2003). The cycle begins when warm water in the western tropical Pacific Ocean shifts eastward along the equator toward the coast of South America. Normally, this warm water pools near Indonesia and the Philippines. During an El Niño, the Pacific's warmest surface waters sit offshore of northwestern South America. Scientists do not yet understand in detail what triggers an El Niño cycle. Not all El Niños are the same, nor do the atmosphere and ocean always follow the same patterns from one El Niño to another. There is also an opposite of an El Niño, called La Niña. This refers to times when waters of the tropical eastern Pacific are colder than normal and trade winds blow more strongly than usual (El Niño, 2015).

\section{Water Vapor Measurement}

Total Column Water Vapor (TCWV) is a measure of the total water vapor in the form of gas contained in a vertical column of atmosphere. It is quite different from the more familiar relative humidity, which is the amount of water vapor in air relative to the amount of water vapor the air is capable of holding (Atmospheric Water Vapor, 2015). Atmospheric water vapor (or Total Precipitable Water) is the absolute amount of water dissolved in air. When measured in linear units (millimeters, $\mathrm{mm}$ ) it is the height (or depth) the water would occupy if the vapor were condensed into liquid and spread evenly across the column. Using the density of water, we can also report water vapor in $\mathrm{kg} / \mathrm{m}^{2}=$ $1 \mathrm{~mm}$ or $\mathrm{g} / \mathrm{cm}^{2}=10 \mathrm{~mm}$ holding (Atmospheric Water Vapor, 2015).

Because of the strong water vapor absorption line near $22 \mathrm{GHz}$, within the microwave range, we can use microwave radiometers to measure columnar (atmospheric total) water vapor. This is a very accurate measurement due to the high signal-to-noise ratio for this measurement. With little diurnal variation, the measurements from different 
satellites at the same location often agree to within a few tenths of a millimeter (Atmospheric Water Vapor, 2015). 


\section{Wet Tropospheric Correction}

There are primarily three methods to correct the delay caused by the wet component of the troposphere: using on-board microwave radiometers, numerical weather models, or GNSS ground-based stations.

In this work, the approach adopted and described in Chapter 4, consists on using WPD values computed from meteorological parameters from an atmospheric model, ERAInterim. In Chapter 5, a combination of WPD values from GNSS stations and from MWR aboard altimetric missions was used.

This chapter gives an overview of the three complementary methodologies. An introduction to WTC is addressed in section 3.1; microwave radiometers aboard satellites is addressed in section 3.2, numerical weather models are presented in section 3.3, Permanent GNSS Networks are presented in section 3.4, and the U. Porto GPD methodology is addressed in section 3.5.

\subsection{Introduction to WTC}

As addressed in Chapter 2, the wet component of the delay of the altimeter and GNSS signals is caused by the presence of water vapor and cloud liquid water in the atmosphere, and is a relatively small, but difficult to estimate, error source, due to the variability of the water vapor and to its fast change in space and time.

Corrections for this component can be determined using passive measurements from on-board microwave radiometers (MWR) or by using meteorological parameters from numerical weather models, or using estimated values from GNSS stations from several permanent networks. The wet tropospheric path delay can also be measured on the ground (using GNSS or upward looking radiometers) and then compared to the one derived from the on-board microwave radiometers (Fernandes et al., 2014).

The WTC determination from on-board microwave radiometers is hampered by the contamination of the radiometer measurements closed to ice and land areas, therefore making these measurements usable only in open ocean. This sensitivity of the correction to land and ice contamination as well as to instrument malfunction in certain epochs has been the aim of recent studies, (see e.g. Desportes et al., 2007; Fernandes et al., 2013; Fernandes et al., 2014).

A methodology for the computation of improved wet delay values for all contaminated, and therefore prone to be rejected, values was created by the University of Porto 
(U. Porto) in the aim of ESA financed projects (GNSS-Path Delay, GPD). Based on this methodology, enhanced products were generated globally for the eight main altimetric missions: ERS-1/2, Envisat, T/P, Jason-1/2, CryoSat-2 e SARAL (Fernandes et al., 2010; Fernandes et al., 2015).

It is well-known that most of the wet tropospheric models are not suitable for processing long time series of satellite altimetry since they possess long-term errors and discontinuities (Scharroo et al. 2004). A comparison between the various methodologies to generate the wet delay can be found in Obligis et al. (2011).

For studies over inland water, Fernandes et al. (2014) recommended that the MWRderived WTC should be adopted whenever available, otherwise the GNSS-derived WTC in regions possessing GNSS permanent stations should be used. In the absence of the previous data types, the adoption of a model-derived correction from ERA-Interim, computed at surface height, provide the highest accuracy $(1-3 \mathrm{~cm})$. Over ocean, the most suitable correction is the GNSS Path Delay Plus (GPD+) WTC (Fernandes et al., 2015).

As more accurate the estimated WTC is, more accurate the inferred parameters in Satellite Altimetry will be.

The various approaches to correct the wet tropospheric error are described below.

\subsection{WPD from Microwave Radiometers}

\section{On-board Satellite Altimetry Missions}

Satellite Altimetry starts with the launch of the first altimetric satellites: GEOS3 and Seasat. Since 1986, with Geosat, these missions have been providing vital information for an international user community (Missions - Aviso, 2015). In July 1991 ESA launched ERS-1. The ERS (European Remote Sensing) satellites main mission is to observe Earth, in particular its atmosphere and ocean (ERS-1 - Aviso, 2015). The following missions were Topex/Poseidon (TP), ERS-2, Jason-1, Envisat, Jason-2. The currently operational missions are SARAL, HY-2, CryoSat-2 and Jason-2 (Missions - Aviso, 2015).

Every satellite has an on-board radar altimeter which emits a radar pulse (microwave pulse) with a frequency of $13.5 \mathrm{GHz}$. The radar pulse interacts with the sea surface and part of the incident radiation reflects back to the altimeter. The basic concept of Satellite Altimetry consists on determining the distance from the radar altimeter to a target surface (sea, land, ice) by measuring the satellite-to-surface round-trip time of the radar pulse 
using precise clock on-board satellites (more precisely, the distance between the radar altimeter and the reference frame, the reference ellipsoid (see Figure 3.1), is measured. A satellite radar altimeter measures three fundamental parameters, inferred from the returned radar pulse: the instantaneous range, the wave height and the wind speed. Instantaneous Sea Surface Height (SSH), the height of the sea surface relative to a known reference ellipsoid, is obtained by subtracting the instantaneous range $(R)$, determined from the pulse travelling time between the satellite and the sea surface, from the satellite orbit height $(\mathrm{H})$.

The observed measurements collected from the altimetric missions allowed to define a Mean Sea Surface (MSS). Sea Level Anomaly (SLA) is derived from the SSH by removing the MSS. SLA can also be estimated using the MSS, the Absolute Dynamic Topography (ADT), the height of sea level above geoid, and the Geoidal Undulation (N), the distance from the geoid to the reference ellipsoid. The last variable, $\mathrm{N}$, is not known accurately for the wavelengths corresponding to the mesoscale $(1-100 \mathrm{~km})$ or smaller, therefore SLA is usually determined using the first combination of variables. The Mean Dynamic Topography (MDT) is obtained by subtracting the N from the MSS. In summary:

- $\mathrm{SSH}=\mathrm{H}-\mathrm{R}$

- $\quad \mathrm{SSH}=\mathrm{MSS}+\mathrm{SLA}$

- $\mathrm{SSH}=\mathrm{ADT}+\mathrm{N}$

therefore, $\mathrm{MSS}+\mathrm{SLA}=\mathrm{ADT}+\mathrm{N} \Leftrightarrow \mathrm{ADT}=(\mathrm{MSS}-\mathrm{N})+\mathrm{SLA}$, being MDT=MSS-N .

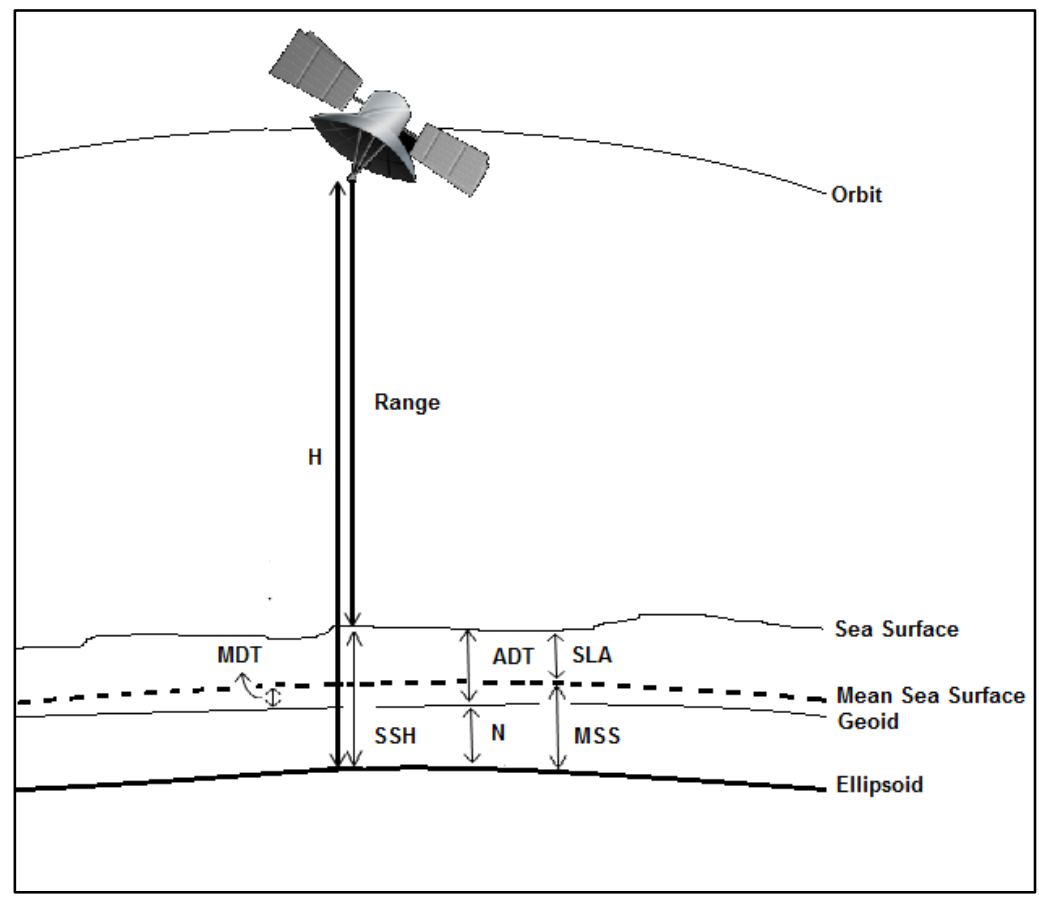

Figure 3.1 - Principle of radar altimetry. 
Interpretation of the measured radar pulse can be performed with more or less accuracy according to the surface characteristics, and the best results are obtained over the ocean, which is spatially homogeneous. In addition, radar signal interferences also need to be taken into account. Atmospheric effects, sea state and a range of other parameters affect the signal round-trip time, thus distorting range measurements. These interferences can be corrected by measuring them with supporting instruments, or at several different frequencies, or by modelling them.

All satellite altimetry missions, with the exception of CryoSat-2 mission, have a passive microwave radiometer (MWR) on board. The MWR is a nadir-looking, with two or three operating frequencies allowing receiving and measuring microwave radiations generated and reflected by the Earth. The received signals can be related to surface temperature but, most importantly, when combined together they provide an estimate of the total water content in the atmosphere. MWR complements the radar altimeter instrument allowing to correct the error introduced by the Earth's troposphere, such as the wet component (Guijarro et al., 2000).

Two main types of nadir-looking radiometers have been deployed in the altimetric satellites: 2-band in ERS-1, ERS-2, Envisat, GFO, SARAL and upcoming Sentinel-3; 3band on TOPEX/Poseidon, Jason-1 and Jason-2. All of them have one band in the water vapor absorption line between 21 and $23.8 \mathrm{GHz}$ plus one or two in "atmospheric window" channels. The "window" channels are required to account for the effect of surface emissivity and for the cloud scattering (Fernandes et al., 2015).

Corrections for the wet component of the troposphere provided by MWR on board satellite altimetry missions were compared in this study to the ones derived from GNSS stations to analyze the dependence of WTC with height, described in detail in Chapter 5. A summary of the altimetric missions used in this work is shown in Table 3.1.

Table 3.1 - Summary of satellite altimeter missions and orbital parameters (Rosmorduc et al., 2011).

\begin{tabular}{lllll}
\hline Mission & Launch & Altitude $(\mathbf{k m})$ & Repetitivity (days) & Inclination $\left(^{(}\right)$ \\
\hline T/P & 1992 & 1336 & 10 & 66 \\
ERS-2 & 1995 & 785 & 35 & 98.5 \\
Jason-1 & 2001 & 1336 & 10 & 66 \\
Envisat & 2002 & 800 & 35 & 98.5 \\
Jason-2 & 2008 & 1336 & 10 & 66 \\
\hline
\end{tabular}




\section{On-board Remote Sensing Missions}

In addition to the dedicated MWR aboard altimetric missions, scanning imaging MWR instruments, also retrieving water vapor data from measurements in several bands of the microwave spectrum, have been flown in various Remote Sensing missions. These passive microwave radiometers have been at the forefront of the emerging field of climate applications of satellite data. Even though the pool of researchers is considerably smaller in passive microwave remote sensing than it is in visible and infrared remote sensing, the characteristics of microwave radiometers in some ways lend themselves more readily to climate applications (Spencer, 2001).

Comparing the types of MWR, the main difference between them is that, at each epoch, the MWR on-board satellite altimetry missions can only make a single measurement in the nadir direction while the scanning image MWR on-board Remote Sensing Missions performs a scan of the sea surface over the instrument swath. While the final product of the first is an along track profile, the second is an along-track image.

Water vapor measurements datasets, given as Total Column Water Vapor (TCWV), from all available scanning imaging MWR (SI-MWR) must be calibrated with respect to a common reference in order to use them in the WTC computation. For this purpose, WTC retrieved by the Advanced Microwave Radiometer (AMR) on board J2 can be used, since this radiometer has been well monitored and the subject of successive calibrations. The main SI-MWR sensors and a description of the calibration of each scanning image MWR derived WTC can be consulted in Fernandes et al. (2013b).

\subsection{Numerical Weather Models}

The two most widely used numerical weather models (NWM) are the European Centre for Medium-Range Weather Forecasts (ECMWF) and the U.S. National Centers for Environmental Prediction (NCEP). Both are delivered on regular grids at regular 6-hour intervals.

\section{ERA-Interim model}

ERA-Interim is a global atmospheric reanalysis project produced by ECMWF. It covers the period since January 1, 1979 to date and provides gridded data products that include a large variety of 3-hourly surface parameters, describing weather as well as oceanwave and land-surface conditions, and 6-hourly upper-air parameters covering the 
troposphere and stratosphere. The data provided by the ECMWF server allows computing WPD all over the world (Dee et al., 2011).

ERA-Interim uses satellite radiances from TIROS (Television Infrared Observation Satellite) Operational Vertical Sounder (TOVS) and Advanced TIROS Operational Vertical Sounder (ATOVS suites of instruments (HIRS (High-Resolution Infrared Sounder), SSU (Stratospheric Sounding Unit), MSU (Microwave Sounding Unit), AMSUA/B (Advanced Microwave Sounding Unit-A/B), MHS (Microwave Humidity Sounder)), from Clear-sky radiances from geostationary satellites (CSRs), from geostationary infrared imagers, and from passive microwave imagers (SSM/I (Special Sensor Microwave Imager), SSMI/S (Special Sensor Microwave Sounder), AMSRE (Advanced Microwave Scanning Radiometer for EOS (Earth Observing System))) (Dee et al., 2011).

\section{Computation of WTC (or WPD)}

For use in satellite altimetry, the WTC can be calculated from global grids of two single-level parameters provided by global atmospheric models, such as the ERA-Interim model, the total column water vapor (TCWV, expressed in $\mathrm{kg} / \mathrm{m}^{2}$ or millimeters $(\mathrm{mm})$, as the length of an equivalent column of liquid water) and near-surface air temperature (two-meter temperature $\mathrm{t} 2 \mathrm{~m}$, here represented as $T_{0}$ ), from the following expression (Bevis et al., 1994):

$$
W T C=-\left(0,101995+\frac{1725,55}{T_{m}}\right) \cdot \frac{T C W V}{1000}
$$

where $T_{m}$ is the mean temperature of the troposphere, which can be modelled from $T_{0}$, according to, e.g., Mendes et al. (2000):

$$
T_{m}=50,440+0,789 T_{0}
$$

Equations (3.1) and (3.2) provide the WTC at the level of the atmospheric model orography.

Since the WTC has always negative values, the symmetric value of WTC, the WPD (Wet Path Delay), will be assumed and analyzed.

\subsection{WPD from Permanent GNSS Networks}

A large number of Continuously Operating GNSS Reference Stations (CORS) are operating today for multi-disciplinary applications ranging from surveying to numerical weather prediction. These stations belong to three Permanent Networks: 
- The International GNSS Service (IGS) is a voluntary federation of over 200 selffunding agencies, universities, and research institutions in more than 100 countries working together to provide the highest precision GPS satellite orbits in the world (IGS About, 2015);

- $\quad$ The EUREF Permanent Network (EPN) is also a voluntary federation of over 100 self-funding agencies, universities, and research institutions in more than 30 European countries. EPN data are used for a wide range of scientific applications such as the monitoring of ground deformations, sea level, space weather and numerical weather prediction (EPN - About, 2015);

- The SuomiNet is a network of GPS receivers located at universities and other locations to provide real-time atmospheric Precipitable Water Vapor (PWV) measurements and other geodetic and meteorological information. SuomiNet stations are located mainly in the United States. SuomiNet online site provides map plots of PWV based on processing results for the US (SuomiNet - About, 2015).

All stations from the different Permanent Networks (IGS, EPN, SuomiNet) comply with a common set of standards for receiver and antenna equipment, data exchange format maintaining up to date, and available online auxiliary data. GNSS measurements have been successfully used in precise positioning, tectonic plate monitoring, ionosphere studies and troposphere monitoring. However all GNSS signals recorded on the ground by CORS (Continuously Operating Reference Stations) are subject to ionosphere delay, troposphere delay, multipath and signal strength loss (Rohm et al., 2013). Nowadays, the GNSS signal delays are gradually incorporated into the Numerical Weather Prediction (NWP) models. Usually at GNSS Stations are used well-established methodologies for the determination of the Zenith Total Delay (ZTD) at the station location, with an accuracy of a few millimeters (Fernandes et al., 2013a). ZTD data have been considered as an important source of water vapor content and assimilated into the NWP models. The ZTD can be separated into the sum of the hydrostatic component, the Zenith Hydrostatic Delay (ZHD), and the wet component, the Zenith Wet Delay (ZWD). GNSS-derived ZWD is also known as WTC, and therefore, WPD is the symmetric variable.

Successful assimilation of these products requires strict accuracy assessment, especially in challenging severe weather conditions. In addition, these GNSS data products are freely available through the internet. 
WTC data estimated at each GNSS station from all Permanent Networks here referred are used in chapter 5 , in order to study the dependency of the wet component with height.

\subsection{U. Porto GPD+}

A methodology for the computation of improved WPD values for all contaminated, and therefore prone to be rejected, values were created in U. Porto in the aim of ESA financed projects. The GNSS Path Delay Plus (GPD+) methodology is based on the combination of wet path delays derived from ZTD calculated at a network of coastal and inland GNSS stations and valid microwave radiometer (MWR) measurements at altimeter nearby points. At each altimeter point with an invalid MWR value, the WTC is estimated from a set of observations, along with the associated mapping error, using a linear space-time objective analysis technique that takes into account the spatial and temporal variability of the WTC field and the accuracy of each data set used (Fernandes et al., 2010, 2015). In the absence of observations, tropospheric delays from the European Centre for Medium-range Weather Forecasts (ECMWF) ReAnalysis (ERA) Interim model are adopted (Fernandes et al., 2015).

Originally designed to improve the WTC in the coastal zone, the GPD+ evolved to include the global ocean, correcting for land and ice contamination in the MWR footprint, or spurious measurements due to e.g. instrument malfunction. Based on this methodology, enhanced products were generated globally for the eight main altimetric missions: ERS-1/2, Envisat, T/P, Jason-1/2, CryoSat-2 e SARAL. Details about the method can be found in Fernandes et al. (2015).

Corrections provided by the GPD+ methodology were used to generate Sea Level Anomaly (SLA) measurements in the scope of the Climate Change Initiative Sea Level (SL_cci) project, funded by the European Space Agency (ESA). The SLA SL/cci products were used in this study to analyze the WPD and SLA correlation. 


\section{Spatio-Temporal Analysis of WPD}

A time-series is a sequence of measurements of the same variable collected over time. Usually, the measurements are made at regular time intervals.

Throughout this study, the analysis of time-series is of major relevance. Time-series analysis is used to forecast future patterns of events or to compare series of different kinds of events.

When the time-series is long, there are also tendencies for measures to vary periodically, called seasonality or periodicity.

When comparing time-series the frequent ask questions are: Are the patterns over time similar for different variables? That is, what are the relationships among two or more time series? In this case, the cross-correlation functions can be used to show how related two time-series are.

The study of the spatio-temporal variability of WPD is addressed in this chapter. It is a fact that WPD is a delay and not an event of climate change, however, the WPD variability is strictly influenced by the variability of the climate variables, such as air and surface temperature, pressure, wind, water vapor and solar radiation, and therefore this work will explore the "whys" of high and low variability in certain regions which can be explained by climate events and then the hydrological cycle.

A description of the data used in this chapter and the processing is addressed in Section 4.1. The WPD and the influence of the Intertropical Convergence Zone is described in Section 4.2. The analysis of the spatial distribution of WPD and its respective components (seasonal, trend and remainder) is addressed in Section 4.3, and the analysis of the temporal distribution is addressed in Section 4.4. The correlation between WPD and several Climate indices is described in Section 4.5, and in Section 4.6 the correlation between WPD and SLA is addressed.

\subsection{Data used and processing}

\section{Generation of WPD products}

In spite of the continuous progress in modeling WPD by means of numerical weather models (NWM), namely the ECMWF (Dee et al., 2011), accuracy of present NWMderived WTC is still not good enough for most altimetry applications such as sea level variation. Indeed, an accurate enough modeling of this effect can only be achieved 
through actual measurements of the atmospheric water vapor content from MWR onboard satellite altimetry missions. However, the ERA-Interim wet tropospheric correction allows us to better characterize the uncertainty of wet troposphere content over the long term (Thao et al., 2014; Legeais et al., 2014), and for the aim of this study the accuracy given by WPD from ERA-Interim is good enough.

Remembering that WPD is the symmetric of WTC, the latter can be obtained from equations 3.1 and 3.2 which use two products of ERA-Interim reanalysis from ECMWF, the NWM described in Section 3. These products, or meteorological parameters, extracted from the ECMWF server (http://apps.ecmwf.int/datasets/data/interim full daily/) were the TCWV (Total Column Water Vapor) and the $12 \mathrm{~m}$ (Two-meter temperature). Both products are time-series of monthly grids with a spatial resolution of $0.75^{\circ}$ (longitude between $0^{\circ}$ and $360^{\circ}$ ), since January 1, 1990 until December 31, 2014, covering a 25-year period, and given in NetCDF format. Although the equations return the WPD in meters, the conversion to centimeters was essential for a better interpretation of the results, since WPD values range, in mean, from 0 to 35 centimeters. After this step, data were manipulated in order to change the longitude range from $0^{\circ}$ to $360^{\circ}$ to $-180^{\circ}$ to $180^{\circ}$.

A Matlab routine was created to generate a gridded product of WPD. With the objective of preparing data for the analysis, each instant of time, given as seconds since 1900, was converted to decimal year, and an ASCII file containing the WPD time-series was generated for each grid point, totaling 115921 WPD time-series (or files). These timeseries allow analyzing the spatial distribution of WPD over the entire world. The set of all grid points is referred as global-grid in this work.

To conduct this study, the variance and RMS (Root Mean Square) statistical measures were chosen. While the first is related to the standard-deviation, the second is related to the square root of the mean of the squares of WPD values. Therefore, the variance and RMS of WPD were calculated for each grid point, along the period of study.

\section{Generation of averaged WPD time-series}

A WPD time-series for each $0.75^{\circ}$ grid point has been generated as mentioned before. For each grid point, a weighted average of WPD time-series has also been computed. A Matlab routine was created to compute time-series with the averaged WPD values (monthly time-series).

The weight given to each WPD value at each grid point was computed according to its associated latitude using Equation (4.1). 


$$
w(x, y)=\cos (\varphi(x, y))
$$

where $\varphi(x, y)$ is the latitude of grid point $(x, y)$, and $w(x, y)$ is the weighting function applied to point $(x, y)$.

These averaged time-series were generated for: Global, North Hemisphere, South Hemisphere, and considering only land or only sea surface for each time-series.

The time-series of both hemispheres were created by limiting the latitude, this is, in the case of the North hemisphere, all points with latitude less than 0 o were not considered, and the opposite was made for the South Hemisphere.

An orography model was used to make the distinction between land and sea surfaces, with the same resolution of WPD data, $0.75^{\circ}$. In this case a Matlab routine was created in order to match each pair of latitude-longitude of WPD data with the ones belonging to the orography model.

\section{Time-series decomposition}

Decomposition methods play a fundamental role in time-series analysis. Traditional decomposition methods are mainly concerned with decomposing the variation in a series into components representing trend and periodic variations, with any remaining variation attributed to non-systematic fluctuations. In this work, the decomposing method was the STL procedure. The STL (Seasonal-trend decomposition procedure based on Loess) is a filtering procedure used for simultaneous decomposition of a time series into seasonal, trend and irregular components (Cleveland et al., 1990). STL is an iterative algorithm based on the lowess smoother yielding a decomposition that is highly resistant to extreme observations, i.e., outliers. The STL procedure consists of two nested and recursive smoothing procedures. At each iteration, trend and seasonal components are progressively refined and improved.

Applying the STL filtering procedure, already implemented in Fortran, to all time-series, those for each $0.75^{\circ}$ grid point and the averaged time-series, led to their decomposition into a seasonal component, a trend component and a remainder (irregular) component. The STL method requires the specification of two parameters, corresponding to the span for each of the lowess smoothers used to estimate the seasonal and the trend component (Cleveland et al. 1990). The seasonal parameter determines the amount of change in the seasonal indices from year to year, and the trend parameter affects the smoothness of the resulting trend component. Therefore, the parameters used to apply the STL decomposition were the same for all of the time-series presented in this study. 
The seasonal component has a period of 12 observations, one per month, and represents the annual pattern of the time-series; the trend is the component that describes data variations with a period longer than $1 \frac{1}{2}$ year, representing the interannual patterns verified along the time-series when the annual pattern is removed; therefore, the seasonal parameter was set for a smoothing window spanning 13 observations and the trend parameter was set for a window covering 21 observations. The remainder component contains the signals that are not detected as annual or trend components by the STL procedure.

An important parameter can be calculated to quantify how much the variance of each component contributes to the variance of the variable in study. The determination coefficient (DC) compares the variance of the original time series and of each modeled component, showing the percentage of the variance explained by each of them.

For a given time-series, the respective total variance and the variance of the extracted seasonal and trend components are estimated, allowing the calculation of the relative contribution of each component to the variance of the original time-series. The determination coefficient is given by Equation (4.2) (Volkov and Van Aken, 2003):

$$
D C_{\text {component }}=\frac{\sigma_{\text {component }}^{2}}{\sigma_{W P D}^{2}} \times 100 \%
$$

Therefore, after decompose each time-series grid point of WPD into three time-series of the same grid point corresponding to the seasonal, trend and remainder components, the variance of each time-series is calculated. In summary, for each grid point, there will be a variance value for the WPD time-series and a variance value for each component time-series. Applying equation 4.2 for each grid point, the result will be a global-grid with percentage values. Each value, as described above, represents the relative contribution of each component to the variance of the WPD time-series.

\section{Climate Indices}

The global atmospheric circulation has a number of preferred patterns of variability, all of which have expressions in surface climate (Christensen et al., 2013).

Water vapor, and hence the WPD, are influenced by sea surface temperature, since the evaporation from the oceans is the primary source of water vapor in the atmosphere (SST and water vapor, 2015). Therefore, it is expected that climate phenomena also cause significant changes in WPD patterns.

A global temporal correlation of WPD and monthly time-series of the main phenomena related with the atmosphere and ocean, also known and referred in this work as climate 
indices, could indicate a description of these relationships. First of all, time-series were standardized because they have different units and magnitude. Therefore, each grid point of WPD data corresponding to a distinct time-series was detrended by applying a linear adjustment (the Least Square Method described in Annex A was applied), then the Matlab's corrcoef function was used to obtain the Pearson correlation coefficient (also described in Annex A) and the p_value associated to it, for each combination of WPD time-series and climate index, since it is an easy way to standardize data in Matlab. The obtained correlation coefficient map is called as teleconnection map (Christensen et al., 2013). To use in the study of these teleconnections, Climate Indices were taken from http://www.esrl.noaa.gov/psd/data/climateindices/list/. A description of them is addressed below.

The atmospheric component tied to El Niño is termed the "Southern Oscillation". Scientists often call the phenomenon where the atmosphere and ocean collaborate together ENSO (EI Niño-Southern Oscillation). ENSO is one of the most important phenomena affecting global climatic variability on interannual time scales. ENSO is a coupled ocean-atmosphere phenomenon resulting from the interaction between the surface layers of the ocean and the overlying atmosphere in the tropical Pacific (Trenberth, 1997). The El Niño represents the oceanographic component and the Southern Oscillation the atmospheric component of the same phenomenon. Therefore, the two principal indices used to characterize ENSO are the Southern Oscillation Index (SOI) and the Nino 3.4 index. The Nino 3.4 index gives the departure in monthly sea surface temperature from its long-term mean averaged over the region $5^{\circ} \mathrm{N}-5^{\circ} \mathrm{S}$ and $170^{\circ} \mathrm{W}-120^{\circ} \mathrm{W}$ (Trenberth, 1997). The one used in this work correspond to anomalies derived by the NOAA (National Oceanic and Atmospheric Administration) Optimum Interpolation (OI) Sea Surface Temperature (SST) V2 monthly fields (Reynolds et al., 2001). The SOI is defined as the normalized difference in sea level pressure between Tahiti and Darwin, Australia, and it gives a measure of the large-scale fluctuations in air pressure occurring between the western and eastern tropical Pacific (i.e., the state of the Southern Oscillation) during El Niño and La Niña episodes (Zebiak, 1999). Negative values of the SOI correspond to EI Niño conditions (weakening of trade winds) while large positive values of the SOI are related with stronger than average trade winds and La Niña conditions.

The Pacific Decadal Oscillation (PDO) is a long-term ocean fluctuation of the Pacific Ocean. The PDO waxes and wanes approximately every 20 to 30 years. The PDO is often described as a long-lived El Niño-like pattern of Pacific climate variability (Zhang et al., 1997). In parallel with the ENSO phenomenon, the extreme phases of the PDO have been classified as being either warm or cool, as defined by ocean temperature 
anomalies in the northeast and tropical Pacific Ocean. The PDO index is defined as the leading principal component of North Pacific monthly sea surface temperature variability (poleward of $\left.20^{\circ} \mathrm{N}\right)$.

A major source of interannual variability in the atmospheric circulation is the North Atlantic Oscillation (NAO), which is associated to changes in the surface westerlies across the North Atlantic onto Europe. The NAO index used in this work is based on sea level pressure (SLP) anomalies over the Atlantic sector, $20^{\circ} \mathrm{N}-80^{\circ} \mathrm{N}, 90^{\circ} \mathrm{W}-40^{\circ} \mathrm{E}$ (Hurrell, 1995).

The Tropical Northern Atlantic (TNA) SST anomaly index is an indicator of the surface temperatures in the eastern tropical North Atlantic Ocean. The TNA index is the anomaly of the average of the monthly SST from $5.5^{\circ} \mathrm{N}$ to $23.5^{\circ} \mathrm{N}$ and $15^{\circ} \mathrm{W}$ to $57.5^{\circ} \mathrm{W}$ (Climate Indices, 2015).

The Tropical Southern Atlantic (TSA) SST anomaly index is an indicator of the surface temperatures in the Gulf of Guinea, the eastern tropical South Atlantic Ocean. The TSA index is the anomaly of the average of the monthly SST from $0^{\circ}-20^{\circ} S$ and $10^{\circ} \mathrm{E}-30^{\circ} \mathrm{W}$ (Climate Indices, 2015).

The Atlantic Multi-decadal Oscillation (AMO) has been identified as a coherent mode of natural variability occurring in the North Atlantic Ocean with an estimated period of $60-80$ years. The AMO index used in this work is the unsmoothed version of time-series calculated from the Kaplan SST dataset which is updated monthly over $0 \div-80 \div \mathrm{N}$ (Trenberth and National Center for Atmospheric Research Staff, 2015).

The Western Pacific (WP) pattern is a primary mode of low-frequency variability over the North Pacific in all months, and has been previously described by both Barnston and Livezey (1987) and Wallace and Gutzler (1981). The WP index is derived from a rotated principal component analysis (RPCA) of normalized 500-hPa height anomalies.

Therefore, in this work SOI, Niño 3.4, NAO, TNA, TSA, WP, PDO and AMO monthly time-series since 1990 until 2014 from NOAA Climate Prediction Center (CPC) were used.

\section{Sea Level Anomalies}

In the last two decades, sea level has been routinely measured from space using satellite altimetry techniques. The accuracy of altimetry-based sea level records at global and regional scales implies improvements that include: reduction of orbit errors and wet/dry atmospheric correction errors, reduction of instrumental drifts and bias, intercalibration biases, inter-calibration between missions and combination of the different sea level data sets, and an improvement of the reference mean sea surface. When 
studying the WPD variability, we can ask "How WPD is related with Sea Level?". The relation between WPD and SLA can be analyzed following the same procedure that was developed to relate WPD and Climate Indices. A description of the SLA data used is addressed below.

In the scope of the CCl sea level project (SL_cci), which aimed to produce a consistent and precise sea level record covering the last two decades, an SLA product was generated for each of 6 missions (TOPEX/Poseidon, Jason-1, Jason-2, ERS-1, ERS-2, Envisat) over the period since 1993 until 2013. The SL_cci products are time-series of monthly grids with a spatial resolution of $0.25^{\circ}$. For use in this work, and before applying the procedure of standardize and correlate data, SLA time-series grids were manipulated in order to obtain time-series grids with a spatial resolution of $0.75^{\circ}$ degrees, having correspondence to the time-series latitude-longitude grids of generated WPD products.

\subsection{WPD and the influence of the Intertropical Convergence Zone}

An important and well-publicized component of the general circulation of the atmosphere has come to be termed the "Intertropical Convergence Zone" (ITCZ).

ITCZ appears as a band of clouds consisting of showers, with occasional thunderstorms, that encircles the globe near the equator (JetStream, 2015), see Figure 4.1. A brief description of what happens in this region and the relation with WPD is given below.

A permanent low-pressure feature that marks the meteorological equator where surface trade winds, laden with heat and moisture from surface evaporation and sensible heating, converge to form a zone of increased mean convection, cloudiness, and precipitation. The latent heat released in the convective cloud systems of the ITCZ is a critical component of the atmospheric energy balance, and the enhanced cloudiness associated with these cloud systems provides an important contribution to the planetary albedo (Waliser and Jiang, 2014). The fluxes of heat, moisture, momentum, and radiation between the atmosphere and the surface differ dramatically between the ITCZ region and the regions to the north and south of the ITCZ. Thus, the position, structure, and migration of the ITCZ play an important role in determining the characteristics of ocean-atmosphere and land-atmosphere interactions on a local scale, the circulation of the tropical oceans on a basin scale, and a number of features of the Earth's climate on a global scale (Hastenrath and Lamb, 1978). The upward motions that dominate the region favor the formation of heavy rainfalls, known as tropical rainfalls, and hence, the ITCZ is the rainiest latitude zone in the entire world, with many locations accumulating more than 200 days of rain each year. This zone is usually called the doldrums (weather situation in which winds are calm). Many areas along the equator are dominated by ITCZ 
year round and experience no dry season. Areas located near the poleward margins of the ITCZ, however, are subject to brief dry seasons as the zone shifts equatorward. Similarly, some areas located on the equatorward edge of the subtropical highs are dry for most of the year, except briefly when the system shifts poleward during the summer. This condition exists in Sahel of Africa, the region bordering the southern margin of Sahara Desert. Unlike the Sahara, which is dry all year, the Sahel normally experiences a brief rainy period each summer as the ITCZ enters the region, and during the rest of the year, prevail dry conditions (Aguado and Burt, 2001).

At the longitudes of the major continents, the low-level tropical wind field exhibits a strong seasonal dependence, with a tendency toward onshore (sea to land) flow during summer and offshore flow during winter. The seasonal reversal is particularly pronounced over Southeast Asia and adjacent regions of the Indian Ocean where the prevailing winds blow from the southwest during summer and northeast during winter. These seasonal wind regimes are known as monsoons (from the Arabic word mausin - a season). Over most of India, the summer (southwest) monsoon is characterized by heavy rainfall while the winter (northeast) monsoon is extremely dry (Wallace et al., 1977).

In summary, we can say that the ITCZ region coincides with the confluence between Northern and Southern hemisphere trades, the zone of maximum sea temperature (SST), the surface pressure trough, and bands of maximum cloudiness and rainfall (Ramage, 1974). The ITCZ follows the sun in its apparent path, so it varies seasonally, and moves north in the northern summer and south in the northern winter, Figure 4.1.

The ITCZ is what is responsible for the wet and dry seasons in the tropics (JetStream, 2015). Therefore, the ITZC plays an important influence on the movement of WPD at each season, along the tropics, as can be observed when comparing WPD (mean values for each grid point) with ITCZ in January, corresponding to the northern winter season, and in July, corresponding to the northern summer season (Figures 4.1, 4.2 and 4.3). 


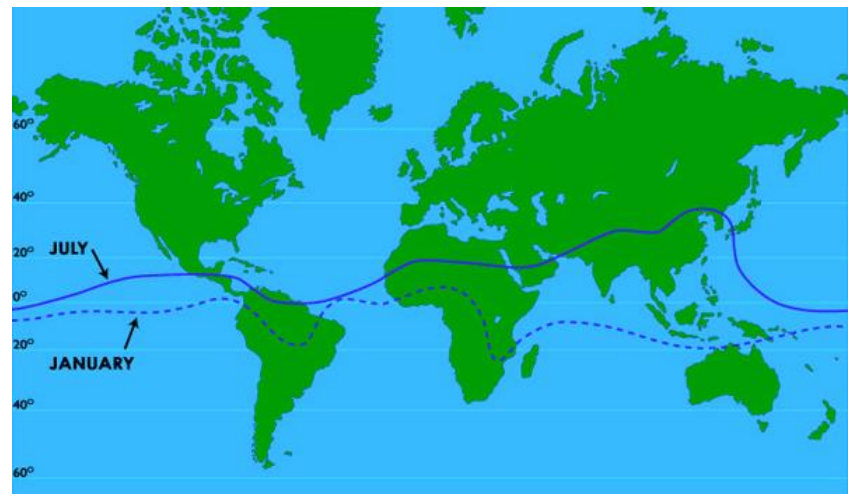

Figure 4.1 - Movement of the Intertropical Convergence Zone (ITCZ). Source: https://courseware.e-education.psu.edu/courses/earth105new/content/lesson07/03.html

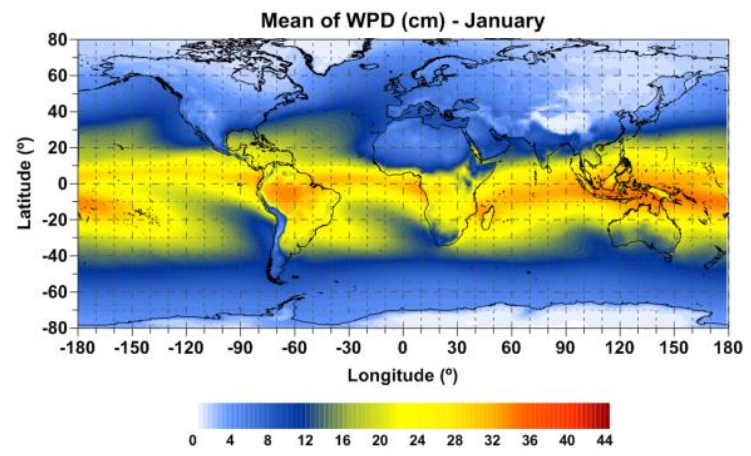

Figure 4.2 - Spatial Distribution of WPD in January - Winter season.

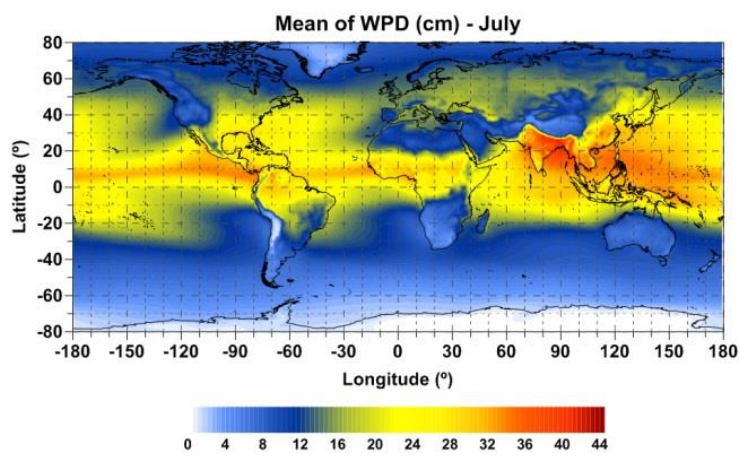

Figure 4.3 - Spatial Distribution of WPD in July - Summer season.

\subsection{Spatial Analysis}

As mentioned in Chapter 3, the WPD computation depends mainly on the amount of water vapor in the troposphere and on the temperature near the surface (see equations 3.1 and 3.2). Therefore, the study of the spatial variability of WPD is important, given the high variability of water vapor.

To perform this study, variance and RMS (Root Mean Square) global-grids of WPD generated in this study, as described in Section 4.1, were used.

According to Figure 4.4, the variance of WPD ranges from $1-25 \mathrm{~cm}^{2}$ near the poles to $100-135 \mathrm{~cm}^{2}$ in the tropics and has a strong dependency on latitude, as Andersen and Scharoo (2011) demonstrated from Jason-1 data, studying the mean and standard deviation of the wet tropospheric correction.

The highest values of WPD variance are found in areas close to the tropics of Cancer and Capricorn ( $\sim 3^{\circ} 30^{\prime} \mathrm{N}$ and $\sim 23^{\circ} 30^{\prime} \mathrm{S}$ respectively). Maximum variance values of WPD are found over the tropics over southern and eastern Asia, northern Australia and parts of western and central Africa. Other regions namely Mexico and the southwest 
USA, and parts of South America and South Africa also reveal high values of WPD variance. These are the regions where the increasing of precipitation is related to the regional monsoon domains, which is linked to the ITZC influence, as seen in the previous section. The monsoon circulation is driven by the difference in temperature between land and sea, which varies seasonally with the distribution of solar heating (Christensen et al., 2013). The duration and amount of rainfall depends on the moisture content of the air, and on the configuration and strength of the atmospheric circulation. The regional distribution of land and ocean also plays a role, as does topography. In fact, looking at the variance of WPD (Figure 4.4), it is noticeable the influence of the Indian and East Asian Monsoon, the Australian Monsoon, South America Monsoons, and West Africa Monsoon (covering the Sahel region). It happens because a longer duration of a precipitation event adds more available moisture to be evaporated into the air (Haby J., 2015), which will contribute to increase the water vapor content in the troposphere, due to the hydrological cycle, and thus will increase the WPD.

The minimum variability of WPD coincides with the minimum quantity of water vapor in the atmosphere and can be found over deserts and polar regions, where values between 0 and $5 \mathrm{~cm}^{2}$ for the variance of WPD can be found.

The RMS values of WPD (Figure 4.2) show a near-zonal dependency, with absolute values ranging from less than $5 \mathrm{~cm}$ at high latitudes to $\sim 35 \mathrm{~cm}$ near the equator and the tropics. Therefore, WPD values are higher near to equator and decreases from equator to polar regions. These results match with WPD measurements and water vapor distributions (Fernandes et al., 2013b). 


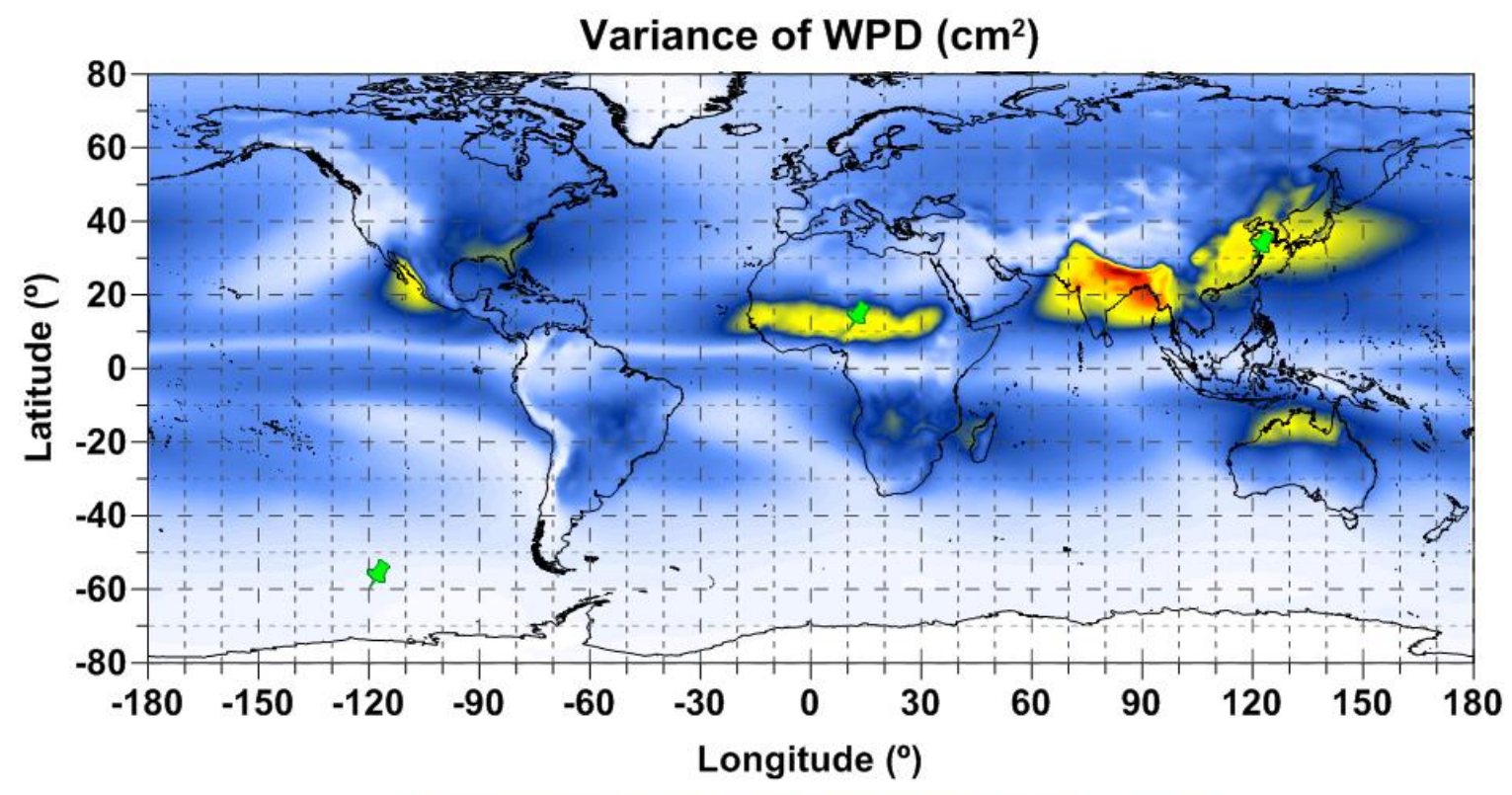

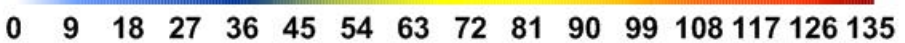

Figure 4.4 - Spatial distribution of the variance of WPD (in $\mathrm{cm}^{2}$ ).

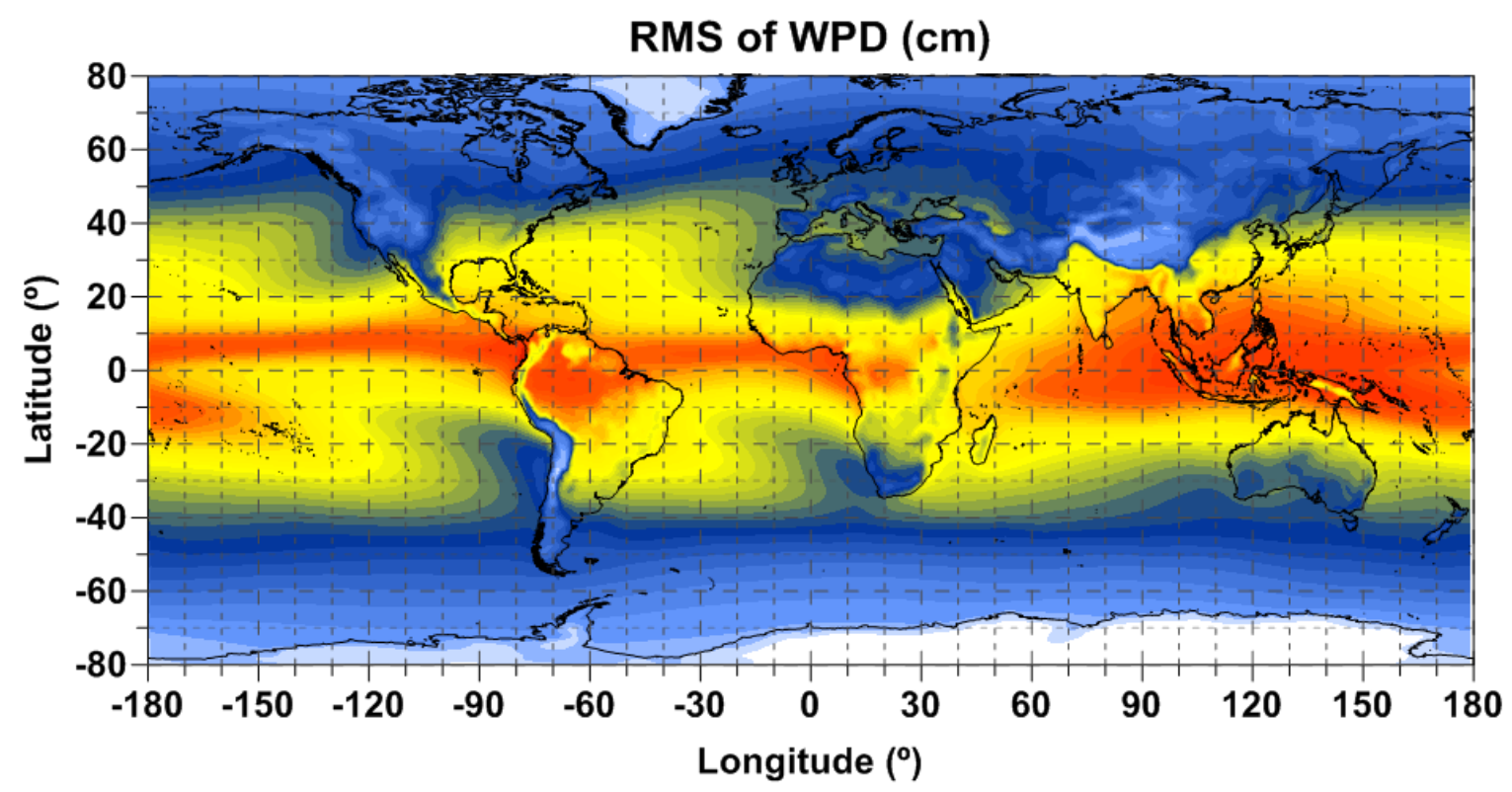

$\begin{array}{lllllllllllllllllll}0 & 2 & 4 & 6 & 8 & 10 & 12 & 14 & 16 & 18 & 20 & 22 & 24 & 26 & 28 & 30 & 32 & 34 & 36\end{array}$

Figure 4.5 - Spatial distribution of the RMS of WPD (in $\mathrm{cm}$ ).

Extracting selected time-series of grid points corresponding to different regions of the globe (notice the three green points in Figure 4.4), we can see that every WPD timeseries has different patterns. Figure 4.6 represents a time-series near the equator line in Africa, Figure 4.7 represents a time-series in the tropics in the South Eastern Asia 
region, and Figure 4.8 represents a time-series in the South Pole. Despite the first two time-series are located at different latitudes, the time-series have identical patterns, having WPD values ranging between 5 and $32 \mathrm{~cm}$, with a mean amplitude of $25 \mathrm{~cm}$. Considering the last figure, we can see that the time-series presents WPD values ranging between 4 and $9 \mathrm{~cm}$, with a mean amplitude of $5 \mathrm{~cm}$, and presents an irregular pattern which hinders the identification of the annual and semi-annual patterns.

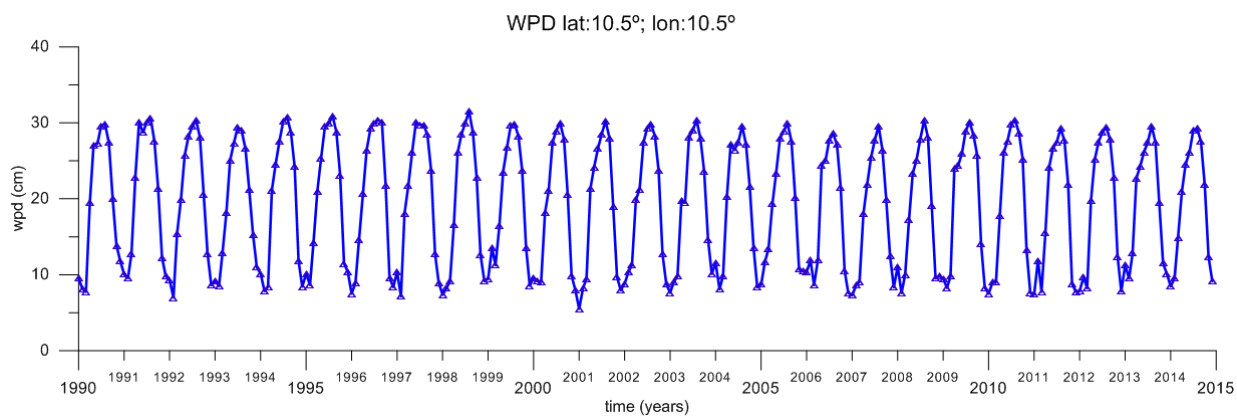

Figure 4.6 - Time-series of WPD at 10.5N, 10.5ㅌ․

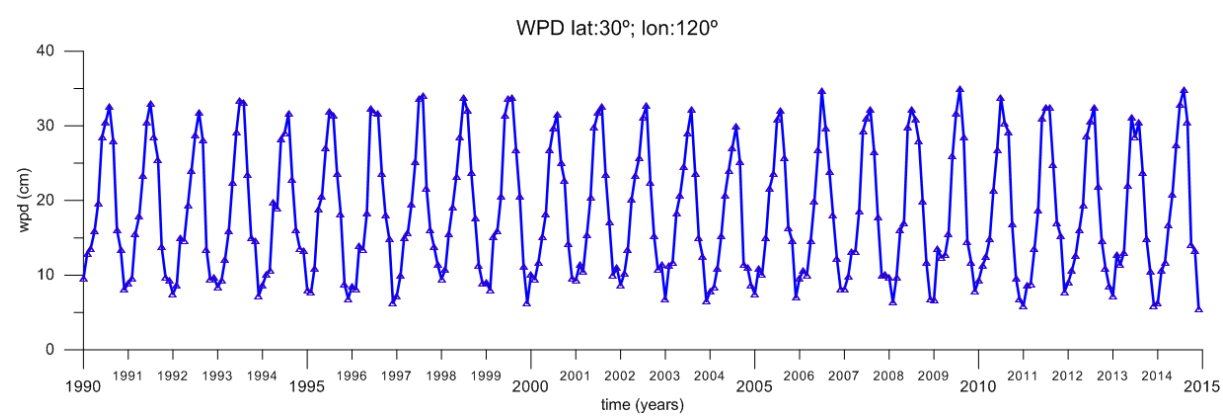

Figure 4.7 - Time-series of WPD at $30^{\circ} \mathrm{N}, 120^{\circ} \mathrm{E}$.

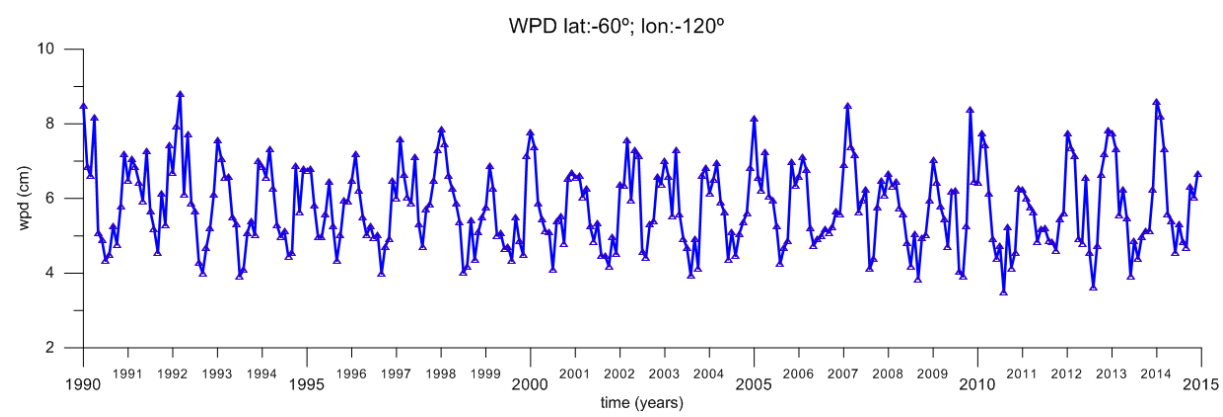

Figure 4.8 - Time-series of WPD at $60^{\circ} \mathrm{S}, 120^{\circ} \mathrm{W}$.

\section{The Annual and Interannual patterns}

As we have seen in Section 4.1, the annual and interannual patterns are described by the seasonal and trend components respectively. 
The variance values of the seasonal component were estimated at each grid point, allowing the calculation of the relative contribution of this component to the total variance of WPD (shown in Figure 4.4), given by the determination coefficient (DC) expressed by Equation (4.1).

The spatial distribution of the determination coefficient of the seasonal component, Figure 4.9, shows that the seasonal component is the principal contribution for the variance of WPD in the Northern Hemisphere.

It is clear that in the equator line this contribution varies between $15 \%$ and $50 \%$, increasing towards polar regions. However, the contribution of the trend component has the opposite behavior (Figure 4.10).

Comparing the contributions of the seasonal and trend components for the total variance of WPD, it is possible to conclude, as expected, that in the areas of the largest variability of WPD, the seasonal component contributes almost $100 \%$, due to the annual patterns of the monsoon events in those regions, whereas the trend component has almost $0 \%$ of contribution. Indeed, the highest interannual values are observed over ocean, and are related to the ENSO phenomenon.

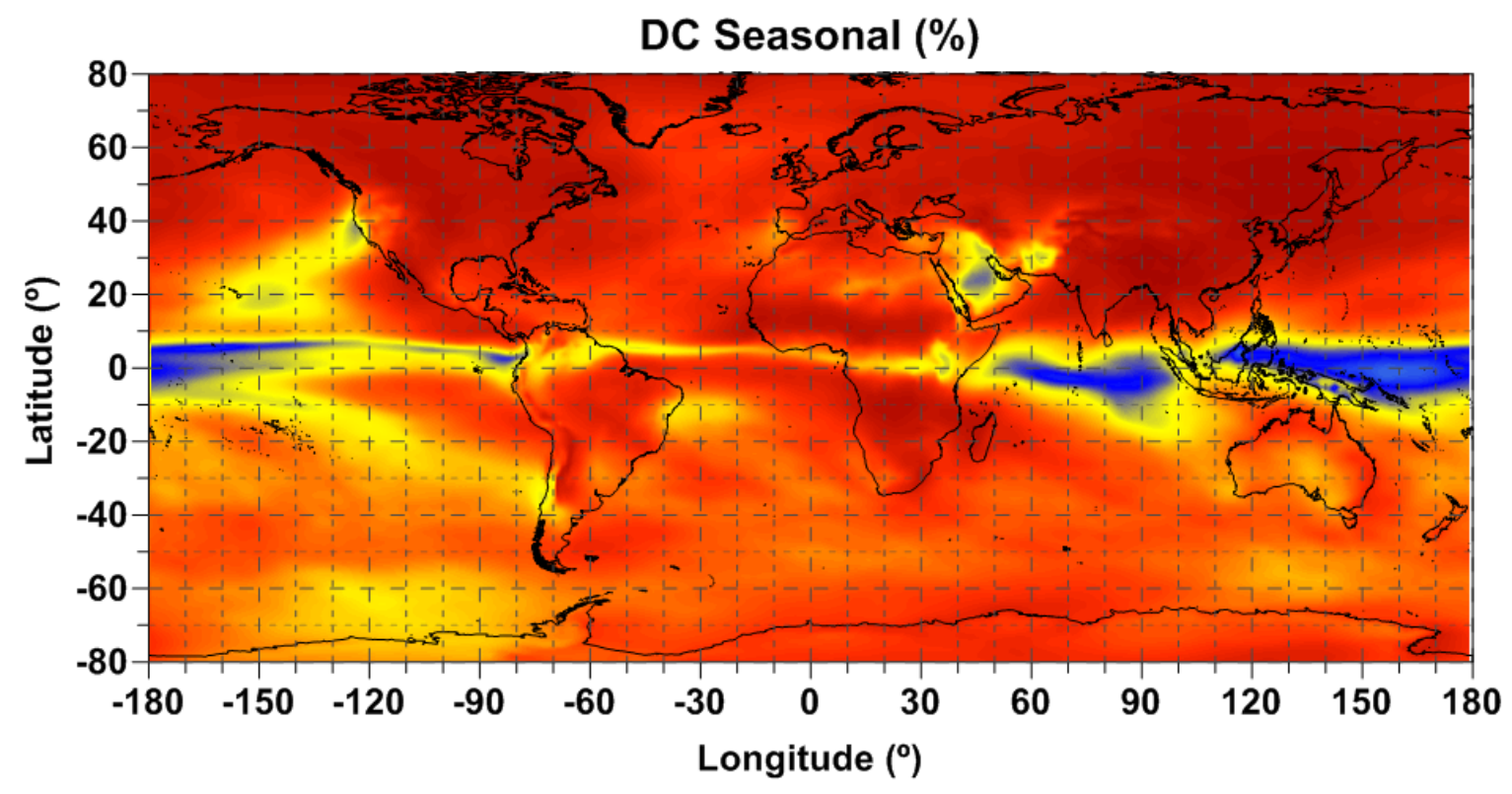

05101520253035404550556065707580859095100

Figure 4.9 - Spatial distribution of the Determination Coefficient (\%) of the seasonal component (DC Seasonal) of WPD variability. 


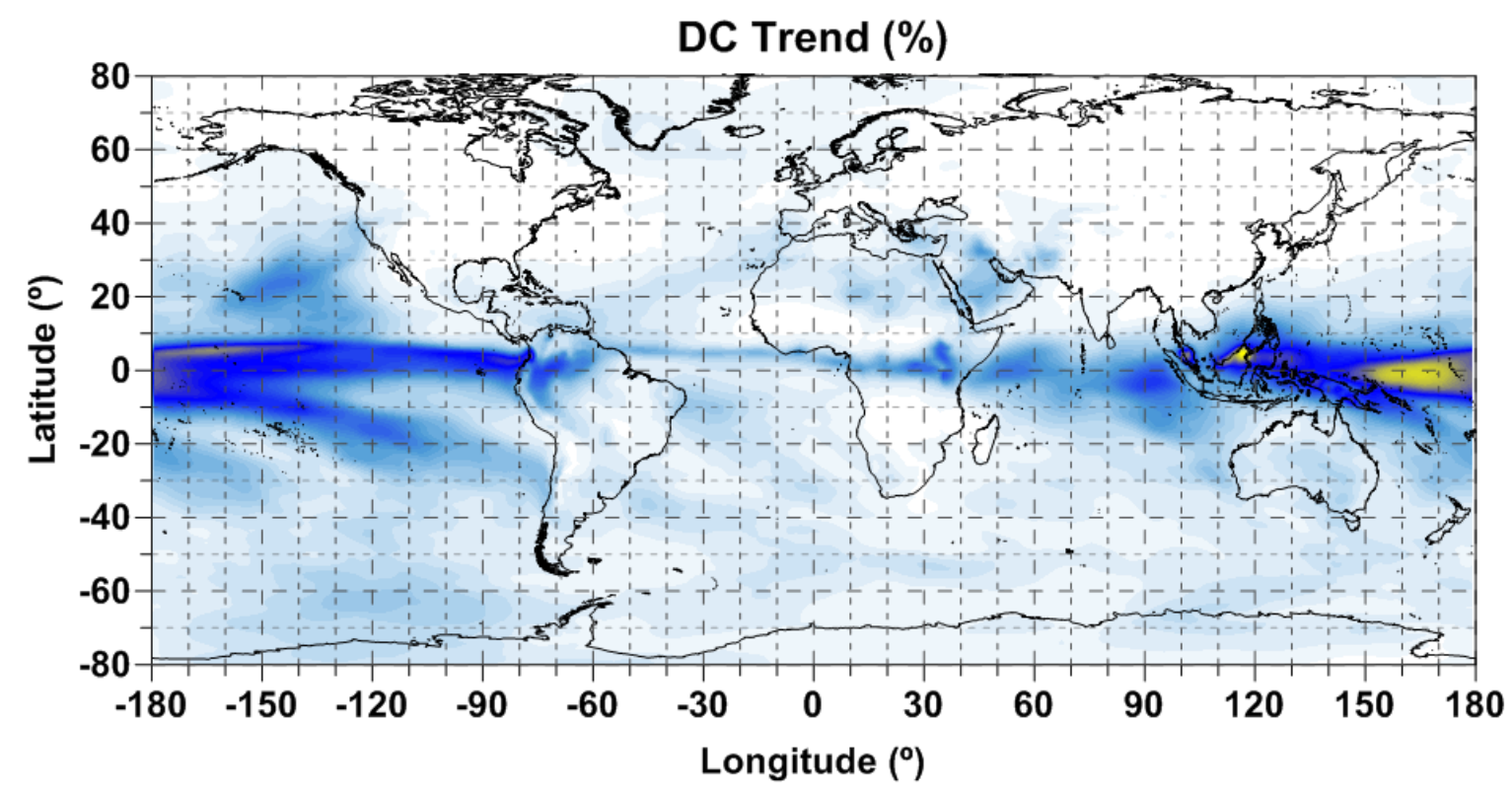

$0 \quad 5101520253035404550556065707580859095100$

Figure 4.10 - Spatial distribution of the Determination Coefficient (\%) of the trend component (DC Trend) of WPD.

Although almost the total WPD variability can be explained by the seasonal and trend components, yet the remainder component presents about $50 \%$ of contribution relatively to the variance of WPD in some regions (Figure 4.11). It happens because there are airsea interactions that are not constant in time, and those situations are not considered in the seasonal or trend components. 


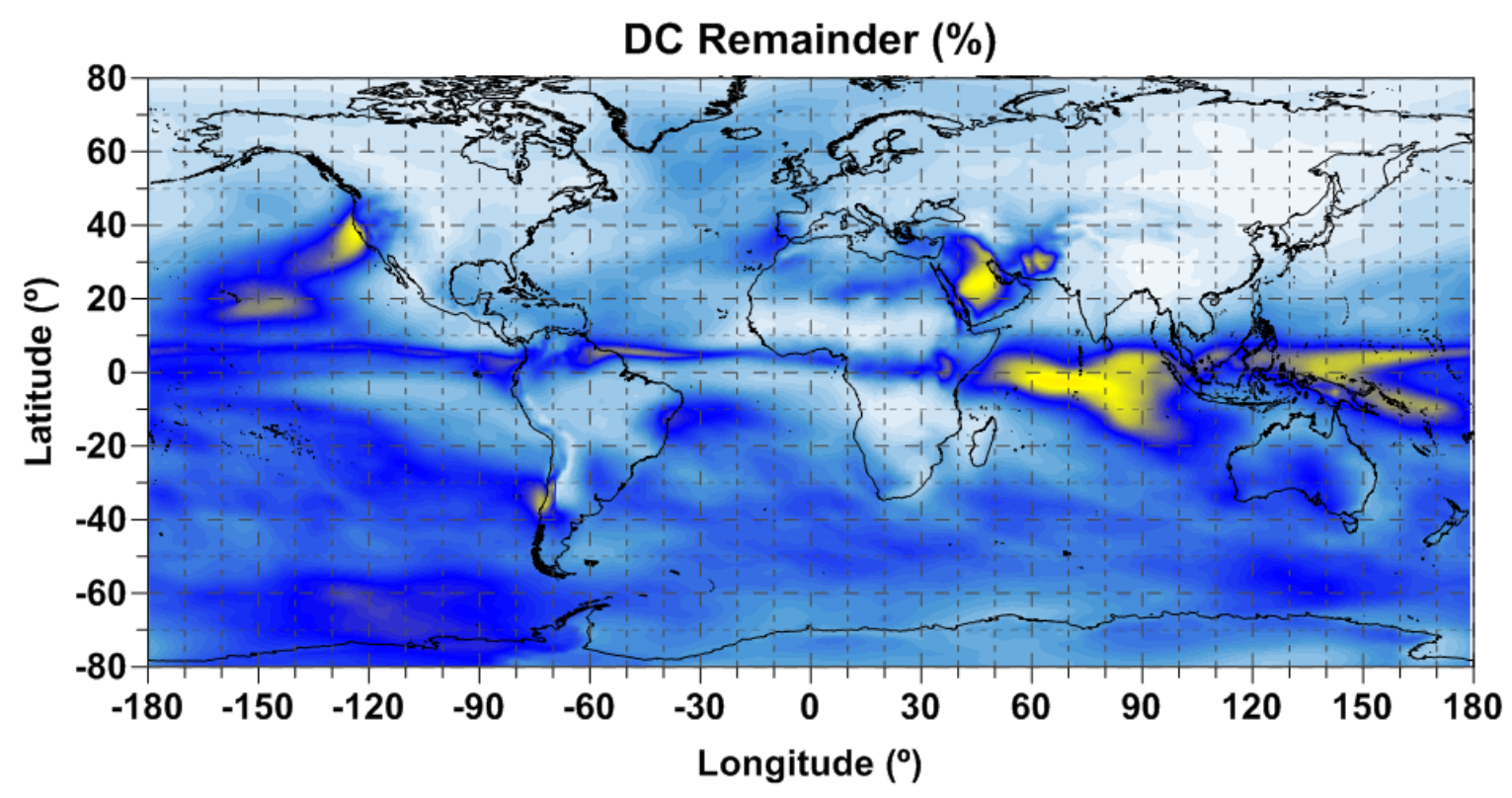

05101520253035404550556065707580859095100

Figure 4.11 - Spatial distribution of the Determination Coefficient (\%) of the remainder component (DC Remainder) of WPD.

The mean peak-to-peak amplitude of the seasonal cycle was computed for each grid point, and the resultant global-grid is shown in Figure 4.12. In this case, and because only the seasonal component is considered, this statistic measure allows to understand the annual variation of WPD.

The mean amplitude of the seasonal component of WPD has values between 0 and 34 centimeters. The maximum amplitudes are located in the regions of highest variability, as it is possible to conclude when comparing this result with the global variance of WPD shown in Figure 4.4. Besides, it is noticeable that the mean amplitude of the seasonal component explains almost every contribution of this component relatively to the variance of WPD.

However, there are some regions of interest with high variance and with maximum contribution of the seasonal component that present minimum values for the mean amplitude of the seasonal component. Among those regions we present in Figure 4.13 the example for the India case. 


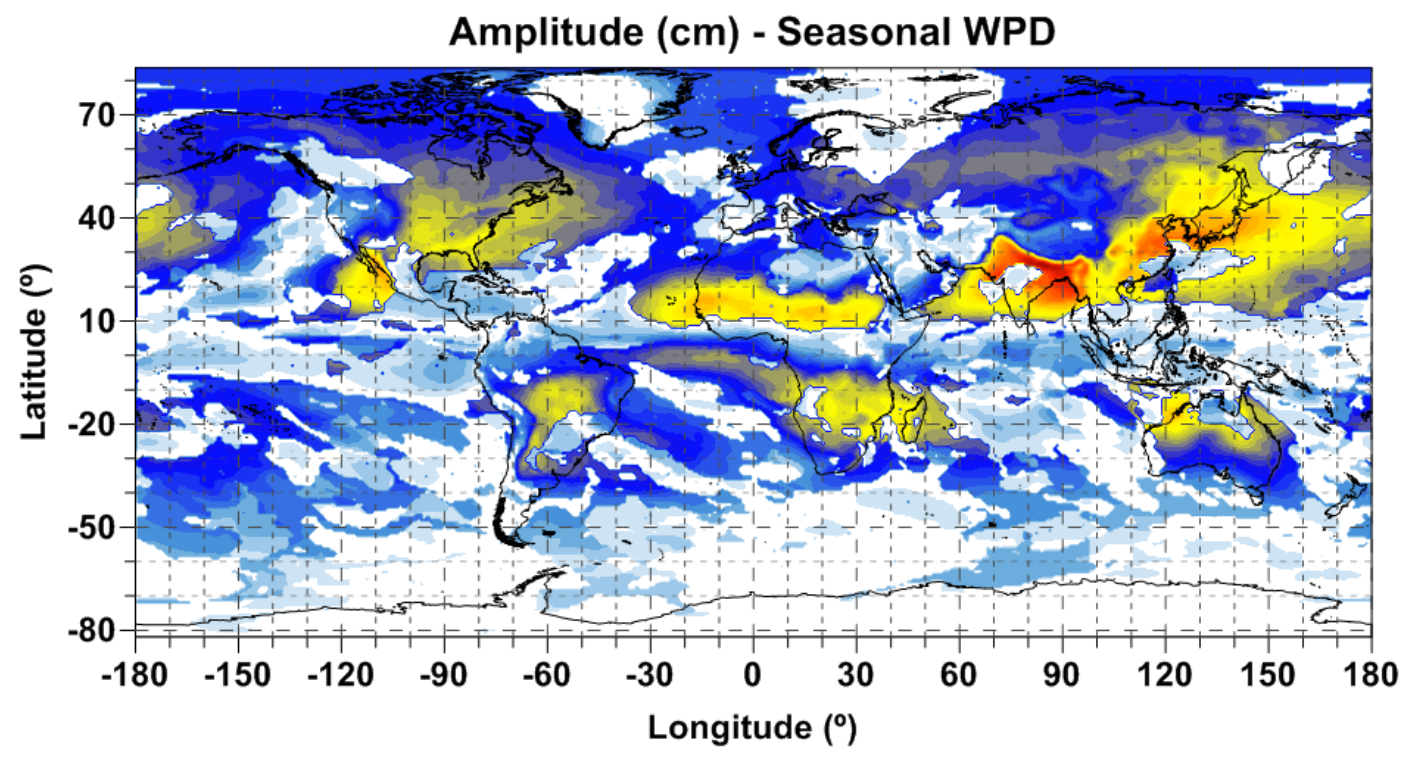

$\begin{array}{llllllllllllllllll}0 & 2 & 4 & 6 & 8 & 10 & 12 & 14 & 16 & 18 & 20 & 22 & 24 & 26 & 28 & 30 & 32 & 34\end{array}$

Figure 4.12 - Spatial distribution of the Amplitude (cm) of the seasonal component of WPD variability.
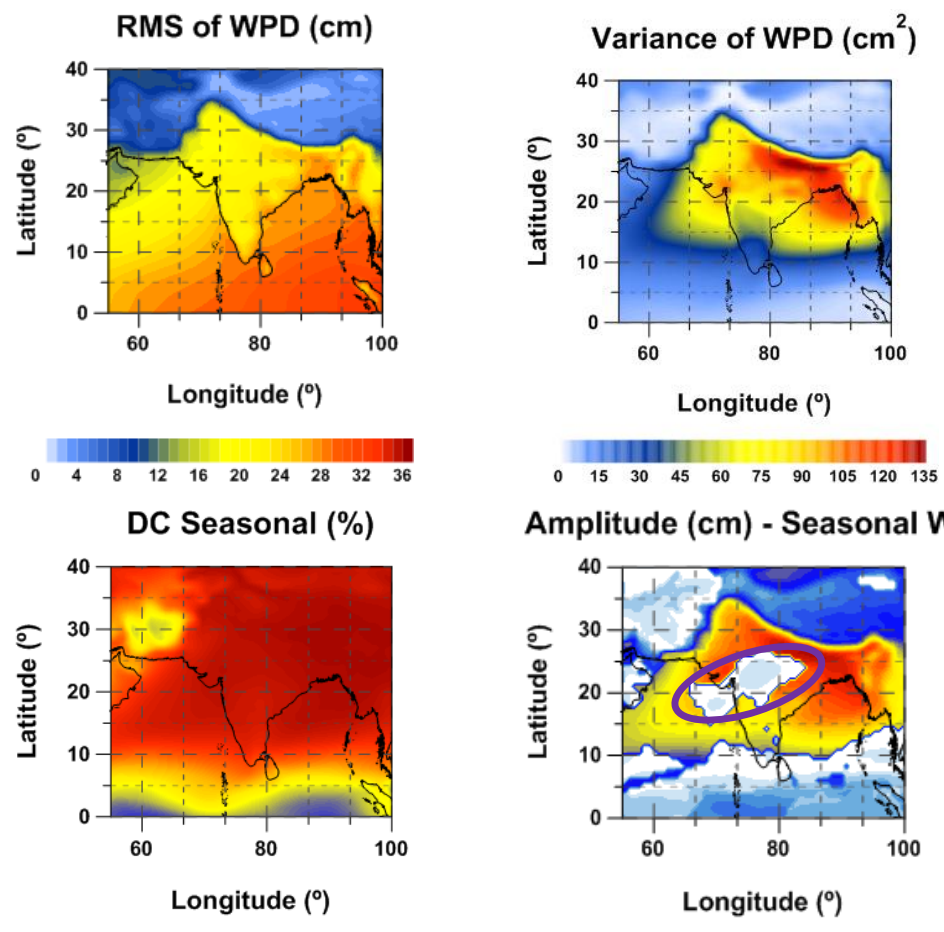

Amplitude (cm) - Seasonal WPD
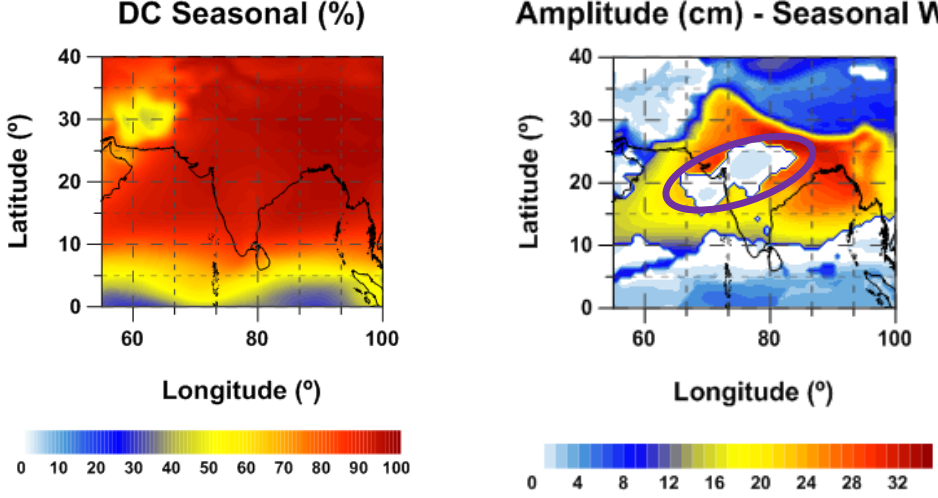

Figure 4.13 - Region of South of Asia, near the India. 
In the same way, the trend (interannual) component time-series for each grid point was adjusted using a linear fit, by applying the Least-Squares method, to obtain a value for the slope and the corresponding value for the R-squared $\left(R^{2}\right.$, or coefficient of determination as described in Annex $A$ ) of the linear regression fit. The $R^{2}$ values are smaller than 0.3, and thus the linear fit only explains the values observed in $30 \%$, meaning that the linear fit is not the most adequate model to adjust these time-series. The slope is an important measure because it gives how much the fitted linear regression is growing in time. As WPD was generated in centimeters the global-grid of slope values is presented in Figure 4.14 in units of $\mathrm{cm} /$ year. However, the slope values are given in $\mathrm{mm} /$ year in the text, as is usually the case.

Comparing the spatial distribution of slopes and the spatial distribution of WPD variance, it is possible to observe that the variance of WPD is not related with the slope of the trend component. It means that, despite some regions are prone to have high variability of WPD, this does not imply rising or declining of WPD.

The minimum value for the slope of the trend component is $-0.16 \mathrm{~mm} / \mathrm{year}$ and the maximum value is $0.18 \mathrm{~mm} / \mathrm{year}$. The range is so small that even if we adjust a better fit, with a high R-squared value, the measured slopes will not be so different than the ones described here.

The minimum values for the slope appear in the Pacific Ocean, and they are related to the El Niño and La Niña phenomena.

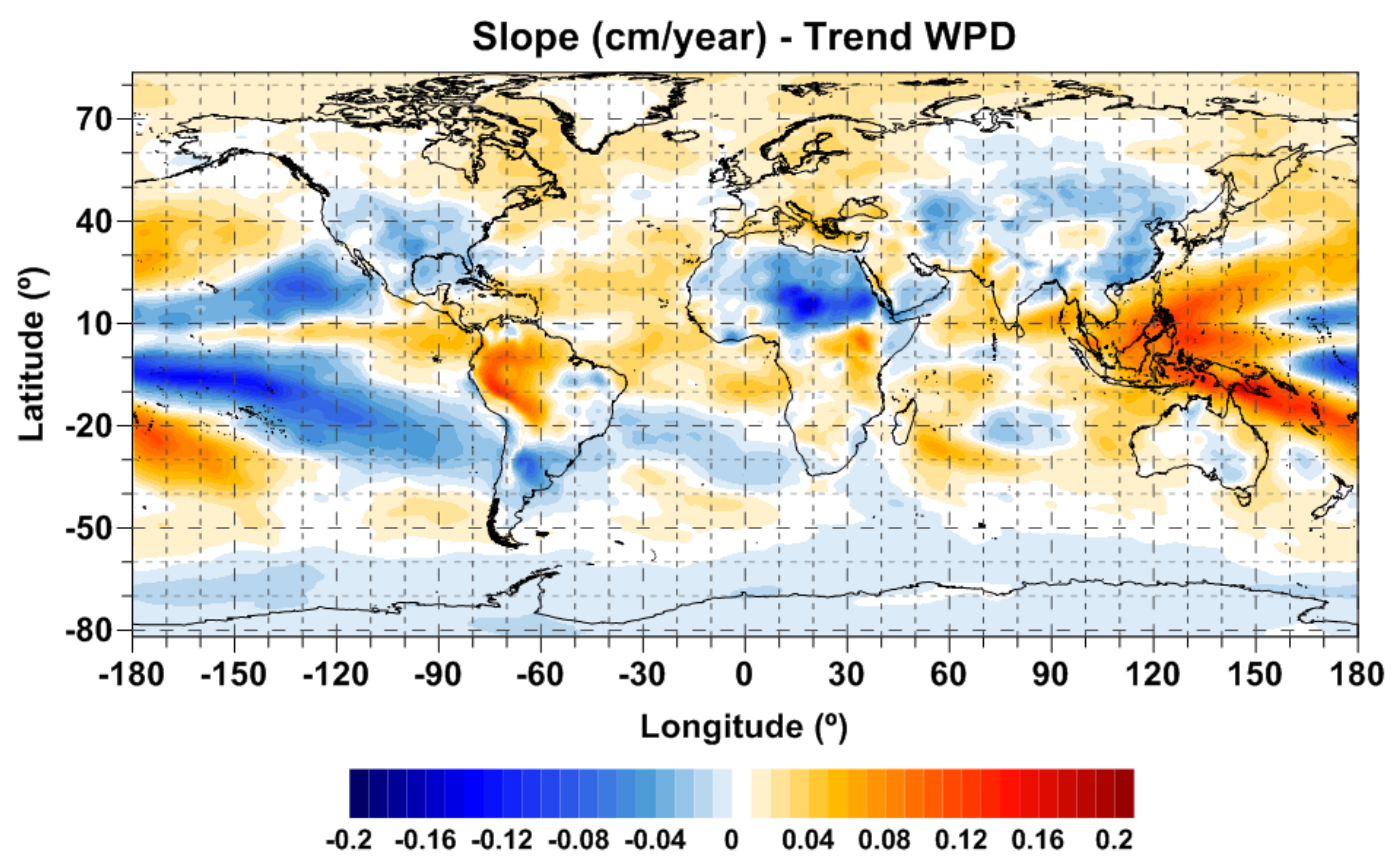

Figure 4.14 - Spatial distribution of the slope (cm/year) of the WPD trend component. 


\subsection{Temporal Analysis}

The temporal analysis consists on studying the global and hemispherical time-series, as well as the correspondent land and sea surface time-series, using the generated averaged WPD time-series described in Section 4.1, that is, time-series of monthly means of WPD values, weighted according to their associated latitude. The same statistical methods used in the spatial analysis were also applied in this analysis.

\subsubsection{Global Time-series}

The global time-series of WPD and the corresponding seasonal and trend time-series, from STL decomposition, are shown in Figure 4.15. The global time-series of WPD clearly shows the effect of the seasonal component. The seasonal component has averaged peak-to-peak amplitude of $1.98 \mathrm{~cm}$. The trend component of the time-series explains how the WPD varies with time, ignoring the seasonal periodicity. Adjusting a linear fit to the trend component, the observed slope has a value of $0.09 \mathrm{~mm} / \mathrm{year}$, and the R-squared has a value of 0.18 .

Considering the global time-series of WPD and the correspondent time-series only in land and only in sea surface, Figure 4.16, we can see that the time-series for oceanic region presents low variability and the annual pattern is affected because we are considering both hemispheres simultaneously.

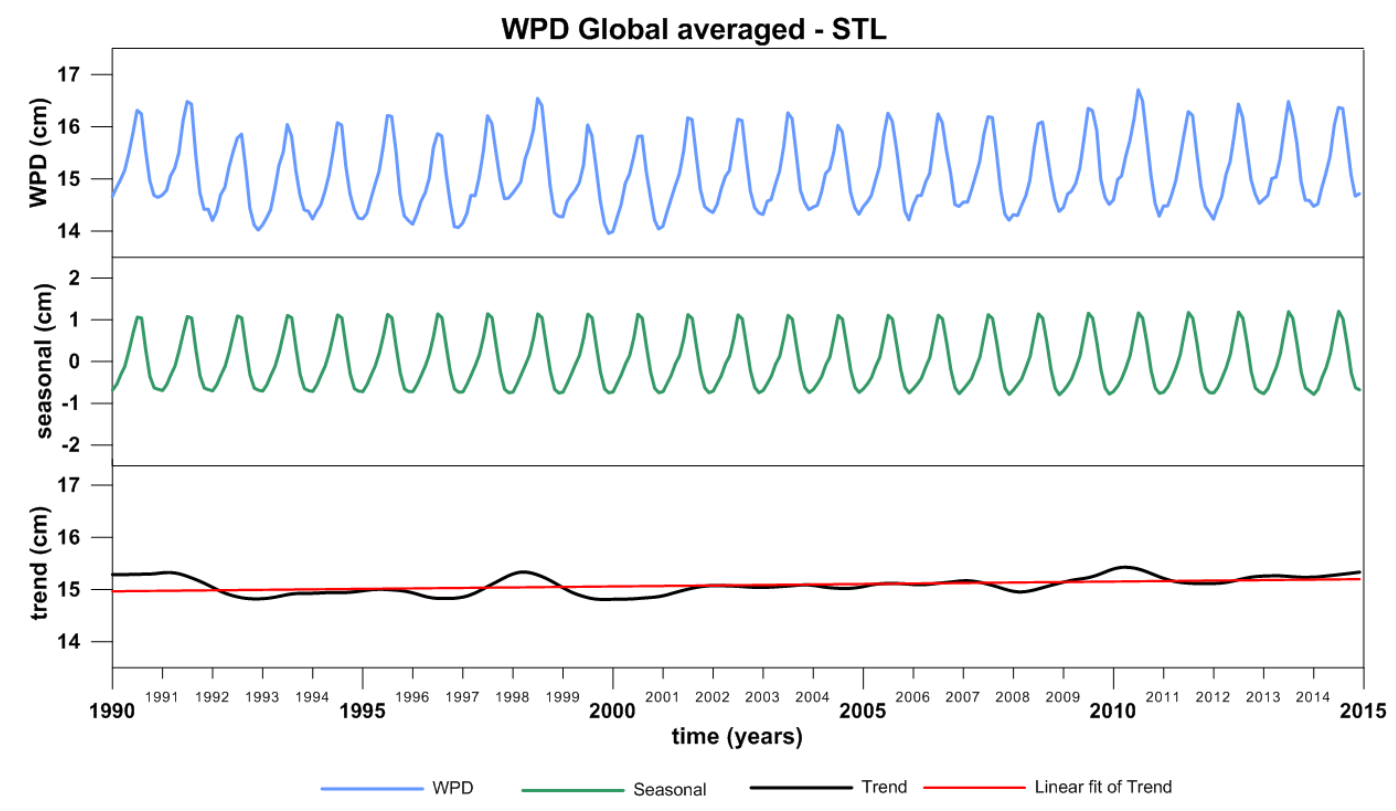

Figure 4.15 - STL decomposition of the Global Time-series. Top panel represents the WPD time-series, middle panel represents the seasonal component and bottom panel represents the trend component and the correspondent linear fit (in red). 


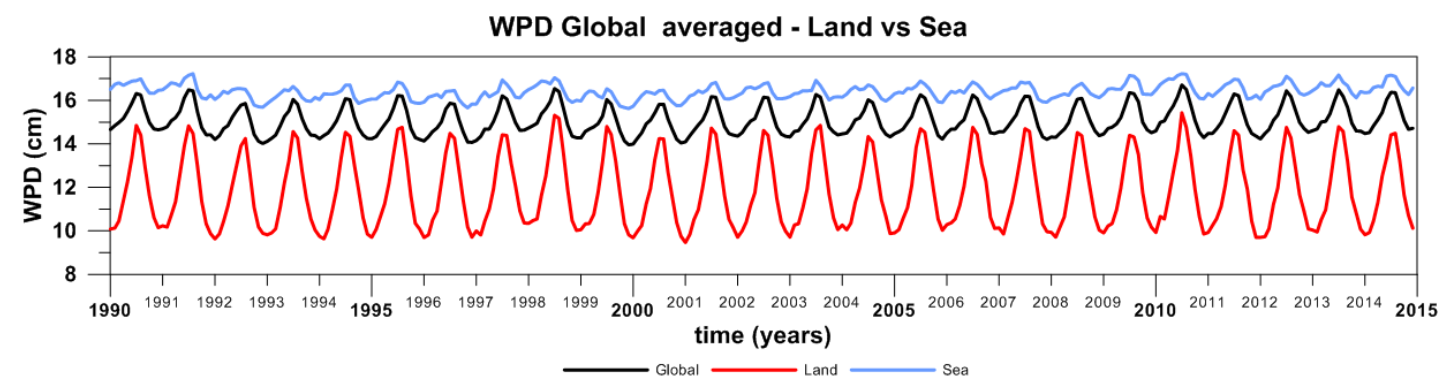

Figure 4.16 - Comparison between global time-series for continental and oceanic regions separately.

\subsubsection{North vs South Hemisphere}

A previous study concerning the Northern Hemisphere reveals slopes for the annual and interannual components of water vapor in the troposphere at different regions. The Pacific Ocean is the region with the highest slopes, with values greater than 1.14 $\mathrm{mm} /$ decade (Ross and Elliott, 2000).

In this work, the same analyses were performed for the North and South hemispheres, which allowed concluding that the global time-series is influenced by the difference in phase between both hemispheres, as can be observed in Figure 4.17, which presents the seasonal components of both global and hemispherical WPD time-series.

Comparing the trend components of the global and hemispherical time-series, Figure 4.18 , it is clear that the analyzed time-series have patterns in common, happening at the same time, that are not explained by the annual cycle (annual component). Therefore, these patterns are expected to be explained from a comparison of the time-series with some Climate Indices, and with Sea Level Anomaly (SLA).

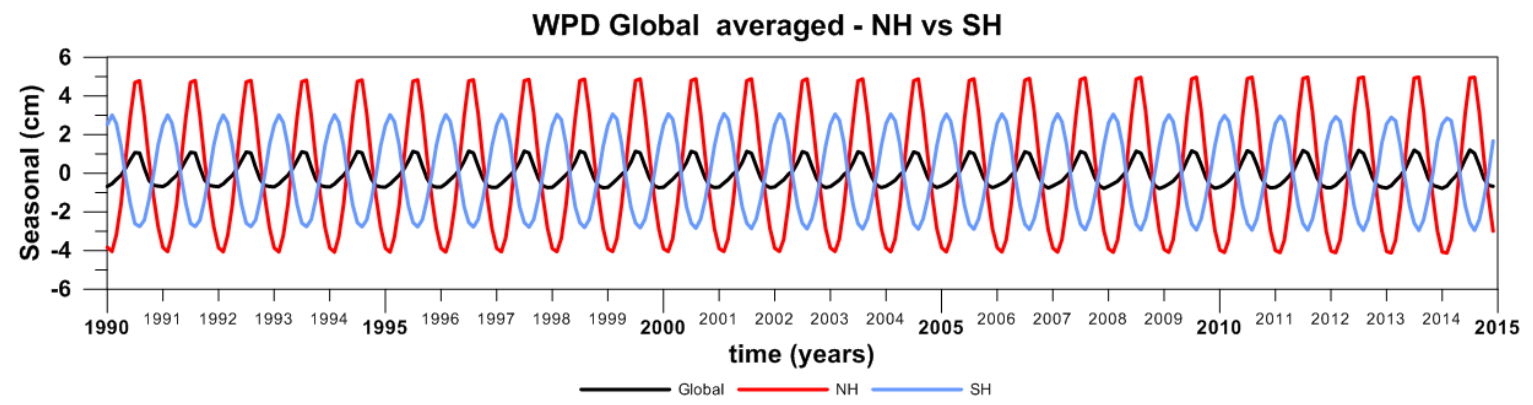

Figure 4.17 - Comparison between the seasonal components of the WPD time-series for Global, North hemisphere and South hemisphere. 
WPD Global averaged - NH vs SH

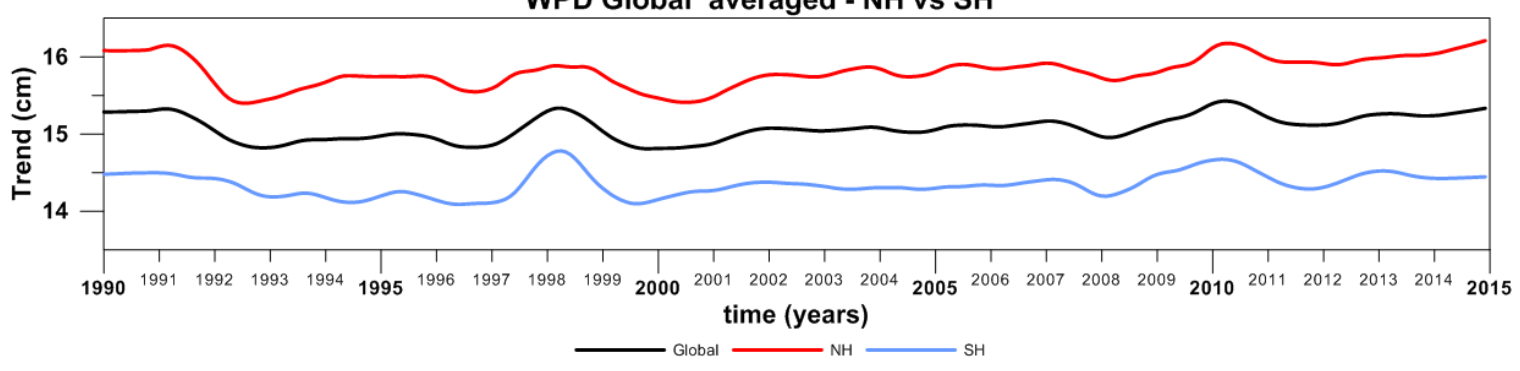

Figure 4.18 - Comparison between the trend components of time-series for Global, North hemisphere and South hemisphere.

\subsection{WPD and Climate Indices}

Correlation exists when two variables have a linear relationship beyond what is expected by chance alone.

We have seen that WPD is related with temperature and water vapor. Throughout this work it was possible to explain some of the "WHYS" that previously arose. Like "Why is the WPD higher along the equator?" Or "Why has the WPD more variability in some distinct regions over the tropics?". These and more questions were answered using climate events that occur in our planet. So, it is important to know how WPD is related with some of these phenomena.

A Climate Index is a time-series that explains the variability of a certain climate phenomenon. In this work SOI, Niño 3.4, NAO, TNA, TSA, WP, PDO and AMO monthly time-series since 1990 to 2014, from NOAA Climate Prediction Center (CPC), as described before in Section 4.1 were used. The WPD time-series for each grid point was correlated with the time-series of each Climate Index. Each correlation coefficient map is known as teleconnection (Christensen $t$ al., 2013), and grid points with an associated correlation coefficient that is not statistically significant, with a confidence level of $95 \%$, is represented in white.

Teleconnection maps for the various Climate Indices are presented in Figures 4.19 and 4.20. The analysis of these maps allowed concluding if and how WPD is related with the phenomena associated to each climate index. 

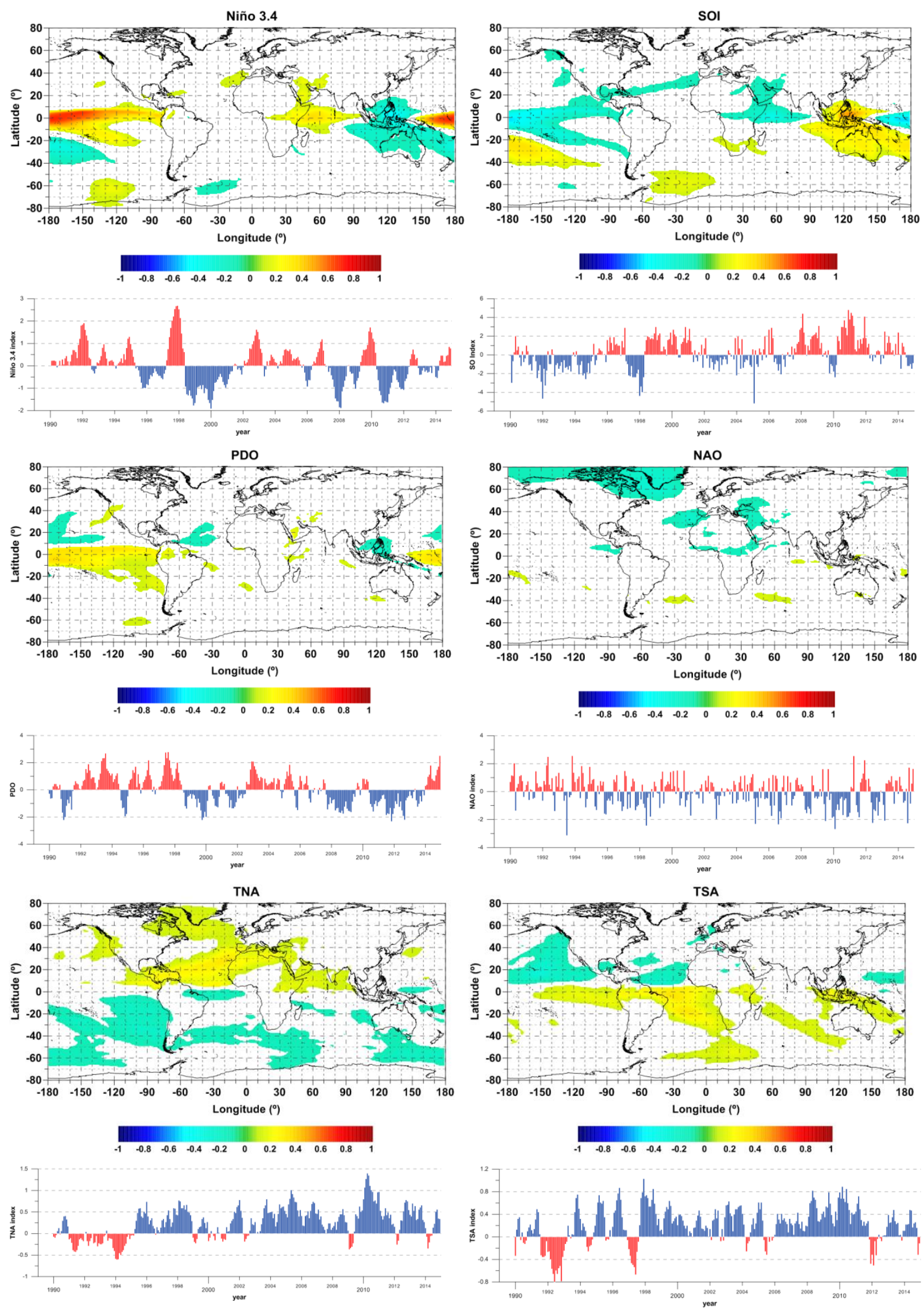

Figure 4.19 - Teleconnections of WPD and Climate Indices: (top) Niño 3.4 and SOI; (middle) PDO and NAO; (bottom) TNA and TSA. 

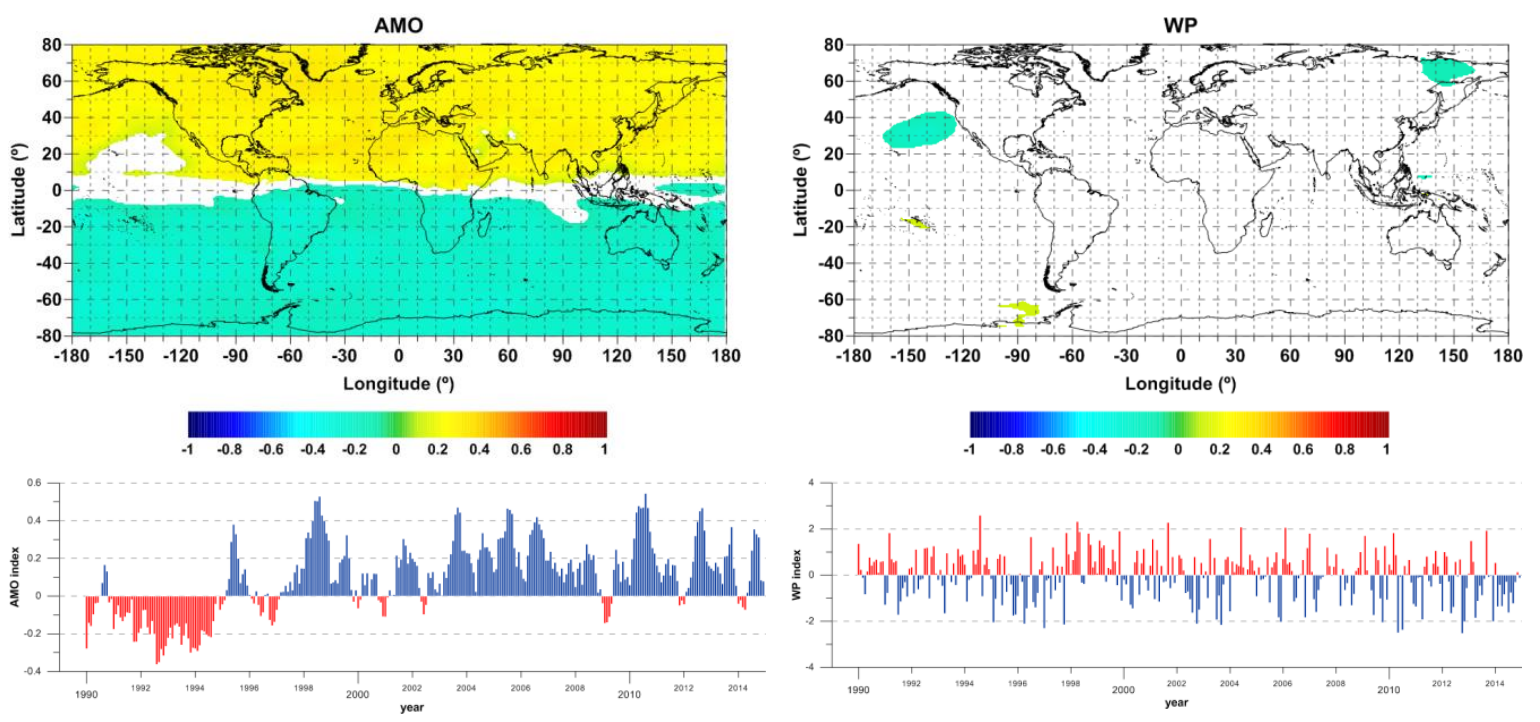

Figure 4.20 - Teleconnections of WPD and Climate Indices AMO and WP.

However, a more detailed analysis can be done if we correlate WPD with Climate Indices for each season. In this way, a Matlab routine was implemented to generate those teleconnections. Defining each season according to the North Hemisphere, different teleconnection maps were created for: the winter season which is composed by December, January and February months (DJF), the spring season which is composed by March, April and May (MAM), the summer season which is composed by June, July and August months (JJA), and finally, autumn which is composed by September, October and November (SON) months.

Starting with the ENSO phenomenon, we can see that the SOI, defined by the out-ofphase relationship between sea level pressure (SLP's) in the western tropical Pacific and the southeastern tropical Pacific, is highly negative correlated with WPD mostly over western tropical Pacific over open ocean in northern winter season, and in the northern autumn season SOI is highly positive correlated with WPD over the north of Australia as shown in Figure 4.21. The out-of-phase pattern is associated with different rainfall and wind field patterns over the Pacific and other parts of the globe (The Southern Oscillation, 2015).

As expected, once WPD values are influenced by precipitation and temperature, these results match with teleconnections of SOI and precipitation and of SOI and surface air temperature already publicized (Christensen et al., 2013).

The teleconnection map of Niño 3.4 and WPD complements these results. 

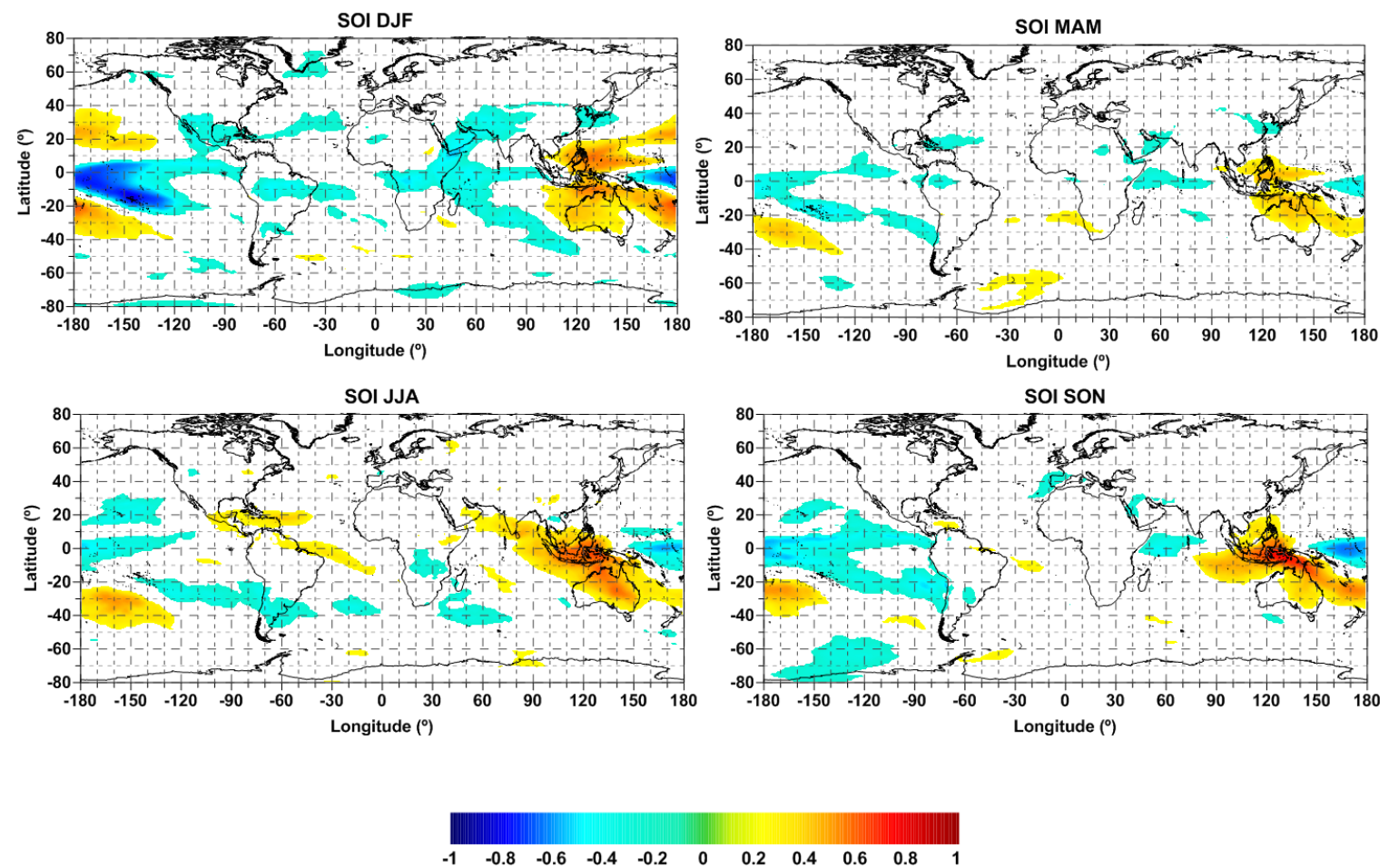

Figure 4.21 - Teleconnection map of WPD and SOI.

Figure 4.22 shows that Niño 3.4 is highly positively correlated with WPD over western tropical Pacific in the northern winter season, and in the northern autumn season, which coincides with high negative correlation between SOI and WPD, as described above. It is important to refer that El Niño is usually associated with drier than average conditions over certain regions, e.g. in the north of Australia, and La Niña is associated with wetter than average conditions over certain regions, e.g. the Maritime Continent (ENSO impacts, 2015). The Maritime Continent includes the archipelagos of Indonesia, New Guinea, and Malaysia, and the surrounding shallow seas (Maritime Continent, 2015). 

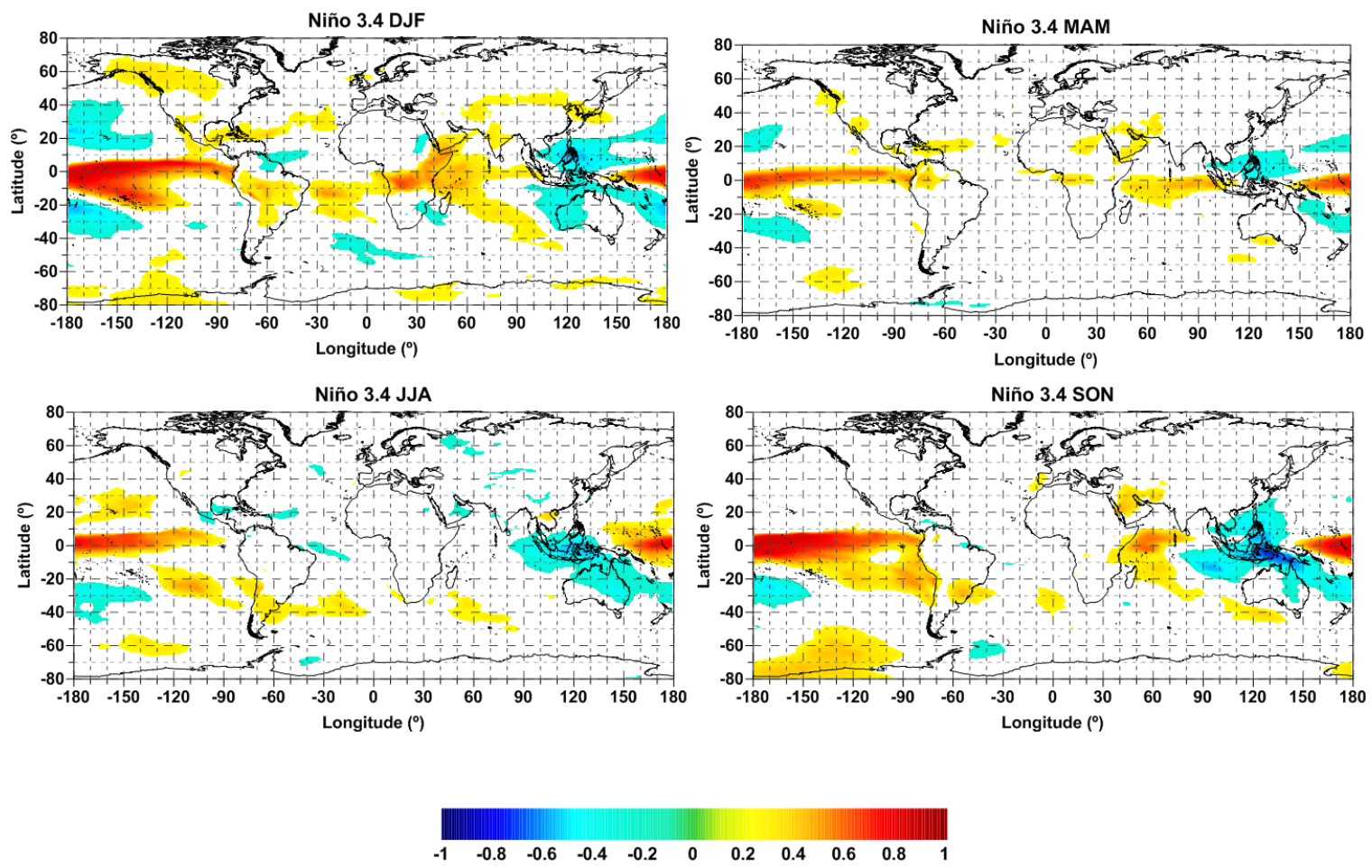

Figure 4.22 - Teleconnection map of WPD and Niño 3.4.

Because NAO influences the North Atlantic jet stream, storm tracks and blocking (Christensen et al., 2013), it is related with precipitation and air temperature thereby affecting winter climate over the North Atlantic and surrounding landmasses, as the Western Europe and Mediterranean basin climates (Christensen et al., 2013). Therefore, the teleconnection between NAO and WPD presents high correlation values over the Northern Hemisphere mostly in winter, as expected, with high significant and negative correlation (with values ranging -0.3 and -0.7 ) over Greenland, the Canadian Artic and presents high significant positive correlation (with values ranging 0.3 and 0.5 ) over the Eastern United States and Northern Europe (Figure 4.23). These results also match with the teleconnections of NAO and temperature and of NAO and precipitation already shown by Christensen et al. (2013). 

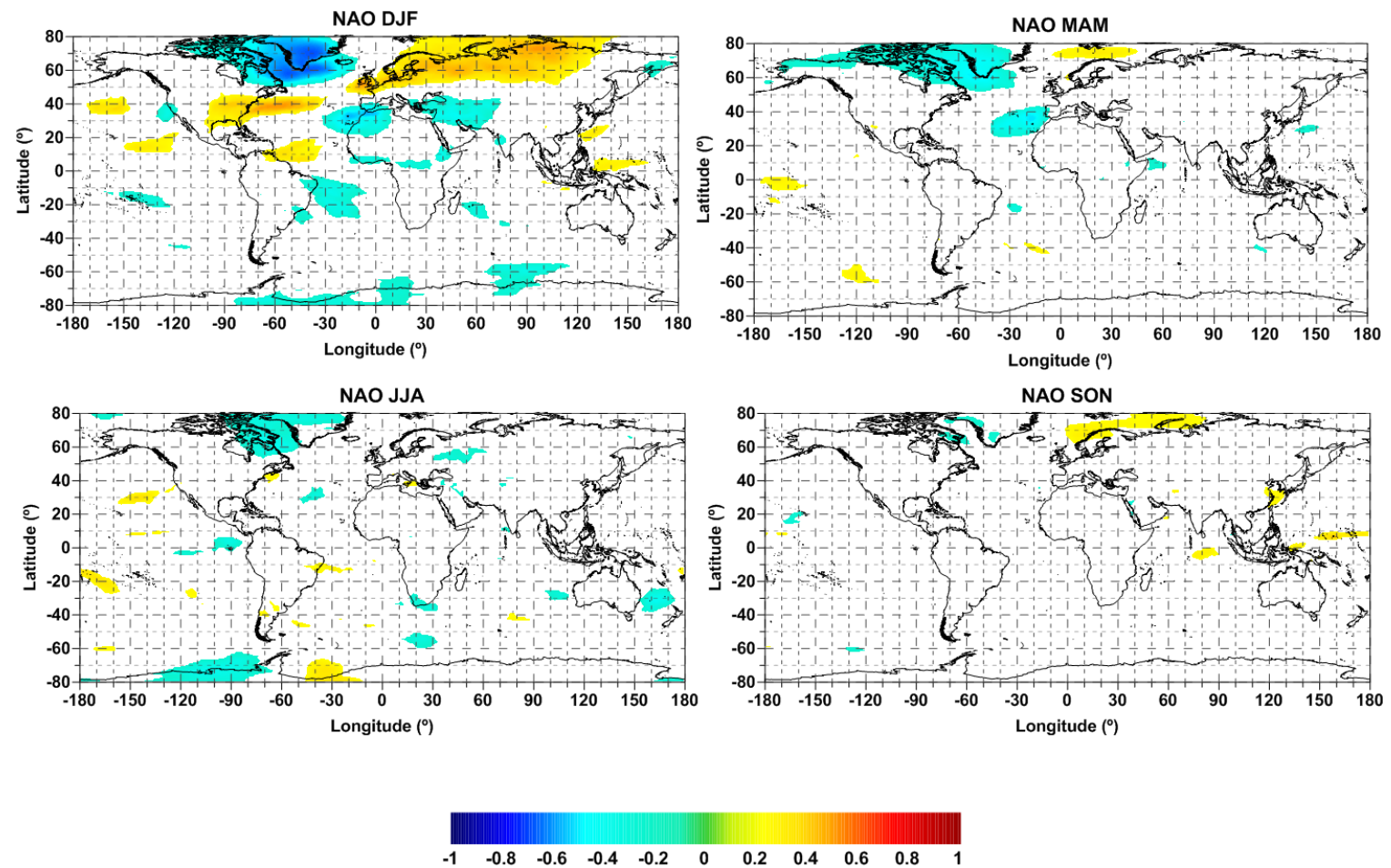

Figure 4.23 - Teleconnection map of WPD and NAO.

In parallel with the ENSO phenomenon, the extreme phases of the PDO are classified as either warm or cool, as defined by ocean temperature anomalies in the northeast and tropical Pacific Ocean (Mantua, 1999). When SST is anomalously cool in the interior North Pacific and warm along the Pacific Coast, and when sea level pressures are below average over the North Pacific, the PDO has a positive value (Mantua, 1999). When the climate anomaly patterns are reversed, with warm SST anomalies in the interior and cool SST anomalies along the North American coast, or above average sea level pressure over the North Pacific, the PDO has a negative value. As is the case with ENSO, characteristic pressure, wind, temperature, and precipitation patterns have been connected with the PDO (Latif and Barnett, 1996, Zhang et al., 1997, Mantua et al.. 1997), therefore it is expected that PDO is connected with WPD. The teleconnection between PDO and WPD (Figure 4.24) shows high significant correlations in the Western Pacific in winter, with positive values ranging between 0.3 and 0.5 , and with negative values ranging -0.2 and -0.5 , and in autumn coinciding with the high positive correlation $(\sim 0.5)$ found in the teleconnection between Niño 3.4 and WPD, which also means that El Niño and PDO are in phase. 

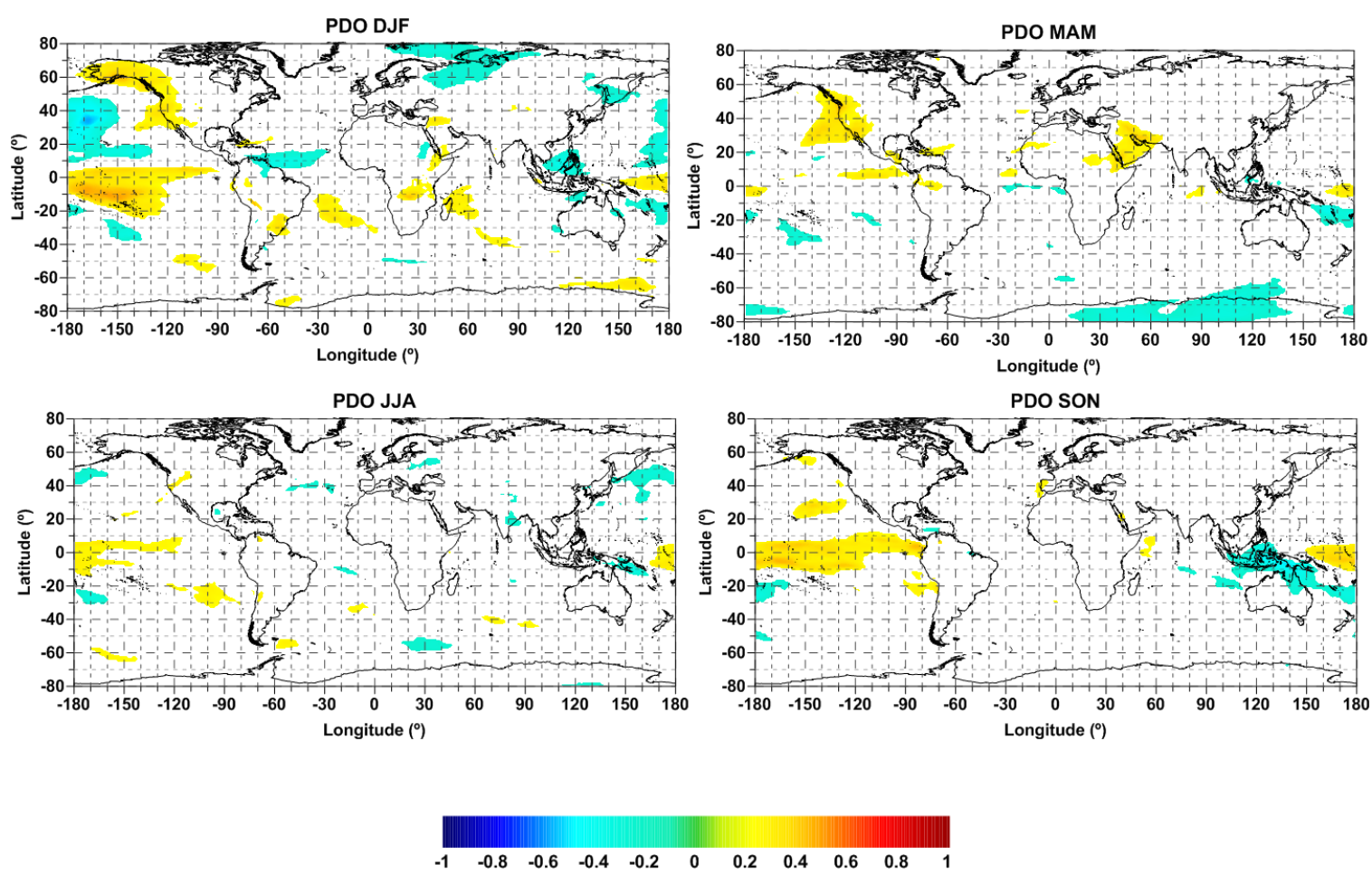

Figure 4.24 - Teleconnection map of WPD and PDO.

The teleconnection between TNA and WPD in winter season shows that the high positive correlations correspond to high negative correlations found in the winter teleconnection between NAO and WPD (Figure 4.25). In spite of that, is in the summer season that the teleconnection between TNA and WPD presents the highest positive correlation which are located over the Tropical North Atlantic (between $10^{\circ} \mathrm{N}$ and $20^{\circ} \mathrm{N}$ ). Since TNA is related to sea surface temperature, because how much warmer the sea surface is, more evaporation will exist, so WPD will increase. Philander (2001) has shown that in summer the surface currents are particularly strong, and the North Brazil Current, which carries very warm water from 5N across the equator, after crossing the equator, veers sharply eastward to feed the North Equatorial Countercurrent.

Like TNA, TSA index is connected with sea surface temperature-. The teleconnection between TSA and WPD shown in Figure 4.26 presents high significant and positive correlation during winter (0.3 to 0.5 ) located in southern hemisphere and in tropical south Atlantic, and is noticeable the relation between this result and the high values of WPD mean values in winter season (Figure 4.3), previously related with the ITCZ impact. 

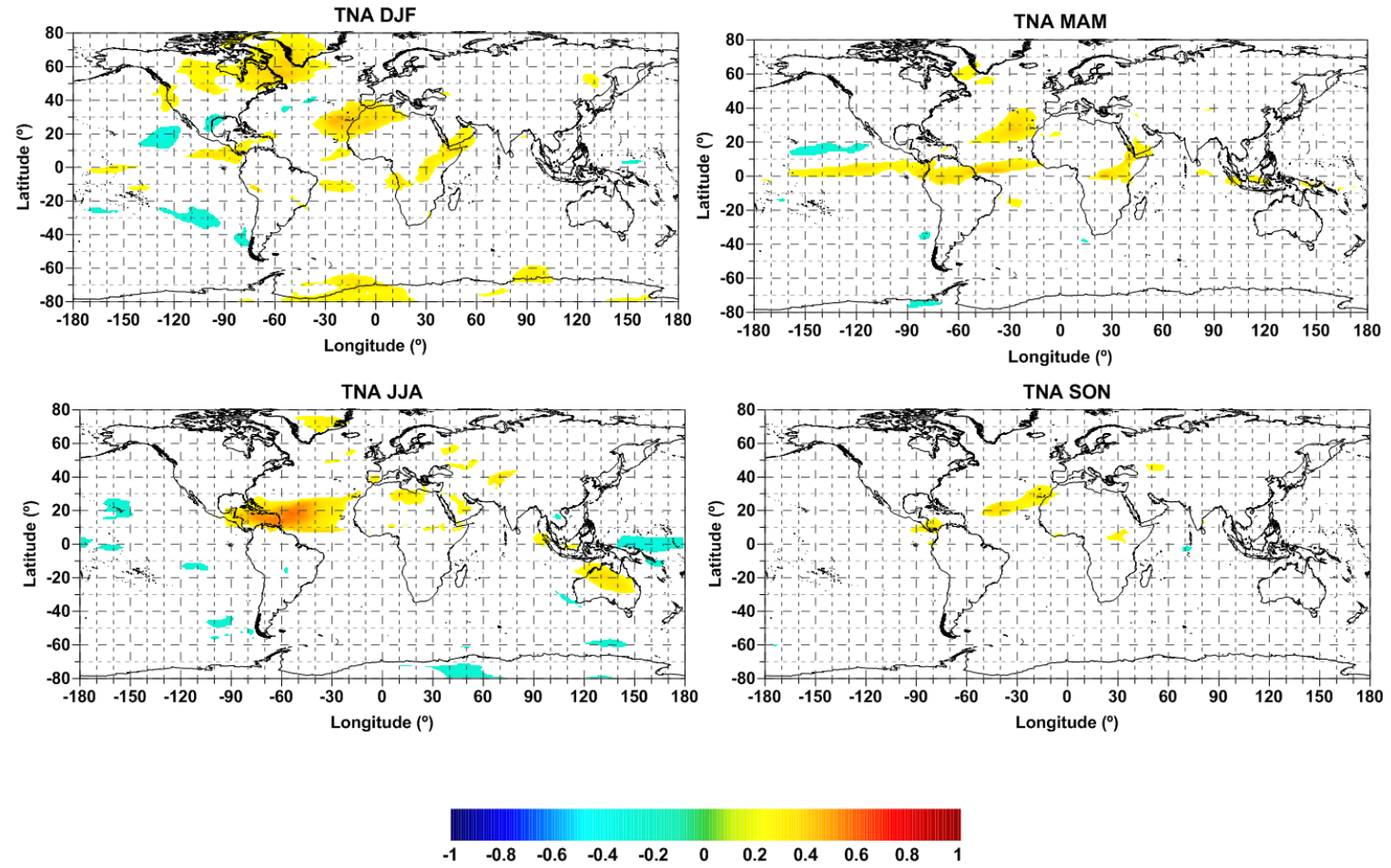

Figure 4.25 - Teleconnection map of WPD and TNA.
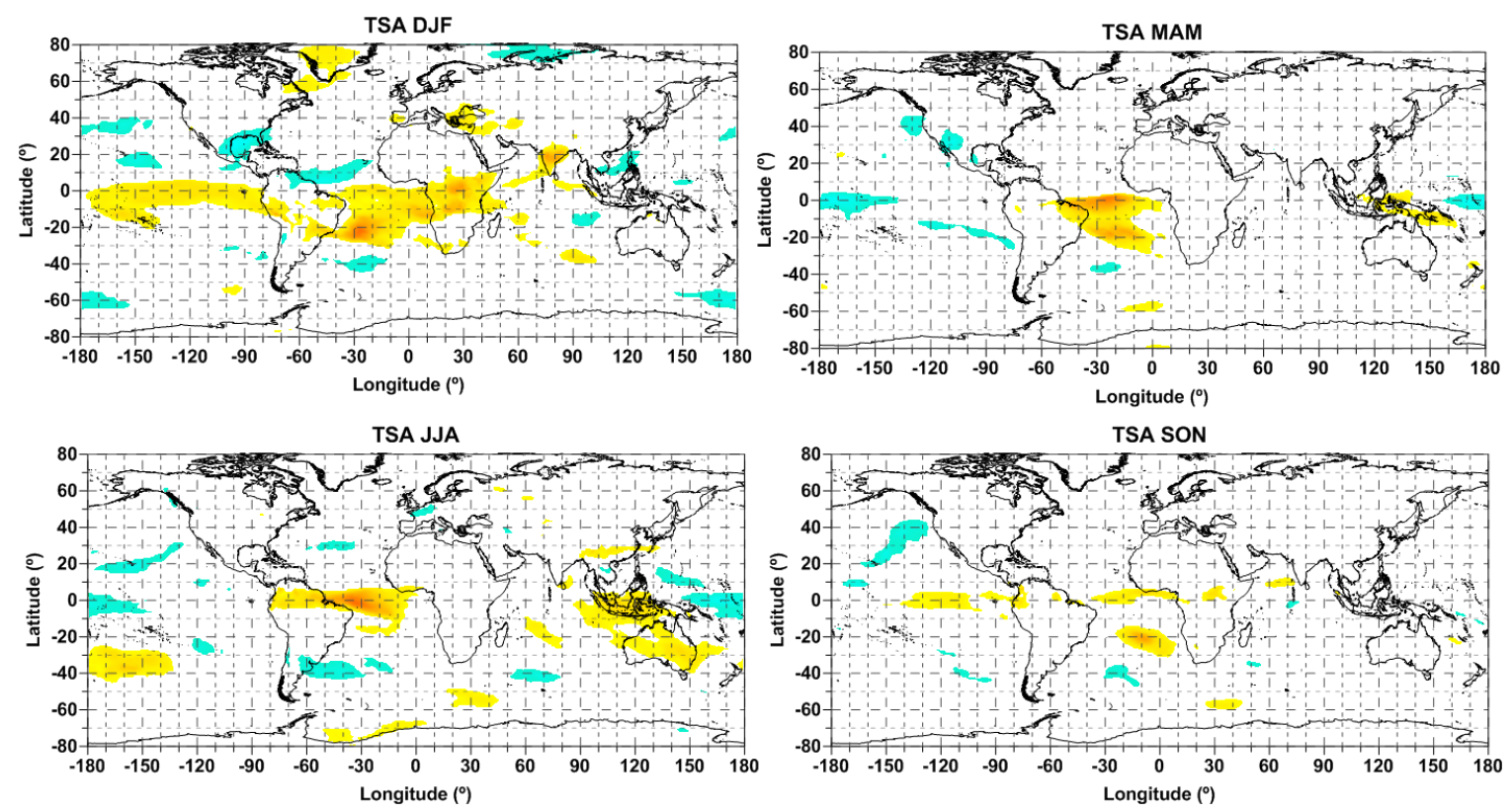

$\begin{array}{lllllllllll}-1 & -0.8 & -0.6 & -0.4 & -0.2 & 0 & 0.2 & 0.4 & 0.6 & 0.8 & 1\end{array}$

Figure 4.26 - Teleconnection map of WPD and TSA. 
The AMO is characterized by the sea surface warming (cooling) of the entire North Atlantic during its warm (cold) phase. The research of Wang et al. (2013) shows that the warm (cold) phase of the AMO is associated with a surface warming (cooling) and a subsurface cooling (warming) in the tropical North Atlantic (TNA). According to the teleconnection generated in this work (Figure 4.27), we can see this relationship in summer. However, is during the autumn that the teleconnection between AMO and WPD presents high correlation, with positive correlation in the Northern Hemisphere, and negative correlation in the South Hemisphere. Generally, is over the North Hemisphere that $\mathrm{AMO}$ have more impact.
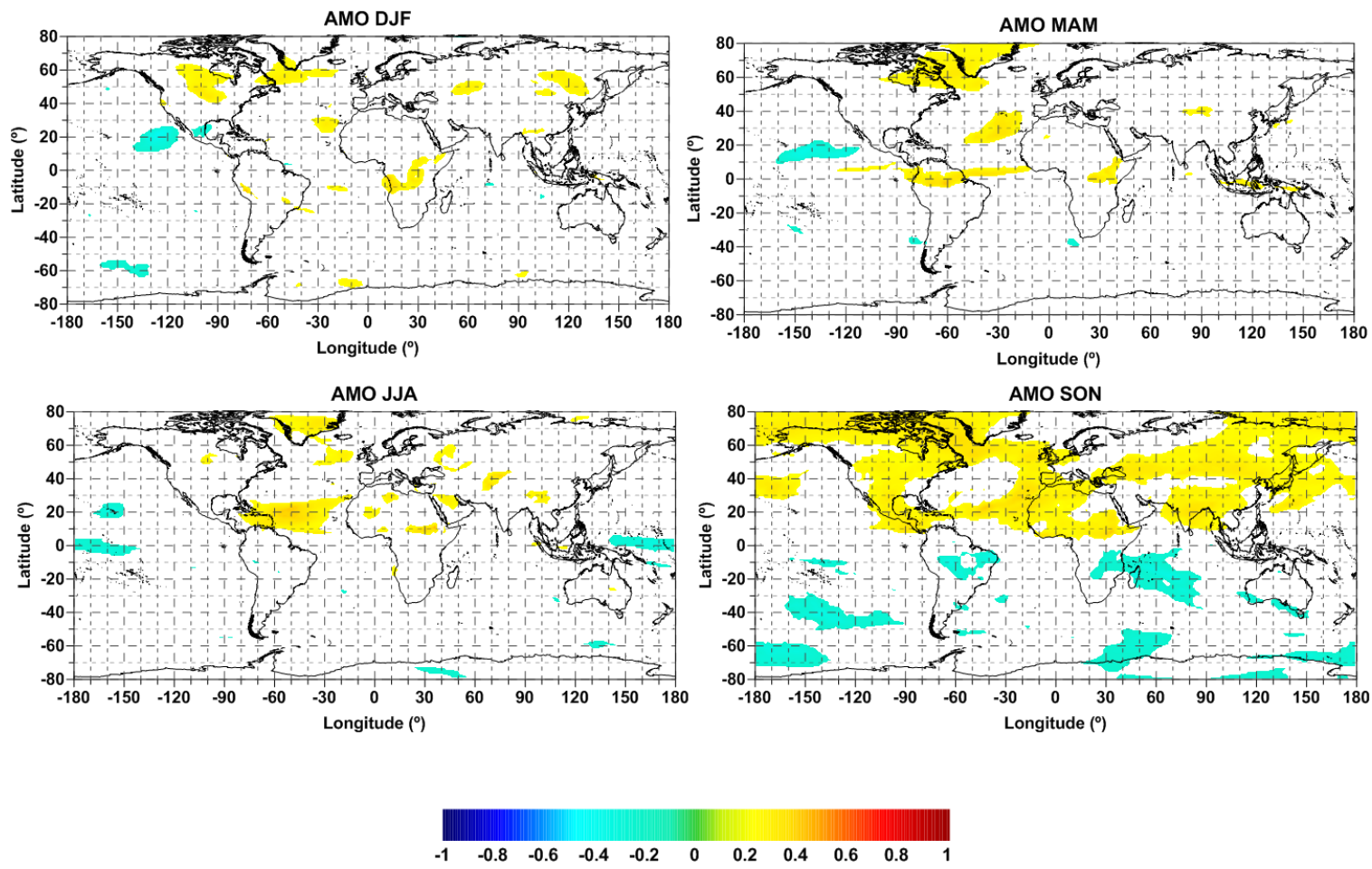

Figure 4.27 - Teleconnection map of WPD and AMO.

The WP pattern has received little research attention in comparison with other patterns, e.g. NAO. This is not surprising given the larger influence of these patterns on winter continental precipitation (Nigam, 2003). The WP pattern is however more dominant in the Northwest Pacific, especially in coastal regions, in the south-central Great Plains (semi-arid prairie ecoregion of the central United States), and, of course, on marginal sea ice zones in the Arctic (Linkin and Nigam, 2008). The teleconnection between WP and WPD (Figure 4.28) shows this influence in the Northwest Pacific during the winter season, but with negative correlation. The high positive correlations coincide with high positive correlations between Niño 3.4 and WPD, which means that WPD is related with the ENSO phenomenon. 

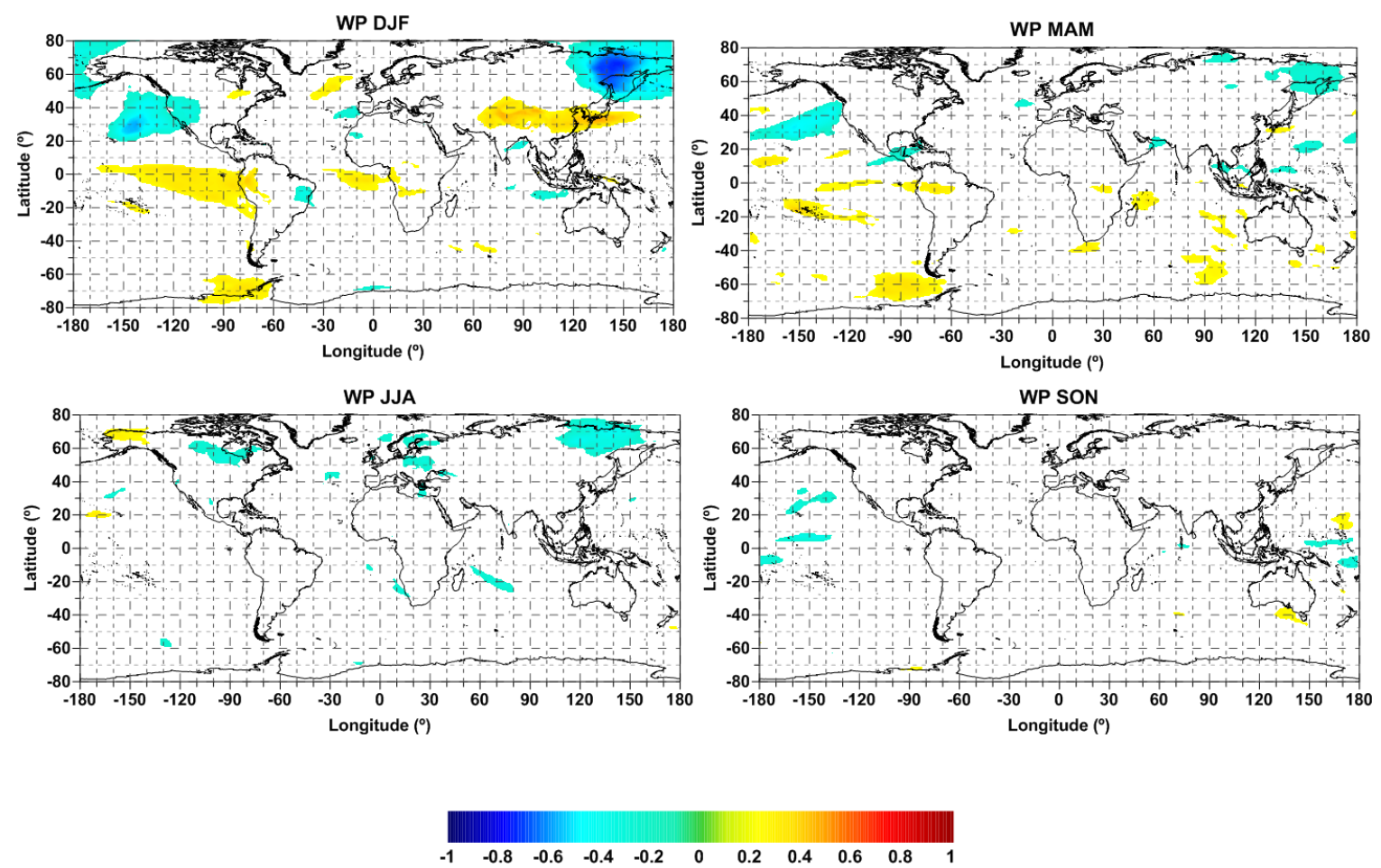

Figure 4.28 - Teleconnection map of WPD and WP.

In summary, in general the boreal winter is the season where WPD is more related with Climate Indices and, so, with the respective phenomena. This result is expected since, first, the WPD has more variability over the North Hemisphere, and second, most of the climate phenomena occur in the North Hemisphere, and at last, the winter season is the rainiest season, and, due to the hydrological cycle, there will be more water vapor in the troposphere, which causes more concentration of WPD.

\subsection{WPD and SLA}

Since the study of Sea Level is very important in Satellite Altimetry, the knowledge of how the WPD is related to Sea Level Anomaly (SLA) is also important. In order to relate WPD and SLA the same methodology used to correlate Climate Indices and WPD was followed, however in this case, since we have SLA gridded data, each grid point of WPD was correlated with the respective grid point of SLA.

The generated map of the spatial distribution of significant Pearson correlation coefficients, with a level of confidence of 95\%, is presented in Figure 4.29.

Analyzing this figure that shows the spatial distribution of the correlation coefficient between WPD and SLA, it is clear that the variables are much related globally. 
The fact that the correlation between the variables under study is higher over the Atlantic than over the Pacific can be explained since there is a northward transport of heat across the equator in the Atlantic but not in the Pacific. The reason is that the northern Pacific is less saline than the northern Atlantic which causes an absence in the formation of deep water in the Northern Pacific (Philander, 2001).

The high negative correlation between SLA and WPD can be explained by a delay in the response of one of the variables. This delay is linked to the duration of a season since there is a delay of the incoming of the northern winter over the north-western Africa due to the upwelling along the West African coast (Philander, 2001)..

Changes in the depth of the thermocline (which separates warm surface waters from the cold water at depth) depend on winds everywhere in the equatorial Atlantic, even the winds off Brazil which are most intense and warm during the northern summer when they cause a shoaling of the thermocline throughout the Gulf of Guinea (Philander, 2001). These seasonal variations of the winds and currents can explain the difference in phase between SLA and WPD over the Atlantic.

Over the Indian Ocean, there are also some regions that present negative correlation between SLA and WPD, but the situation is somewhat different. Here, in the western Indian Ocean, because of the dominant influence of the cold Somali current during northern summer, a zonal anomaly of surface temperature is maintained between the western and the eastern parts of the equatorial ocean almost throughout the year.

There is also the Indonesian warm pool where high positive correlation between WPD and SLA can be found.

A more complete analysis of the correlation between SLA and WPD could be achieved using decomposition into seasons, as has been done in the study of the correlation between Climate Indices and WPD, or using a lagged correlation. 

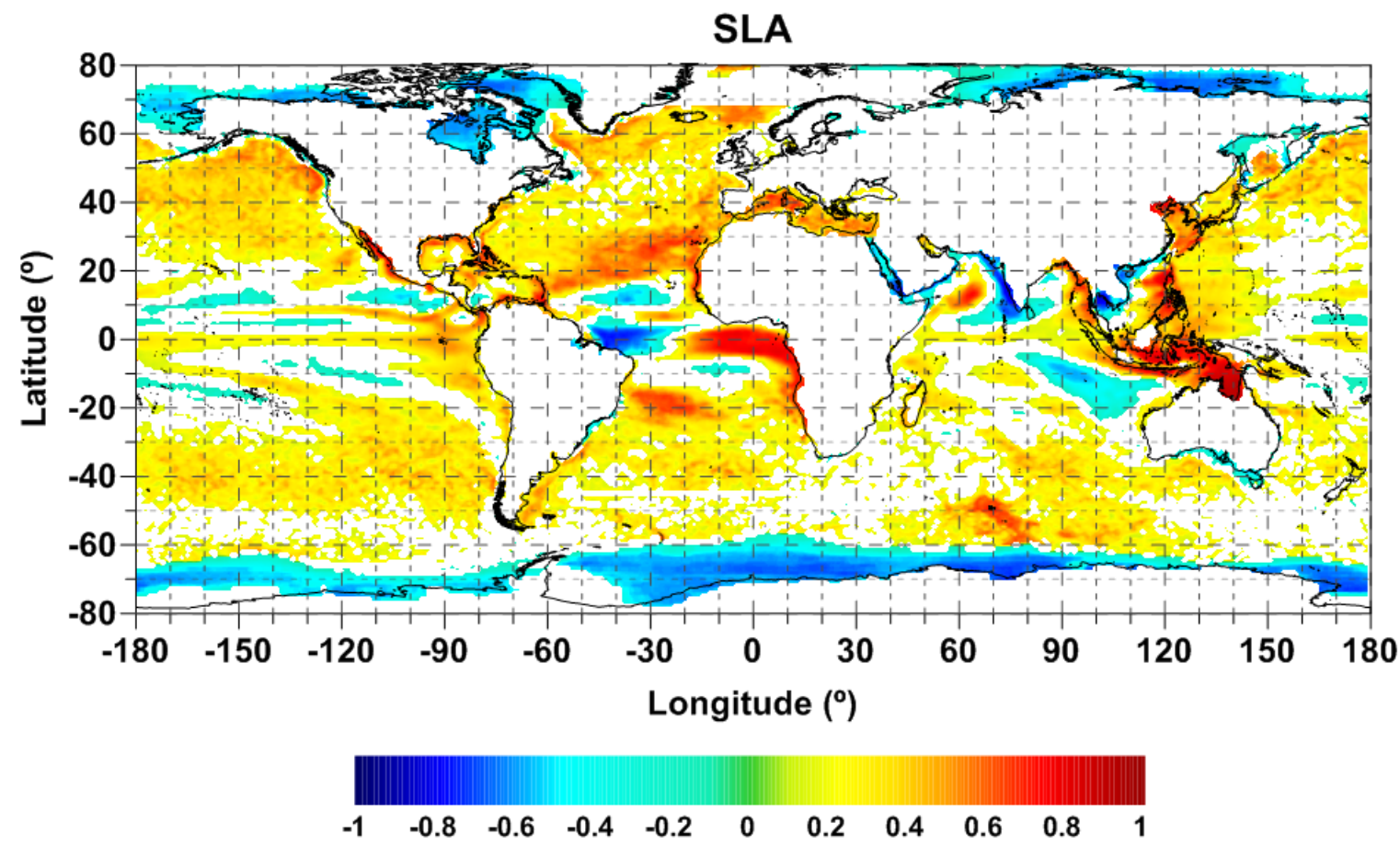

Figure 4.29 - Correlation Coefficient of WPD and SLA. 


\section{Variability of WTC with altitude}

The variability of the wet component of troposphere with the altitude above sea level is of major importance, since the GPD+ methodology relies on ZWD (Zenith Wet Delay) values reduced to sea level.

Since the height dependence of water vapor is not easy to model, due to its large variability, Kouba (2008) proposed the following empirical expression:

$$
Z W D_{\text {rad }}\left(h_{S}\right)=Z W D_{G N S S}\left(h_{0}\right) e^{\frac{h_{0}-h_{S}}{2000}}
$$

where $h_{S}$ and $h_{0}$ are the ellipsoidal heights of the model orography and surface, respectively, or, alternatively the corresponding heights above sea level.

The study performed by Kouba (2008) was based on punctual and scarce ZWD data acquired from radiosondes and, according to the author, equation (4) should only be used with height reductions up to $1000 \mathrm{~m}$.

In this chapter, the study of the ZWD variability (also named WTC), with altitude, using WTC data, derived from GNSS stations from IGS, EPN and SuomiNet permanent networks, and WTC data from MWR on-board several satellite altimetry missions, as described in Section 3, is addressed for the period of January, 1995 to September, 2014. A description of the data processing methodology is addressed in Section 5.1. The results and the corresponding analysis are presented in Section 5.2.

\subsection{Processing data}

In the ZWD reduction to sea level, the procedure developed by Kouba (2008) has been adopted and the results obtained so far indicate that it is suitable for coastal stations (distances from the coast up to 20-30 km) and heights below $1000 \mathrm{~m}$ (Fernandes et al., 2012).

In the case of this study, $h_{S}=0$ because it is the height at sea level, and $h_{0}$ is the altitude above sea level of the GNSS station. So manipulating Equation (5.1), it is possible to obtain the following expression:

$$
\frac{Z W D_{\text {rad }}\left(h_{S}\right)}{Z W D_{G N S S}\left(h_{0}\right)}=e^{\frac{h_{0}-h_{S}}{k}}
$$


where the coefficient of 2000 was substituted for an unknown variable named $k$.

Equation (5.2) allows the determination of $k$ values checking if Equation (5.1) can be reasonably applied at any altitude.

The WTC was estimated at GNSS stations from several networks (IGS, EPN, SuomiNet) and the corresponding WTC derived from MWR on-board five altimetric missions were used (ENVISAT, ERS-2, Jason-1, Jason-2 and TOPEX).

The first step consists on interpolating the GNSS-derived ZWD for the instants of the MWR measurements, and therefore selecting the altimeter points without invalid parameters located at a distance less than $100 \mathrm{~km}$ from any GNSS station, i.e., points near the coast.

The adjustment of an exponential fit, according to Equation (5.2) was performed taking into account two main approaches:

1. Considering data grouped by year; for each year, a file containing all interpolated values for all MWR and all GNSS values for the correspondent year was generated.

2. The same previous approach, but considering a restriction of the distance to coast between 30 and $50 \mathrm{~km}$.

3. Considering data grouped by permanent network and altimetric mission, restricting the distance to coast between 30 and $50 \mathrm{~km}$.

Applying the approach 1, $k$ values ranging from 1486 to 2323 were obtained. An example of the adjustment is presented in Figure 5.1 for the year 1999.

According to Sibthorpe et al. (2011), the variance of the WTC differences (GNSS-MWR) due to land contamination decreases significantly when distances to coast between 30 and $50 \mathrm{~km}$ are considered.

Applying approach $2 k$ values less than 2095 were determined. Figure 5.2 shows the adjustment of this approach for the 1999 year.

Applying approach 3, $k$ values ranging from 1007 to 1724, with a maximum of 2530 found for the combination SuomiNet+Envisat were found.

These results reveal that the value of $k$ is similar to the value found by Kouba (2008). Further analysis is required using, for example, data from an atmospheric model such as ERA Interim. 


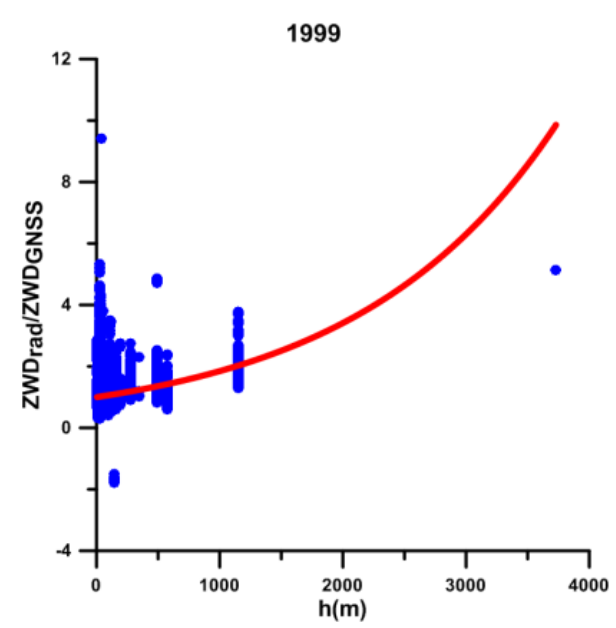

Figure 5.1- Adjustment of ZWD to altitude for the year 1999 considering distances from GNSS stations less than $100 \mathrm{~km}$.

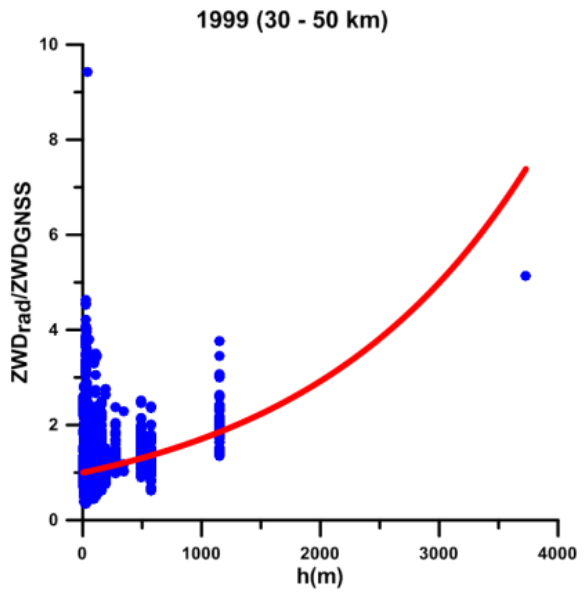

Figure 5.2 - Adjustment of ZWD to altitude for the year 1999 considering distances from GNSS stations less than $100 \mathrm{~km}$ and distance to coast between $30-50 \mathrm{~km}$. 


\section{Conclusions and future work}

Looking further beyond Geographic Engineering, this thesis explored the "whys" behind the variability of one of the most difficult source of errors in satellite altimetry, the wet path delay (WPD).

This study allowed understanding the variability of the distribution of the WPD and the causes of the observed variability both in space and time. Considering the period since January 1,1990 to December 31, 2014, it can be concluded that the WPD variability has a strong dependency on latitude, and that the maximum values of WPD variance are found in the Northern Hemisphere. Climate Phenomena are the cause for this high variability, since they affect the water vapor and temperature. Maximum values of WPD variance are found over the tropics of southern and eastern Asia and northern Australia and parts of western and central Africa. Other regions, namely Mexico, the southwest USA, and parts of South America and South Africa, which coincides with the ITCZ ("Intertropical Convergence Zone"), and thus are under the monsoon domain, also reveal high WPD variability.

The seasonal component of WPD is related to the annual patterns presented in those regions, and contributes almost $100 \%$ to the variance of WPD. The trend component has a maximum contribution of $55 \%$ in the equatorial region, where the contribution of the seasonal component decreases, and is related to the ENSO (EI Niño Southern Oscillation) phenomenon.

The analysis of the global and hemispherical time-series of WPD allows concluding that WPD is increasing with time by approximately $0.1 \mathrm{~mm}$ per year. The maximum and minimum values for the trend component occur in the aforementioned regions. The global time-series is influenced by the difference in phase between both hemispheres.

Since WPD variability can be related to atmospheric and ocean events, the correlation with Climate Indices and with SLA was analyzed. The temporal correlation of WPD with various Climate Indices (SOI, Niño 3.4, NAO, TNA, TSA, WP, PDO and AMO) shows that WPD is highly related with El Niño phenomenon, and with the others phenomena. Results from this study show high correlation principally in the northern winter. The analysis of the correlation between WPD and SLA allowed to conclude that WPD is highly related with SLA, however, areas where SLA and WPD are or not in phase were identified, meaning that future work can be done using lagged correlations and/or using a decomposition into seasons similar to that used in the WPD and Climate Indices correlation. 
The second part of the work consisted on the study of the WTC variability with altitude, by adjusting an exponential expression with a variable coefficient, with the objective of improving the original expression published by Kouba (2008). However, the obtained results do not allowed its improvement due to the scarceness of coastal GNSS stations at high altitudes. Therefore, the study reveal that further analysis is required using, for example, data from a numerical weather model (NWM). 


\section{References}

"Altimetry Missions", online http://www.esa.int/Our_Activities/Observing_the_Earth/Copernicus/Altimetry_missions [Accessed 22 August 2015].

"Altimetry Principles", online https://sentinel.esa.int/web/sentinel/user-guides/sentinel-3altimetry/overview/altimetry-principles [Accessed 20 August 2015].

"Atmospheric Water Vapor", online http://www.remss.com/measurements/atmosphericwater-vapor [Accessed 3 October, 2015].

"Climate Indices", online http://www.esrl.noaa.gov/psd/data/climateindices/list/ [Accessed 21 September, 2015].

"Correlation Coefficient, 2015", online https://www.medcalc.org/manual/correlation.php [Accessed 6 June, 2015].

"El Niño", online http://www.livescience.com/3650-el-nino.html [Accessed 20 October, 2015].

"ENSO impacts", online http://www.cpc.ncep.noaa.gov/products/precip/CWlink/ENSO/regressions/readme.sht $\mathrm{ml}$ [Accessed 10 November, 2015].

"EPN - About”, online http://www.epncb.oma.be/_organisation/about.php [Accessed 2 September 2015].

"ERS-1 - Aviso", online http://www.aviso.altimetry.fr/en/missions/past-missions/ers1.html [Accessed 1 September 2015].

"IGS - About”, online http://igs.org/network/information [Accessed 1 September 2015].

"JetStream", online http://www.srh.noaa.gov/jetstream/tropics/itcz.htm [Accessed 2 October 2015].

"Linear Regression", online http://www.stat.yale.edu/Courses/1997-98/101/linreg.htm [Accessed 5 June, 2015].

"Maritime Continent", online http://web.science.unsw.edu.au/ nicolasjourdain/Maritime_Continent.html [Accessed 10 November , 2015].

"Missions - Aviso", online http://www.aviso.altimetry.fr/en/missions.html [Accessed 1 September 2015].

"NASA " http://www.nasa.gov/topics/earth/features/vapor_warming.html

"Peak-to-peak amplitude" online http://whatis.techtarget.com/definition/peak-to-peak-pkpk [Accessed 5 June, 2015].

"Radar Altimetry Tutorial", online http://www.altimetry.info/html/alti/ [Accessed 27 August 2015].

"Regression Analysis", online http://blog.minitab.com/blog/adventures-instatistics/regression-analysis-how-do-i-interpret-r-squared-and-assess-the-goodnessof-fit [Accessed 5 June, 2015]. 
"SST and water vapor online http://earthobservatory.nasa.gov/GlobalMaps/view.php?d1=MYD28M\&d2=MYDAL2_ M_SKY_WV [Accessed 20 September, 2015].

"SuomiNet - About", online http://www.unidata.ucar.edu/data/suominet/ [Accessed 3 September 2015].

"The Southern Oscillation", online http://www.esrl.noaa.gov/psd/enso/enso.atlas.html [Accessed 2 November 2015].

Aguado E., Burt J. E. (2001). Understanding Weather and Climate, Second Edition, Prentice Hall pp. 81.

Andersen, O. B., Scharoo, R. (2011), Range and Geophysical Corrections in Coastal Regions: And Implications for Mean Sea Surface Determination. In Coastal Altimetry; Vignudelli, S., Kostianoy, A.G., Cipollini, P., Benveniste, J., Eds.; Springer-Verlag: Berlin/Heidelberg, Germany, pp. 113-116.

Barnston, A. G., Livezey, R. E. (1987), Classification, Seasonality and Persistence of Low-Frequency Atmospheric Circulation Patterns.Mon. Wea. Rev., 115, 1083-1126.

Bengtsson, L. (2010). The global atmospheric water cycle. Environ. Res. Lett. 5(2), D025001. DOI: 10.10881/1748-9326/5/2/025001.

Bevis, M., Businger, S., Chiswell, S., Herring, T.A., Anthes, R.A., Rocken, C., Ware, R.H. (1994). GPS meteorology-Mapping zenith wet delays onto precipitable water. J. Appl. Meteorol. 33, 379-386.

Broch, J. T. (1981). Principles of Analog and Digital Frequency Analysis. Tapir.

Christensen, J.H., K. Krishna Kumar, E. Aldrian, S.-I. An, I.F.A. Cavalcanti, M. de Castro, W. Dong, P. Goswami, A. Hall, J.K. Kanyanga, A. Kitoh, J. Kossin, N.-C. Lau, J. Renwick, D.B. Stephenson, S.-P. Xie and T. Zhou, 2013: Climate Phenomena and their Relevance for Future Regional Climate Change. In: Climate Change 2013: The Physical Science Basis. Contribution of Working Group I to the Fifth Assessment Report of the Intergovernmental Panel on Climate Change [Stocker, T.F., D. Qin, G.K. Plattner, M. Tignor, S.K. Allen, J. Boschung, A. Nauels, Y. Xia, V. Bex and P.M. Midgley (eds.)]. Cambridge University Press, Cambridge, United Kingdom and New York, NY, USA. Cleveland, R.B., Cleveland, W.S., McRae, J.E., Terpenning, I. (1990). STL: a seasonal-trend decomposition procedure based on loess. J. Offshore Stat. 6, 3-73.

Davis, J.L.; Herring, T.A.; Shapiro, I.I.; Rogers, A.E.E.; Elgered, G. (1985) Geodesy by Radio Interferometry-Effects of atmospheric modeling errors on estimates of baseline length. Radio Sci. 20, 1593-1607.

Debye, P. (1929). Polar molecules; Dover, New York. Cited in: http://gnss.be/troposphere_tutorial.php\#XMARTIN-PM-HALL-1979

Dee, D.P., Uppala, S.M., Simmons, A.J., Berrisford, P., Poli, P., Kobayashi, S., Andrae, U., Balmaseda, M.A., Balsamo, G.; Bauer, P., et al. (2011), The ERA-Interim reanalysis: Configuration and performance of the data assimilation system. Q. J. R. Meteorol. Soc., 137, 553-597.

Desportes, C., Obligis, E., Eymard, L. (2007). On the wet tropospheric correction for altimetry in coastal regions. IEEE Trans. Geosci. Remote Sen., 45, 2139-2149.

Enfield D. B. (2003). [online] The "El Niño" FAQ, Available: http://www.aoml.noaa.gov/general/enso_faq/ [Accessed 2 November 2015].

Fernandes M. J., C Lázaro C., M Ablain M., N Pires N. (2015). Improved wet path delays for all ESA and reference altimetric missions, Remote Sensing of Environment. 
Fernandes M.J., Lázaro C., Nunes A.L. (2013b). Analysis and Inter-Calibration of Wet Path Delay Datasets to Compute the Wet Tropospheric Correction for CryoSat-2 over Ocean. Remote Sens. 5, 4977-5005.

Fernandes M.J., Lázaro C., Nunes A.L., Pires N., Bastos L., Mendes V.B. (2010). GNSSderived Path Delay: an approach to compute the wet tropospheric correction for coastal altimetry. IEEE Geosci. Remote Sens. Lett. 7 (3), 596-600.

Fernandes M.J., Pires N., Lázaro C., Nunes A.L. (2013a). Tropospheric delays from GNSS for application in coastal altimetry. Adv. Space Res, 51, 1352-1368.

Fernandes, M. J., Lázaro, C., Nunes A. L., Scharroo, R. (2014). Atmospheric Corrections for Altimetry Studies over Inland Water, Remote Sens, 6, 4952-4997.

Guijarro J., Auriol A., Costes M., Jayles C., Vincent P. (2000) [online] MWR and DORIS - Supporting Envisat's Radar Altimetry Mission. ESA Bulletin, 104, Available: http://www.esa.int/esapub/bulletin/bullet104/guijarro104.pdf.

Haby J. (2015) [online] How Quickly can precipitation saturate air? Available: http://www.theweatherprediction.com/habyhints/218/

Hall, M. P. 1979. Effects of the troposphere on radio communication. Peter Peregrinus LTD on behalf of the Institution of Electrical Engineers. Cited in: http://gnss.be/troposphere_tutorial.php\#XMARTIN-PM-HALL-1979.

Hartmann, G., Leitinger, R. (1984). Range errors due to ionospheric and tropospheric effects for signal frequencies above $100 \mathrm{MHz}$. Bull. Geod. 58: 109-136.

Hastenrath, S., and P. Lamb P., (1978). On the dynamics and climatology of surface flow over the equatorial oceans. Tellus,30,436-448.

Hopfield, H.S. (1969). Two-quartic tropospheric refractivity profile for correcting satellite data. J. Geophys. Res. 74, 4487-4499.

Hurrell, J.W. (1995). Decadal Trends in the North Atlantic Oscillation: Regional Temperatures and Precipitation. Science: Vol. 269, pp.676-679.

Kouba, J. (2008). Implementation and testing of the gridded Vienna Mapping Function 1 (VMF1). J. Geod. 82, 193-205.

Latif, M., Barnett T.P. (1996). Decadal climate variability over the North Pacific and North america: dynamics and predictability. Journal of Climate, 9: 2407-2423.

Linkin, M. E., Nigam, S. (2008). The North Pacific Oscillation-West Pacific Teleconnection Pattern: Mature-Phase Structure and Winter Impacts. American Meteorological Society.

Mantua N. J. (1999). [online] The Pacific Decadal Oscillation and Climate Forecasting for North America, Available: http://www.atmos.washington.edu/ mantua/REPORTS/PDO/PDO_cs.htm [Accessed 2 November 2015].

Mantua, N.J., Hare S.R., Zhang Y., Wallace J.M., Francis R.C. (1997). A Pacific decadal climate oscillation with impacts on salmon. Bulletin of the American Meteorological Society, Vol. 78, pp 1069-1079.

Mendes, V.B., Prates, G., Santos, L., Langley, R.B. (2000). An Evaluation of the Accuracy of Models of the Determination of the Weighted Mean Temperature of the Atmosphere. In Proceedings of the ION 2000 National Technical Meeting, Anaheim, CA, USA, 26-28.

Montenbruck, O., Eberhard, G. (2000). Satellite orbits: Models, methods, and applications. Berlin: Springer. 
Nerem R. S. (1999). Measuring very low frequency sea lev el variations using satellite altimeter data. Global and Planetary Change, (20):pp. 157-171.

Niell, A.E., Coster, A.J., Solheim, F.S., Mendes, V.B., Toor, P.C.,Langley, R.B., Upham, A. (2001). Comparison of measurements of atmospheric wet delay by radiosonde, water vapor radiometer, GPS, and VLBI. J. Atmos. Oceanic Technol. 18, 830-850.

Nigam, S. 2003. Teleconnections. Encyclopedia of Atmospheric Sciences, J. R. Holton et al., Eds., Academic Press, 2243-2269.

Obligis, E., Desportes, C., Eymard, L., Fernandes, J., Lázaro, C., Nunes, A. (2011). [online] Tropospheric Corrections for Coastal Altimetry. In Vignudelli, S., Kostianoy, A., Cipollini, P., Benveniste, J. (Eds.), Coastal Altimetry. Springer, Heidelberg, Available: http://dx.doi.org/10.1007/978-3-642-12796-0_6 [Accessed 1 September 20015].

Pacione, E., Pace, B., Vedel, H., de Haan, S., Lanotte, R., Vespe, F. (2011). Combination methods of tropospheric time series. Adv. Space Res. 47, 323-335.

Philander S. G. (2001). Atlantic Ocean Equatorial Currents, Academic Press. 188.

Ramage, C. S. 1974. Structure of an oceanic near equatorial trough deduced from research aircraft traverses. Mon. Wea. Rev. 102, 754-759.

Reynolds, R.W., Rayner N.A., Smith T.M., Stokes D.C., and Wang W. (2002), An improved in situ and satellite SST analysis for climate. J. Climate, 15, 1609-1625.

Rohm, W., Yuan, Y., Biadeglgne, B., Zhang, K., Marshall, J. L., (2013). Ground-based GNSS ZTD/IWV estimation system for numerical weather prediction in challenging weather conditions. Elsevier B.V.

Rosmorduc, V., Benveniste J., Bronner E., Dinardo S., Lauret O., Maheu C., Milagro M., Picot N. (2011). Radar Altimetry Tutorial, J. Benveniste and N. Picot Ed.

Ross R. J., Elliott W. P. (2000). Radiosonde-Based Northern Hemisphere Tropospheric Water Vapor Trends, Journal of Climate, Vol.4.

Saha, K. (2010). Tropical Circulation Systems and Monsoons. Springer - Verlag Berlin, Heidelberg, pp.28.

Samama, N. (2008). Global positioning: technologies and performance. John Wiley and Sons, pp. 363.

Seidel, D. J. Water Vapor: Distribution and Trends. (2002). Encyclopedia of Global Environmental Change.

Sibthorpe, A., Brown S., Desai S. D., Haines B. J. (2011). Calibration and Validation of the Jason-2/OSTM Advanced Microwave Radiometer Using Terrestrial GPS Stations, Marine Geodesy, pp. 425.

Scharroo R., Lillibridge J. L., Smith W. H. F. , Schrama E. J. O. (2004). Cross-calibration and long-term monitoring of the microwave radiometers of ERS, TOPEX, GFO, Jason and Envisat. Mar Geod 27:279-297.

Spencer, R. W. (2001). [online] The role of passive microwave radiometers in climate monitoring. Available: https://ams.confex.com/ams/pdfpapers/24320.pdf

Stockwell, I. Introduction to Correlation and Regression Analysis. SAS Global Forum Statistics and Data Analysis. 2008; pp.1-2.

Subirana J. S., Zornoza J.M.J., Hernández-Pajares M. (2013), GNSS Data Processing, Vol. I: Fundamentals and Algorithms. ESA TM-23/1. 
Subirana J. S., Zornoza J.M.J., Hernández-Pajares M. (2011). [online] Tropospheric Delay. Available: http://www.navipedia.net/index.php/Tropospheric_Delay.

Thurman H. V., Burton E. (2001). Introductory Oceanography, Nine Edition, Prentice Hall.

Trenberth K. E., Fasullo J., Smith E. L. (2005), Trends and variability in columnintegrated atmospheric water vapor. Climate Dynamics 24: 741-758

Trenberth K. E., Stepaniak D. P. (2003a), Co-variability of components of poleward atmospheric energy transports on seasonal and interannual timescales. J. Climate 16:3690-3704.

Trenberth, K. E. (1997), The Definition of El Niño. Bulletin of the American Meteorological Society, 78, 2771-2777.

Trenberth, K., and National Center for Atmospheric Research Staff (Eds). (2015). "The Climate Data Guide: Atlantic Multi-decadal Oscillation (AMO)." Retrieved from https://climatedataguide.ucar.edu/climate-data/atlantic-multi-decadal-oscillation-amo. See more at: https://climatedataguide.ucar.edu/climate-data/atlantic-multi-decadaloscillation-amo\#sthash.m4b7KrC3.dpuf.

Volkov, D.L., Aken H.M. (2003), Annual and interannual variability of sea level in the northern North Atlantic Ocean. Journal of Geophysical Research. 108 (C6), 3204.

Waliser, D. E., Jiang, X. (2014). Tropical Meteorology: Intertropical Convergence Zone. Elsevier Ltd.

Wallace, J. M., Gutzler, D. S. (1981), Teleconnections in the Geopotential Height Field during the Northern Hemisphere Winter. Mon. Wea. Rev., 109, 784-812.

Wallace, J. M., P. V. Hobbs, 1977: Atmospheric Science: An Introductory Survey. Academic Press, 467.

Wang, C. Zhang, L. (2013). Multidecadal Ocean Temperature and Salinity Variability in the Tropical North Atlantic: Linking with the AMO, AMOC, and Subtropical Cell. J. Climate, 26, 6137-6162.

White N. J., Church J. A., Gregory J. M. (2005). Coastal and global averaged sea level rise for 1950 to 2000. Geophysical Research Letters, 32(L01601).

Zebiak, S. (1999). El Niño and the Science of Climate Prediction. Consequences Vol. 5, No. 2.

Zhai P., Eskridge R.E. (1997), Atmospheric Water Vapor over China. J. Climate, 10, 2643-2652.

Zhang, Y., Wallace, J.M., Battisti, D.S. (1997). ENSO-like interdecadal variability: 190093. J. Climate, 10, 1004-1020. 


\section{Annex A}

\section{Linear Regression}

Linear regression attempts to model the relationship between two variables by fitting a linear equation to observed data. The equation is in the form $\mathbf{Y}=\mathbf{a}+\mathbf{b X}$, where $\mathbf{X}$ is the explanatory variable and $\mathbf{Y}$ is the dependent variable (Linear Regression, 2015).

The slope of the line is $\mathbf{b}$, and $\mathbf{a}$ is the intercept (the value of $\mathbf{y}$ when $\mathbf{x}=0$ ). The slope is an important measure because it gives how much the fitted linear regression is growing in time. According to this description, this measure is often applied to the extracted trend component of a time-series, allowing estimating the averaged rise or decreasing rate of the variable in study.

The Least-Squares Method is a common method for fitting the regression line. A description of this method is presented below.

\section{Least-Squares Method}

The Least-Squares method calculates the best-fitting line for the observed data by minimizing the sum of the squares of the vertical deviations from each data point to the line (if a point lies on the fitted line exactly, then its vertical deviation is 0 ). Because the deviations are first squared, then summed, there are no cancellations between positive and negative values (Linear Regression, 2015) .

\section{Coefficient of Determination}

The coefficient of determination $\left(R^{2}\right)$, also known as $R$-squared, is a statistical measure that gives information about how close the data are to the fitted regression line (Regression Analysis, 2015). The definition of the coefficient of determination is fairly straight-forward; it is the percentage of the response variable variation that is explained by a linear model. The value of $R^{2}$ is always between 0 and 1 . A value of 0 indicates that the linear model explains none of the variability of the response data around its mean; and a value of 1 indicates that the linear model explains all the variability of the response data around its mean. In general, the higher the $\mathrm{R}^{2}$ is, the better the linear model fits the data in study. This measure have some limitations, such as the fact that $R^{2}$ value does not indicate whether a regression model is adequate. Therefore, a low $R^{2}$ value can be a result for a good model, or a high $\mathrm{R}^{2}$ value can be a result for a model that does not fit the data. The further the fitted line is away from the points, the less it is able to explain 
(Regression Analysis, 2015). In summary, the $\mathrm{R}^{2}$ denotes the strength of the linear association between $\mathrm{x}$ and $\mathrm{y}$, it is the ratio of the explained variation to the total variation.

\section{Peak-to-peak amplitude}

The averaged peak-to-peak amplitude is a measure applied to a time-series or to a function, and is defined as the difference between the maximum and minimum values of each cycle of the waveform (Peak-to-peak amplitude, 2015), averaged over the entire period of study (see Figure A.0.1).

High values for the averaged peak-to-peak amplitude implies that time-series have a high variability along time. And small values have the inverse meaning.

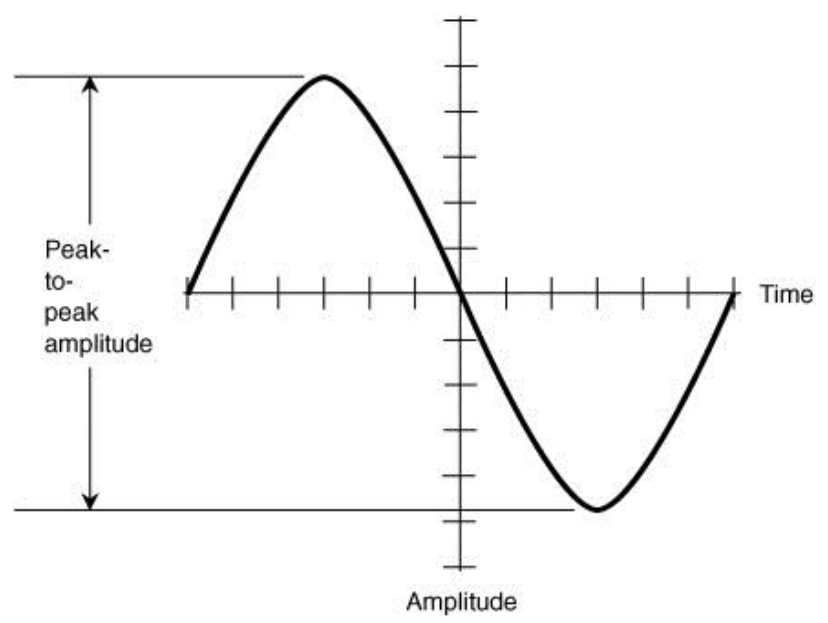

Figure A.0.1 - Illustration of the peak-to-peak amplitude measurement. Source: https://www.chegg.com/homework-help/definitions/amplitude-expressions-4.

\section{Pearson Correlation Coefficient}

The cross-correlation function is a quantitative operation in the time domain used to describe the relationship between data measured at a point and data obtained at another observation point (Broch, 1981). The result of applying the cross-correlation function can be interpreted as an estimate of the correlation between two data samples. This correlation, also known as Pearson's correlation, exists when both data in study have a linear relationship beyond what is expected by chance alone.

The correlation coefficient, $r$, is a statistic measure that quantify the strength of an association between two continuous variables. The correlation coefficient can range from -1 to 1 . A value of -1 represents "perfect negative correlation", while a value of 1 represents "perfect positive correlation". The closer a correlation is to these extremes, the "stronger" the correlation between the two variables (Stockwell, 2008). When the correlation coefficient is close to 0 (zero), it does not imply that there is no relationship 
between the variables, it only implies that there is no linear correlation between them. Looking to the sign of the correlation coefficient, a positive value means that as variable 1 increases, variable 2 increases, and conversely, as variable 1 decreases, variable 2 decreases.

Besides the information given by the numerical value and by the sign of the correlation coefficient, it is important to take in account the statistical significance of the correlation given by the probability level ( $p$-value). The smaller the $p$-level is, the more significant the relationship is.

The $p$-value is the probability to have found the current result if the correlation coefficient were in fact zero (null hypothesis) (Correlation Coefficient, 2015). If this probability is lower than the conventional $5 \%(p$-value $<0.05)$ the correlation coefficient is called statistically significant. In other words, small p-values (e.g. $p<0.05)$ mean that the null hypothesis can be rejected (the null hypothesis for these analyses is that $r=0$ ).

If two variables are correlated, there may or may not be a causative connection, furthermore this connection can be indirect. Correlation can only be interpreted in terms of causation if the variables under investigation provide a logical basis for such interpretation. 